\title{
Detailed trilobite biostratigraphy across the proposed GSSP for Stage 5 ("Middle Cambrian" boundary) at the Wuliu-Zengjiayan section, Guizhou, China
}

\author{
FREDERICK A. SUNDBERG, YUANLONG ZHAO, JINLIANG YUAN \& JIHPAI LIN
}

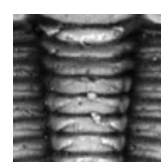

\begin{abstract}
Quarrying across a potential GSSP of the base of Cambrian Stage 5/Series 3 at the Wuliu-Zengjianyan section in south China indicates a significant change in trilobite and brachiopod faunas. The Wuliu Quarry spans approximately $4.5 \mathrm{~m}$ across the potential boundary, which is the FAD of Oryctocephalus indicus (Reed, 1910) in the Wuliu-Zengjiayan section of the Kaili Formation. Trilobite taxa found consist of one Pagetia, one Redlichia, one Burlingia, two Olenoides, eleven oryctocephalid, and seven ptychopariid species. Non-trilobite taxa found in the Wuliu Quarry, but not described in this publication, include tubular shells, inarticulate and articulate brachiopods, molluscs, echinoderm plates, sponges, algae, acritarchs, and trace fossils. Collected specimens display both flattening, secondary calcite preservation, and tectonic distortion. Many of the species have previously been based on length to width ratios. Given the range of morphologies demonstrated in these collections, several previously named species have been synonymized. Detailed collections from the Wuliu Quarry show that the faunas of the Ovatoryctocara cf. granulata-Bathyonotus holopygus and the $O$. indicus zones changed in a $20 \mathrm{~cm}$, relatively barren interval. This faunal turnover does not coincide with a lithologic change and suggests that the section would be a good location for the GSSP of the base of Cambrian Stage 5/Series 3. - Key words: Cambrian, trilobites, Kaili Formation, South China.
\end{abstract}

SundBerG, F.A., ZHAO, Y.L., YUAN, J.L. \& Lin, J.P. 2011. Detailed trilobite biostratigraphy across the proposed GSSP for Stage 5 ("Middle Cambrian" boundary) at the Wuliu-Zengjiayan section, Guizhou, China. Bulletin of Geosciences 86(3), 423-464 (22 figures). Czech Geological Survey, Prague. ISSN 1214-1119. Manuscript received September 6, 2010; accepted in revised form August 23, 2011; published online September 22, 2011; issued September 30, 2011.

Frederick A. Sundberg (corresponding author), Show Low High School, 500 W. Old Linden Rd., Show Low, AZ 85901, USA; freddeb85@cableone.net•Yuanlong Zhao, College of Resource and Environment Engineering, Guizhou University, Guiyang 550003, China; zhaoyuanlong@126.com•Jinliang Yuan, Nanjing Institute of Geology and Palaeontology, Chinese Academy of Sciences, No. 39 East Beijing Road Nanjing, 210008, China; yuanjl403@ sohu.com • Jihpai Lin, State Key Laboratory of Paleobiology and Stratigraphy, Nanjing Institute of Geology and Palaeontology, Chinese Academy of Sciences, 39 E. Beijing Road, Nanjing, 210008, China; jplin@nigpas.ac.cn

The lower boundary of Stage 5 of the Cambrian has yet to be determined. Recent work (Sundberg 2009, McCollum \& Sundberg 2010) by the "Lower-Middle" Cambrian Boundary Working Group has narrowed down the biohorizon possibilities that should be considered for defining this boundary. The first candidate is the first appearance datum (FAD) of Oryctocephalus indicus (Reed, 1910), the second candidate is the FAD of Ovatoryctocara granulata Tchernysheva, 1962. A potential GSSP for this boundary using O. indicus has been proposed by Zhao et al. (2005a, see for further references) and is located at the Wuliu-Zengjiayan section near Balang, Guizhou Province, China (Fig. 1).

This paper reports on the trilobites of a quarry excavated next to the proposed GSSP at the Wuliu-Zengjiayan section (Fig. 2). This quarry is here referred to as the "Wuliu Quarry". The intent of this study is to provide detailed stratigraphic and biostratigraphic information for ap- proximately $4.5 \mathrm{~m}$ of section that transects the FAD of O. indicus. A preliminary report on this quarry was published by Sundberg et al. (2010b). This report contained a stratigraphic range chart (Sundberg et al. 2010b, fig. 1); however some taxonomic nomenclature has been changed. These changes are mentioned below in the systematic section.

The general depositional environment of the Kaili Formation has been discussed by Zhou et al. (1980), Zhao et al. (1994a), Zhang et al. (1996), Zhu et al. (1999) and Lin (2008, 2009). The Kaili Formation occurs in the Jiangnan Slope Belt between the shallow water Yangtze Platform and the deeper water Jiangnan Basin (Lu et al. 1974b; Zhou et al. 1980; Zhao 1990; Zhang et al. 1996; Yuan et al. 2002; Lin 2008, 2009). The claystones of the Kaili Formation have an absence of siliciclastic silt and sand, common mm scale lamina and common layers of concentrated trilobite 


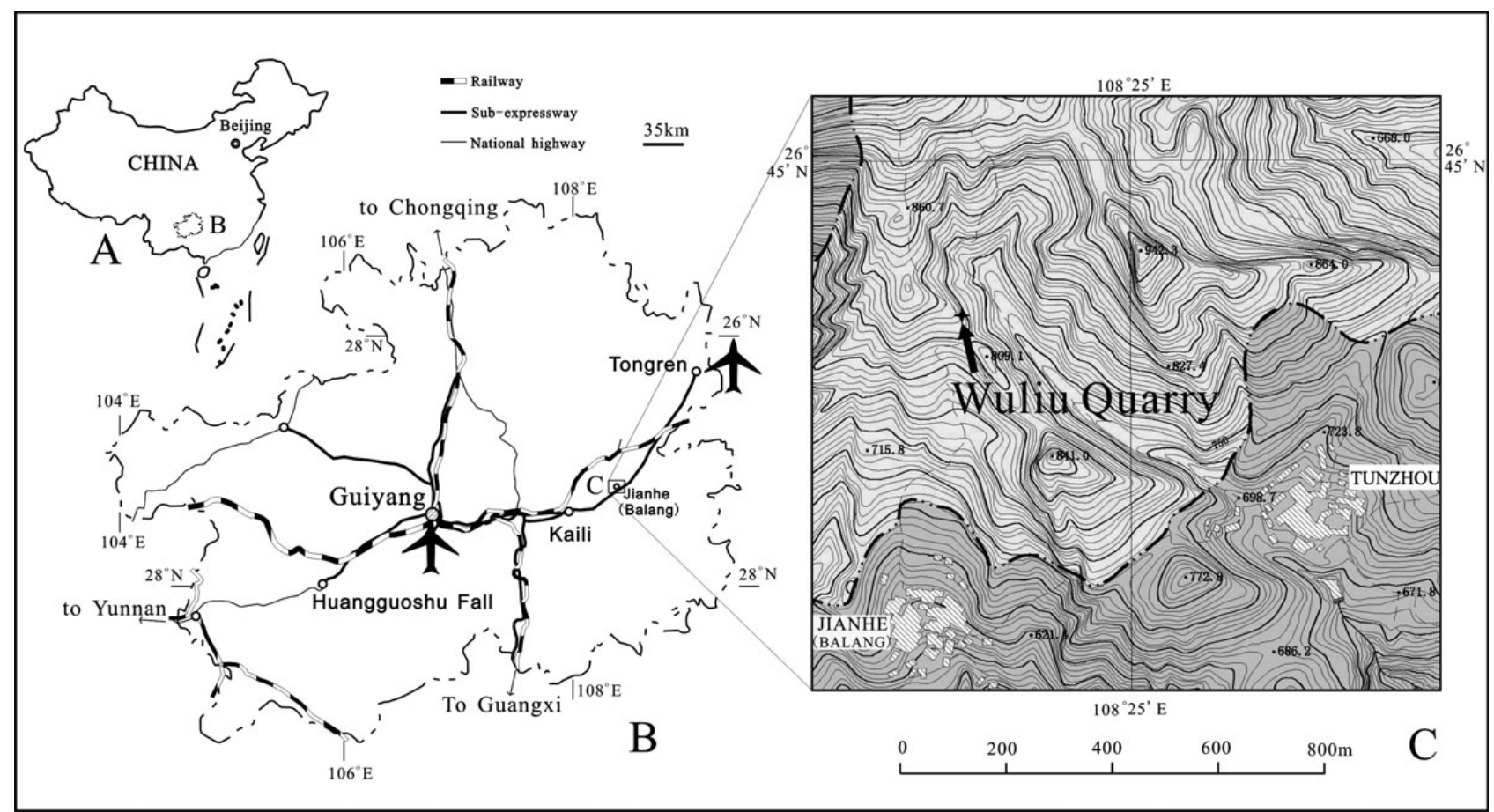

Figure 1. A - map of China showing the Guizhou Province. $\bullet B$ - map of the Guizhou Province, China, showing the position of the Wuliu-Zengjiayan section. $\bullet \mathrm{C}$ - topographic map showing the precise location of the Wuliu Quarry at the location of the potential GSSP in the Wuliu-Zengjiayan section, modified from 1:10,000 scale topographic map G-49-37-47 of the Wuhe Area (Surveying and Mapping Bureaus of Guizhou and Shanxi provinces 1990).

sclerites suggest that the sediments were deposited below storm-wave base by turbid suspension gravity flows (Gaines et al. in press), but probably within the lower limit of the photic zone based on potentially in situ algal flora (Lin 2009). The presence of truncation surfaces and small scale slumping next to or in the Wuliu Quarry (Fig. 3) suggests failure close to the sediment water interface (Gaines 2011, personal communication), indicating a paleoslope. The Kaili Formation is inturpeted to be a $3^{\text {rd }}$ order cycle with the maximum flooding surface located at or near the FAD of $O$. indicus (Wang et al. 2006, Lin 2009, Gaines et $a l$. in press). In addition, a negative carbon isotopic excursion occurs within $4 \mathrm{~m}$ below the FAD of $O$. indicus (Yang et al. 2003; Guo et al. 2005, 2010; Lin 2009, 2010, 2011).

\section{Methods}

Wuliu Quarry. - The quarry (Figs 2,4) was selected adjacent to the proposed GSSP at the Wuliu-Zengjiayan section, near the town of Balang, Jianhe County, Guizhou Province, China $\left(26^{\circ} 44.846^{\prime} \mathrm{N}, 108^{\circ} 24.830^{\prime} \mathrm{E}\right.$, elevation $803 \pm 11$ m; UTM N 242789.9, E 2961075.3, Zone 49; Fig. 1). The upper third of the quarry was $1.2 \mathrm{~m}$ below the $56 \mathrm{~m}$ mark of the proposed GSSP section and less than $1 \mathrm{~m}$ away. The lower two thirds of the quarry were moved 2 to $3 \mathrm{~m}$ away from the proposed section to insure that no damage was done to the established section.
Excavation of the quarry involved the removal of layers (levels) of strata in approximately 0.25 to $0.5 \mathrm{~m}^{2}$ to a depth of $10 \mathrm{~cm}(10.0 \pm 2.1 \mathrm{~cm})$. Based on the measured width, length and depth of each level, the volume of rock excavated for each level averaged $0.036 \pm 0.014 \mathrm{~m}^{3}$ (Fig. 5). The total volume of rock excavated was approximately $1.6 \mathrm{~m}^{3}$. Levels of strata were removed parallel to their dip that ranged from $12^{\circ}$ to $21^{\circ}$. The base of each level was excavated along bedding planes, but some levels produced irregular bottoms due to fractures and/or poorly splitting layers. The most irregular surfaces were in the middle portion of the quarry (levels FZX11-30, Figs 4, 5).

Stratigraphic logging was done after the quarry was finished. The total depth excavated was $452 \mathrm{~cm}$, which was determined by adding individual level depths together. Correcting for the dip, the total depth was $434 \mathrm{~cm}$, a $5.3 \%$ difference. Once the quarrying was finished, the location of each level marker was done again, correcting for the additive errors resulting from the individual level measurements and stratigraphic dip. This measurement indicated a stratigraphic thickness of $428 \mathrm{~cm}$, which is only a $1.4 \%$ difference from the calculated thickness corrected for dip.

Bulk material from each level was kept separate and placed on plastic sheets to avoid mixing during the search for specimens. Once the specimens were collected, the material was trimmed down and wrapped in newspaper labeled with the level number. 


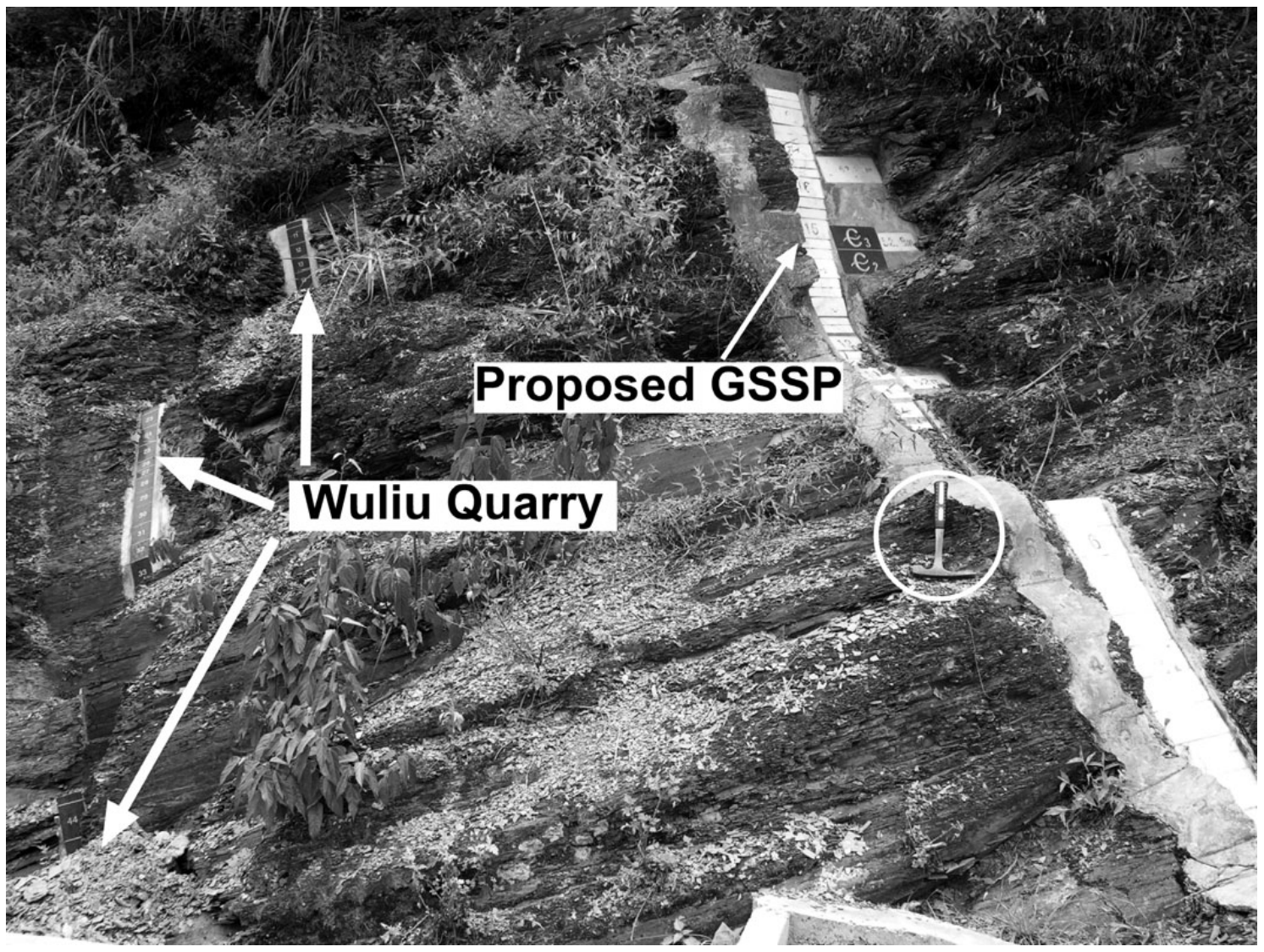

Figure 2. Outcrop photograph of the proposed GSSP for the Cambrian Stage 5 in the Wuliu-Zengjiayan section (white marble markers, arrow points to the proposed GSSP) and the Wuliu Quarry studied in this paper (black gabbro markers). The top of the Wuliu Quarry is not visible in photograph, but is located nearly a metre from the proposed GSSP section. Rock hammer (circled) for scale. Photograph by Yuning Yang.

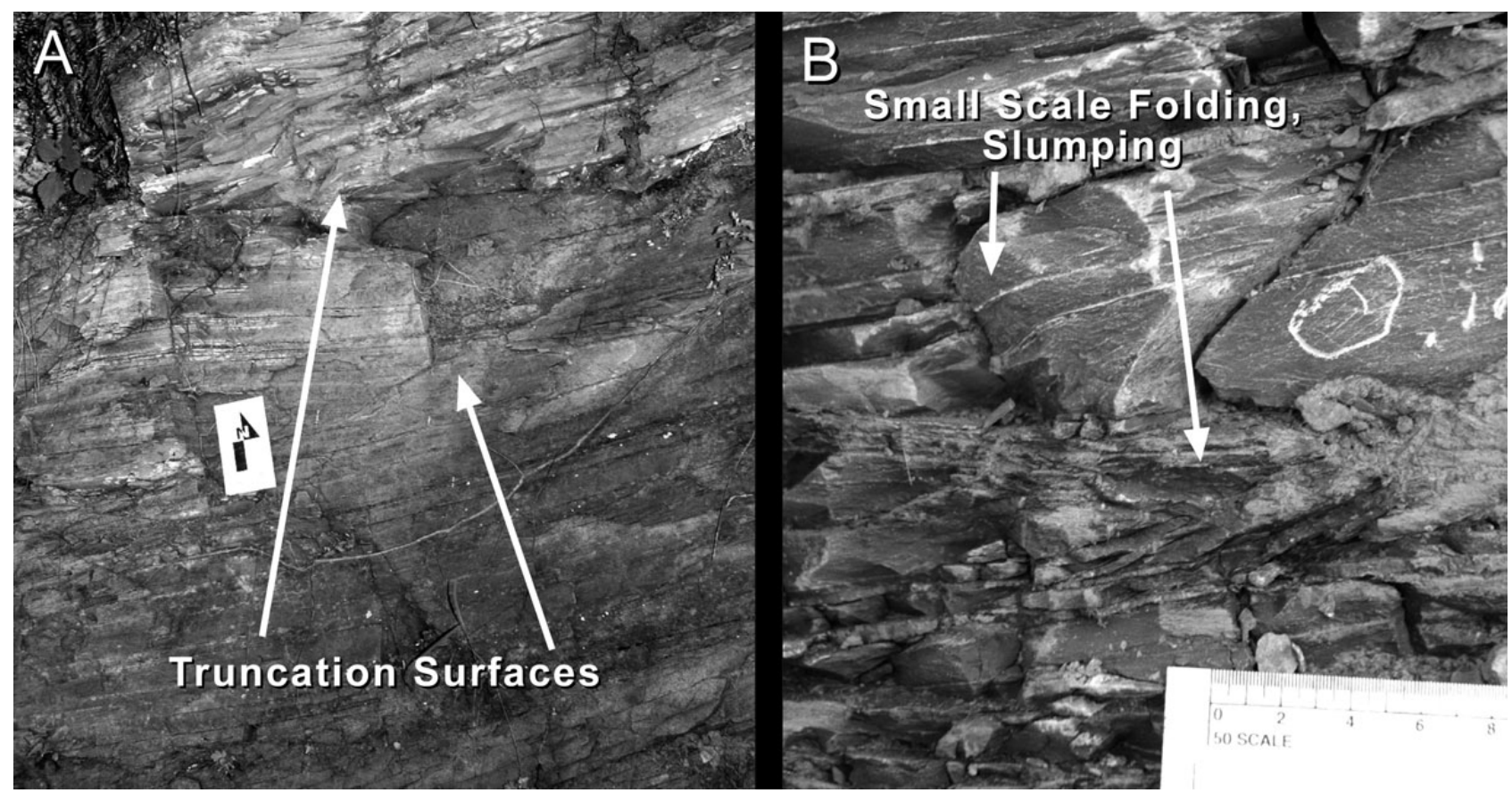

Figure 3. Sedimentary features indicating a depositional paleoslope of the Kaili Formation near and in the Wuliu Quarry. • A - outcrop exposure of truncation surfaces in the mudstones. $\bullet \mathrm{B}-$ small scale folding indicating slumping. 


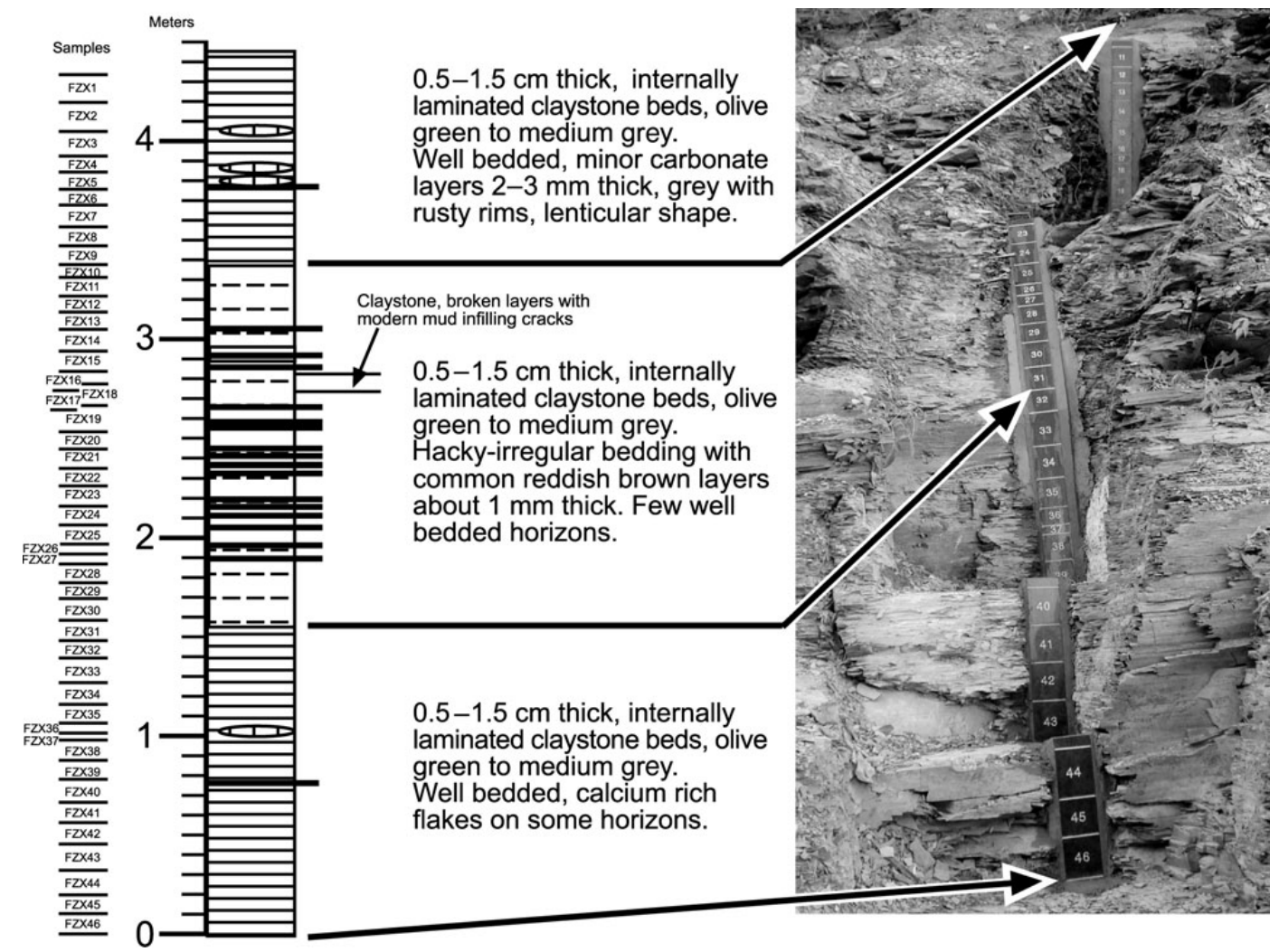

Figure 4. Stratigraphic profile of the Wuliu Quarry showing the levels and lithologies. The photograph illustrates the bottom portion of the quarry showing the boundary between the lower laminated claystones and the middle irregularly bedded mudstones. Grey bars of excavation volumes inticate the total volume excavated for FZX18, which overlapped the levels FXZ16 and 17 due to the moving of the quarry outwards; FZX26+27 inticates the total additional volume of the $10 \mathrm{~cm}$ level collected in detail below the FAD of $O$. indicus; and FZX36+37 indicates the total volume of the $10 \mathrm{~cm}$ level that was broken into two intervals due to a limestone layer (FZX37). Photograph of quarry by Tongshu Tai.

Trilobite identifications. - Identification of the ptychopariid trilobites and to a lesser extent the other trilobites was complicated primarily as the result of: 1) tectonic distortion; 2) compaction; 3) glabella similarity of several genera; 4) the lack of pygidium for generic identification; 5 ) over splitting of species/genera based on distorted specimens; and 6) specimens missing or having calcite replaced exoskeletons. Large collections of specimens of a species were needed to determine the effects of distortion. The figured specimens illustrate the range of distortions and ontogenetic stages. Several features were used for identification, but the comparison of width vs. length ratios were avoided because these features are strongly affected by tectonic distortion (Fig. 6). Features such as the length (sag., exsag.) of the glabella, cranidium, palpebral lobes, posterior area of the fixigena, preglabellar field, and anterior border were commonly compared. Widths (tr.) of the fixigena, glabella, posterior area of the fixigena, and anterior and posterior glabellar were also compared. Pygidial features include the length and width of the axis relative to the entire pygidium, number of axial rings, depth of pleural/interpleural furrows, marginal border, and relative changes in the doublure from the anterior to the posterior margin.
Due to tectonic and compressional distortion of the specimens from the Wuliu Quarry and Wuliu-Zengjiayan section in general, emended diagnoses for the taxa are also presented to provide a guide for the criteria used to identify the different species. Suggested synonymies are presented below; but without a detailed taxonomic/taphonomic study of each species, these synonymies are still questionable. Specimens from the nearby Miaobangpo section (Yuan et al. 2002) appear to be less distorted and would be a better database for a taxonomic revision. A detailed morphometric study is out of the scope of this paper.

Abundance. - The minimum numbers of individuals are illustrated in Figs 5 and 7. All late meraspids and holaspides of each species were counted. The identification of late meraspids were based on having growth sequences of several of the taxa and that only one species of Pagetia Walcott, 1916, was identified. Specimens were recorded as cranidia or pygidia, either positives or negatives. Over 15,000 cranidia and pygidia were counted, however the minimum number of individuals is based on the highest count of either positive or negative of either cranidia or pygidia for each species for each excavated level. For example, if 20 


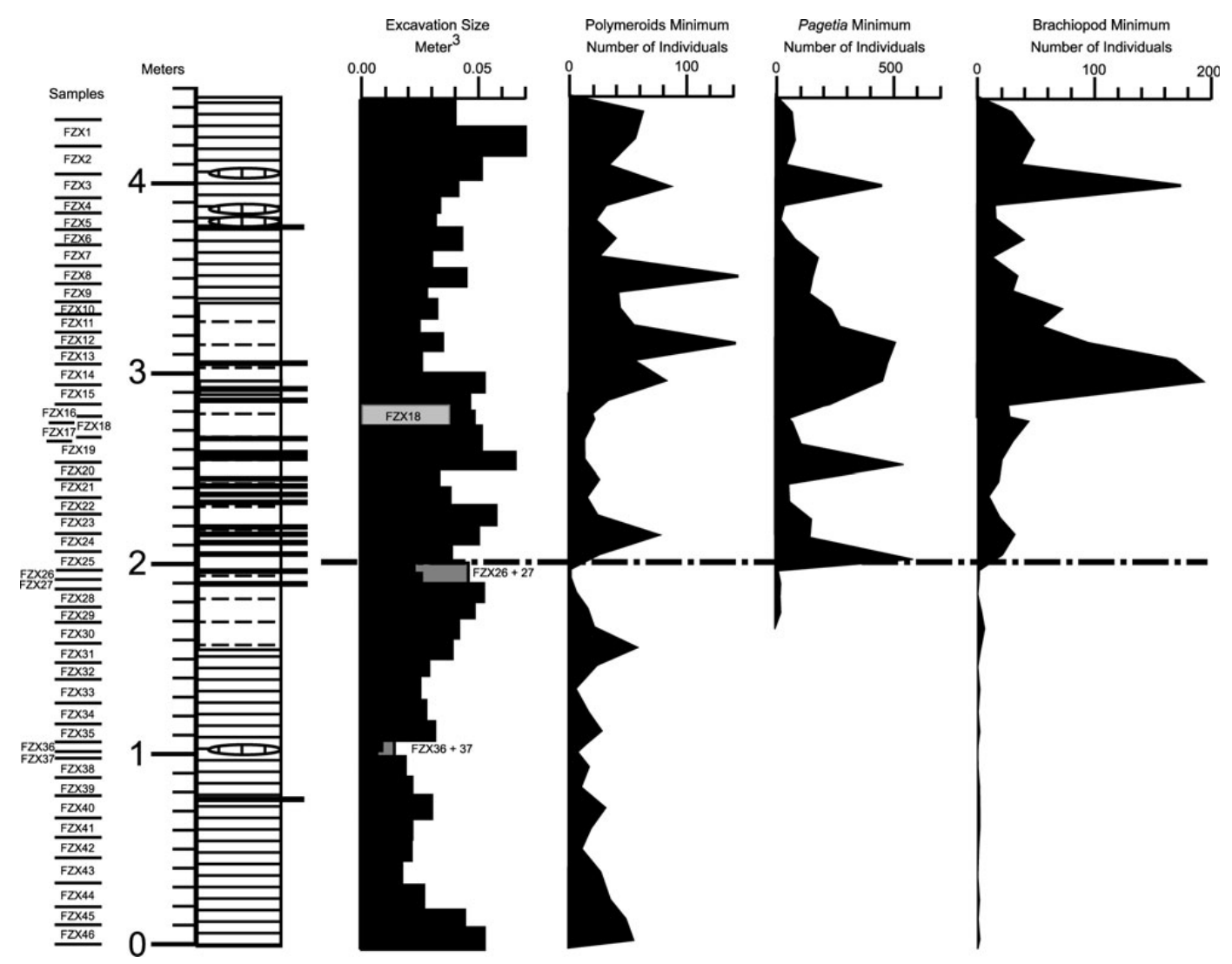

Figure 5. Stratigraphic profile of the Wuliu Quarry illustrating the amount of rock excavated from each level and the minimum number of individual or polymeroid trilobites, Pagetia taijiangensis Yuan \& Zhao in Yuan et al., 1997, and brachiopods (the sum of the abundant inarticulate and the rarer articulate brachiopods). Dashed line is the FAD of Oryctocephalus indicus. Note that the Pagetia count scale is five times greater than the other count scales.

positive cranidia, 13 negative cranidia, 7 positive pygidia, and 10 negative pygidia of a particular species were from a particular excavated level, the minimum number of individuals for that species for that level is 20. Occasionally other sclerites were used to document the number of specimens if the species did not have either cranidia or pygidia present in a level. Specimens of questionable taxonomic assignment were assigned to the closest and/or most abundant species in the surrounding levels. Levels that contain only questionably assigned species are marked with a question mark next to the abundance curves.

The minimum number of individuals differs from the total number of specimens listed under Materials in the systematic section. This number is the sum of each level's maximum number of cranidia (positive or negative), pygidia (positive or negative), and partial or complete shields (positive or negative) for the entire quarry. Using the example given above, this would give a total of 20 cranidia and 10 pygidia for a particular species from a particular excavated level; a total of 30 specimens from that level, not the minimum number of individuals of 20 as given above.

Brachiopods were counted as either positives or negatives. No distinction was made between brachial and pedicle valves due to the difficulty of identifying the differences between the two valves given the molds and casts and poor preservation of some of the material. Because of the lack of distinction between the two valves, abundances of brachiopods were divided in half to provide a minimum number of individuals.

\section{Results}

Lithology. - The Wuliu Quarry section is predominately composed of olive-green to medium-grey claystone (Fig. 4). The stratigraphic package is divided into three units. The upper and lower units are well-bedded claystones with 5 to $15 \mathrm{~mm}$ thick beds, internally laminated. The lower unit is $1.55 \mathrm{~m}$ thick and contains several secondary calcite flakes and layers. One $5 \mathrm{~cm}$ thick micrite nodule occurs at about $1 \mathrm{~m}$ from the bottom of the section. The upper unit is $1.1 \mathrm{~m}$ thick with minor lenticular carbonate layers 2 to $3 \mathrm{~mm}$ thick, grey in color with rust colored rims (altered pyrite; Gaines et al. in press).

The middle unit, which contains the FAD of $O$. indicus, is $1.8 \mathrm{~m}$ thick and composed of irregular bedded claystones with few well-bedded horizons. Beds range from 5 to 


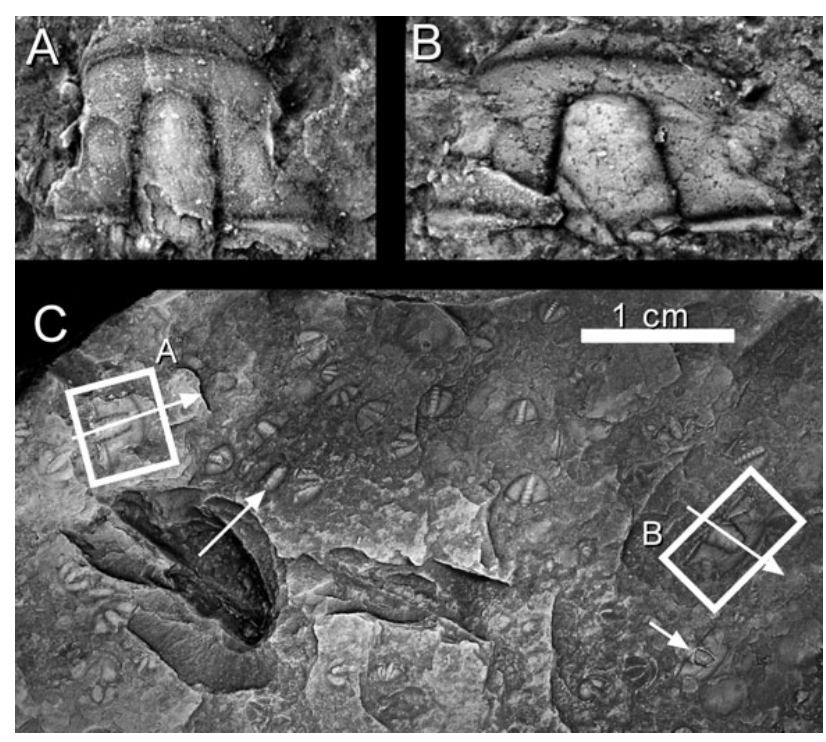

Figure 6. Claystone sample with tectonically distorted specimens of Xingrenaspis xingrenensis Yuan \& Zhou in Zhang et al., 1980, and Pagetia taijiangensis Yuan \& Zhao in Yuan et al., 1997, FZX23. • A - sagittally elongated, partially exfoliated cranidium of Xingrenaspis xingrenensis, $\times 6$, GK B3 0001. $\bullet \mathrm{B}$ - transversely elongated, exfoliated cranidium of Xingrenaspis xingrenensis, $\times 6$, GK B3 0002. $\bullet \mathrm{C}$-claystone slab showing the nearly $90^{\circ}$ orientation of specimen A and B (boxes); arrows point anteriorly, the adjacent cranidia marked with arrows only show the same morphology, $\times 1.6$.

$15 \mathrm{~mm}$ in thickness with internal lamination. Coarser layers are common throughout this unit. These units are typically rusty colored and are the result of altered pyrite (Gaines et al. in press). Many of these layers contain molds and casts of trilobite sclerites suggesting that the carbonate has been dissolved.

Preservation. - Trilobite specimens within the quarry are preserved as isolated specimens or in the current concentrated deposits. Most specimens are disarticulated, although articulated or partially articulated specimens are found in both the claystones and in the current concentrated layers. Specimen size ranges from small meraspids $(\sim 1 \mathrm{~mm})$ to $1 \mathrm{~cm}$ or larger in nearly all horizons. Almost all specimens are molds and casts, few have exoskeletons preserved. Calcite layers separating the mold and cast are common. This calcite is clearly secondary because of the extension of the material into the surrounding bedding plane and its crystalline appearance (also see Zhu et al. 1999).

Trilobite specimens are commonly compressed and cracked due to compaction of the sediments and tectonically distorted. Shear planes cutting through the section and tectonic lineation further document the distortion of the specimens.

Taxonomic distributions. - A total of one Pagetia, two Olenoides Meek, 1877, one Redlichia Cossmann, 1902, eleven oryctocephalid, and seven ptychopariid species were identified from the quarry. The total of 22 trilobite species is less than previously reported (see discussion below) as a result of the more conservative taxonomic approach due to preservation. Only one species of articulate brachiopod and one of inarticulate brachiopod were identified from the quarry.

Detailed collecting throughout the quarry shows considerable variation in the minimum number of individuals found in each level (Fig. 5). The polymeroids average $22 \pm$ 17 minimum number of individuals per excavated level. Correcting for average volume of each excavated level, the average density of the polymeroid minimum number of individuals is about 625 individuals per cubic meter. In contrast, specimens of Pagetia taijiangensis Yuan \& Zhao in Yuan et al., 1997, are much more abundant when they occur (FZX1-29). The average minimum number of Pagetia individuals in these levels is $145 \pm 192$ (skewed distribution produces a large variance) and about 4000 individuals per cubic meter. Brachiopod minimum number of individuals differs below and above the FAD of $O$. indicus. Below the FAD, Eoconcha sp. (Leonid Popov 2010, personal communication; = Nisusia sp. in Huang et al. 1994) averages $2 \pm 1$ individuals in each excavated level were they occur. Above the FAD, Linnarssonia cf. constans Koneva in Gorjansky \& Koneva, 1983 (Leonid Popov 2010, personal communication $=$ L. agyrekensis Koneva, 1979 of Huang et al. 1994) are more abundant, with the minimum number of individuals averaging $19 \pm 13$ per excavated level.

There are several levels that have very low specimen counts; the most significant are FZX26 to 28 where very few fossil specimens are found despite additional collections made from these levels (Fig. 5, FZX26+27, grey rectangle). This relatively barren zone is $20.5 \mathrm{~cm}$ thick within the middle unit of the lithologic section, but does not mark a distinct change in lithology. This barren zone, however, marks the boundary between two distinct assemblages that represent the Ovatoryctocara cf. granulata-Baythyonotus holopygus Zone and the overlying Oryctocephalus indicus Zone (see below).

Non-trilobite fossils found in the Wuliu Quarry, but not discussed further in this publication, range from very rare to abundant. Sponges are represented by rare isolated spicules of Chancelloria (FZX39, 46) and Choia (FZX39). The brachiopods are Linnarssonia cf. constans (FZX1-25, 29-31) and Eoconcha (FZX3, 9, 15, 30, 31, 33, 35, 39-41, 44, 46). The tubular shelly fossil is represented by Cambrovitus balangensis Mao et al., 1992 (FZX32, 34, 35, 39, 40). The molluscs are Scenella radians Babcock \& Robison, 1988 (= Scenella taijiangensis Huang \& Dai, 1998) (FZX16, 31, 34, 41, 43, 45, 46); Helcionella terraustralis Runnegar \& Jell, 1976 in Mao et al. (1993) (FZX9, 12, 14); Latouchella taijiangensis Mao et al., 1993 (FZX5, 13, 14); an unidentified hyolithid (FZX1, 4, 8, 9, 


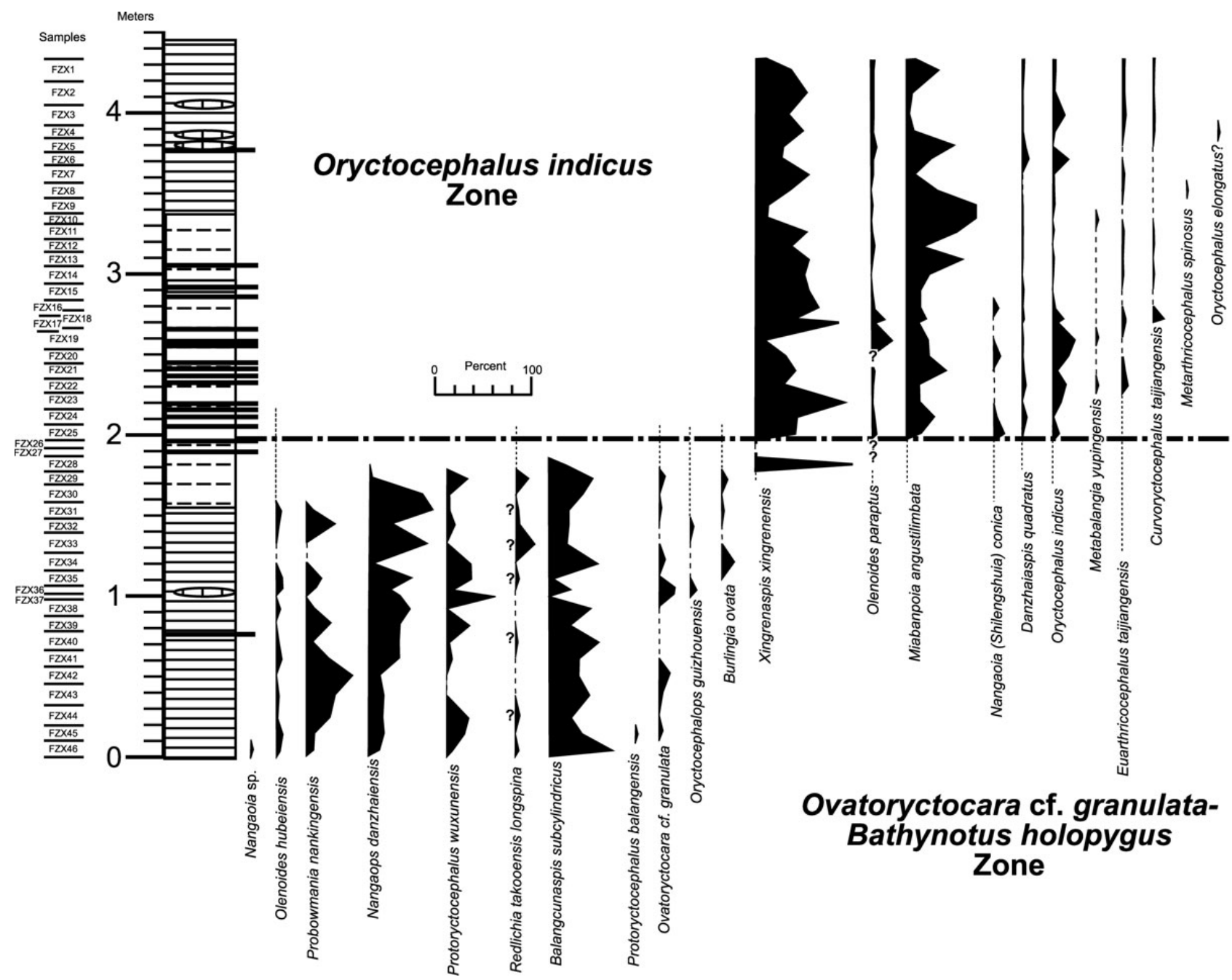

Figure 7. Distribution of the polymeroid trilobites and their relative abundances for each level in the Wuliu Quarry. Relative abundance based on minimal number of individuals and exclusive of Pagetia and brachiopods. The thin dashed lines at the top or bottom of taxa ranges indicate potential range extentions of taxa near the FAD of $O$. indicus. See text for discussion.

12, 14, 16, 23, 29, 33); and isolated sclerites of Wiwaxia taijiangensis Zhao et al., 1994b (FZX2, 7, 14, 15, 18-20, 24, 32, 39, 43, 45). Isolated echinoderm plates probably represent eocrinoids (FZX1, 6-12, 14, 15, 21, 25). The algae are Bosworthia simulans Walcott, 1919, in Mao et al. (1994) (FZX42, 45, 46). The trace fossils are dominated by Trichophycus pedum (Seilacher, 1955) in Lin et al. (2010) (FZX2, 5, 10, 11, 20, 21). The acritarchs from the Kaili Formation and from the Wuliu Quarry have been published by Yin et al. (2010, see for further references).

Biostratigraphy. - The quarry crosses through the boundaries of the regional Qiadongian-Wulingian series, DuynianTaijiangian stages and the Ovatoryctocara cf. granulataBathynotus holopygus and the Oryctocephalus indicus zones (Zhao et al. 2005a). The Wulingian Series, Taijianian Stage and Oryctocephalus indicus Zone are defined by the first occurrence of $O$. indicus. In the Wuliu Quarry, the first occurrence of $O$. indicus is in level FZX25 (Figs 5, 7), approximately $2 \mathrm{~m}$ above the base of the quarry and approximately $52.5 \mathrm{~m}$ above the base of the Kaili Formation.

The Ovatoryctocara cf. granulata-Bathynotus holopygus Zone is the same as the Ovatoryctocara granulataBathynotus holopygus Zone (Yuan et al. 2001, 2002; Zhao et al. 2005a, 2007), but specimens of the index fossil "Ovatoryctocara granulata" were misidentified and is here referred to as the Ovatoryctocara cf. granulata. In addition, this zone has also been referred to as the Bathynotus-Nangaops Zone (Zhao et al. 2001a, b), Bathynotus holopygus-Ovatoryctocara granulata Zone (Zhao et al. 2007), Bathynotus holopygus-Ovatoryctocara cf. granulata Zone (Yuan et al. 2011, Zhao et al. 2011), Ovatoryctocara granulate [sic] Zone (Zhao et al. 2010) and Bathynotus-Redlichia Zone (Lin 2009). 
Common taxa in the lower $2 \mathrm{~m}$ of the quarry (Fig. 7; Ovatoryctocara cf. granulata-Bathynotus holopygus Zone) are the ptychopariids Balangcunaspis subcylindricus Yuan \& Zhao in Yuan et al., 1997, Nangaops danzhaiensis (Zhou in Lu et al., 1974a), and Probowmania nankingensis Lin, 1965, and the oryctocephalid Protoryctocephalus wuxunensis Zhou in Lu et al., 1974b. Rarer species include the corynexochid Olenoides hubeiensis (Sun, 1984); the oryctocephalids Oryctocephalops guizhouensis Zhao \& Yuan in Yuan et al., 2002, Ovatoryctocara cf. granulata and Protoryctocephalus balangensis Zhao \& Yuan in Yuan et al., 2002; the redlichiid Redlichia (Redlichia) takooensis longspina Guo \& Zhao, 1998, and the articulate brachiopod Eoconcha sp. Pagetia taijiangensis and Xingrenaspis xingrenensis Yuan \& Zhou in Zhang et al., 1980, are also rare, but are limited to $40 \mathrm{~cm}$ below the FAD of $O$. indicus.

Common taxa in the upper $2.35 \mathrm{~m}$ of the quarry (Figs 5, 7; Oryctocephalus indicus Zone) are the ptychopariids Miabanpoia angustilimbata (Yuan in Zhang et al., 1980) and Xingrenaspis xingrenensis; the corynexochid Olenoides paraptus Zhao et al., 1994c; the eodiscoid Pagetia taijiangensis, which is the numerically dominate taxon, and the inarticulate brachiopod Linnarssonia cf. constans. Rarer species include the ptychopariids Danzhaiaspis quadratus Yuan \& Zhou in Zhang et al., 1980 and Nangaoia (Shilengshuia) conica Yuan \& Zhao in Yuan et al., 2002; and the oryctocephalids Curvoryctocephalus taijiangensis Zhao \& Yuan in Yuan et al., 2002, Euarthricocephalus taijiangensis Yuan \& Zhou in Yuan et al., 2002, Metabalangia yupingensis Qian \& Yuan in Zhang et al., 1980, Metarthrioceiphalus spinosus Zhao \& Yuan in Yuan et al., 2002, and Oryctocephalus indicus.

Regional index fossils are relatively rare in the quarry. The "lower Cambrian" taxon Redlichia is represented by just 12 specimens (10 minimum individuals) from eight levels, including meraspids, librigena, or cranidia too incomplete to allow specific identification. The "lower Cambrian" taxon Ovatoryctocara cf. granulata is more common, but is still known from only 12 specimens (10 minimum individuals) from eight levels. The last appearance datum (LAD) of both taxa is in level FZX29, approximately $20 \mathrm{~cm}$ below level FZX25 that contains the FAD of $O$. indicus. The "middle Cambrian" taxon Oryctocephalus indicus is more common, but individual levels contain one to three minimum numbers of individuals. Seventy-seven specimens (minimum 60 individuals) of $O$. indicus have been identified from the quarry. Nearly every level from FZX25 to FZX1 (top of section) contains one or more specimens of $O$. indicus.

Analysis of the taxa ranges at or near the FAD of $O$. indicus indicate that the faunal changes illustrated in figure 7 are relatively accurate and not the result of small sample sizes. The probability of each species occurring in an adjacent level(s) to its last or first occurrence was determined. Using the binomial distribution, this analysis evaluate the probability of the minimum number of individuals of that species found in that adjacent level (0), the expected minimum number to be found (mean $\bullet$ sample size), and the sample size ( $\mathrm{n}=$ minimum number of individuals from that level). The sample size increased as the next level up (if the LAD of the species is below the FAD of $O$. indicus) or down (if the FAD of the species is near the FAD of O. indicus) is added to the analysis. The sample size would be the increased and the probability is recalculated. The thin dashed lines in figure 7 show the potential extention of taxa ranges based on this analysis $(p>0.05)$. Most extensions range through the relatively barren zone FZX26 to 28. Those potentially ranging upwards from this barren zone include Olenoides hebeiensis into FZX24 and Redlichia takooensis, Ovactoryctocara cf. granulata, Oryctocephalops guizhouensis, and Burlingia ovata Zhou \& Yuan (in Zhang et al., 1980) into FZX25. Those potentially ranging downwards from this barren zone include Oryctocephalus indicus, and Olenoides paraptus into FZX29; Nangaoia (Schilengshuia) conica to FZX30 and Euarthriocephalus taijiangensis into FZX33. Analyses were not done on Nangaoia sp., Metabalangia yupingensis, Curvoryctocephalus taijiangensis, Metarthriocephalus spinosus or Oryctocephalus elongatus? (Zhao et al., 1997) based on their overall rarity and stratigraphic distance away from the FAD of $O$. indicus.

\section{Discussion}

Comparison to previous work. - Zhao et al. (2005a, fig. 7) provided a detailed range chart from a $4 \mathrm{~m}$ section across the proposed boundary located about $10 \mathrm{~m}$ away from the proposed GSSP. The taxa reported here are less diverse than that reported in that preliminary report. Differences in the reported taxa result from this study's more conservative approach to specific identification due to tectonic distortion, mold and cast preservation, and compaction of specimens, which resulted in the over-splitting of taxa. For example, Zhao et al. (2005a) identify Nangaops brevicus [sic $=$ brevis $]$ Yuan \& Sun in Zhang et al., 1980, N. danzhaiensis, N. elongatus Yuan \& Sun in Zhang et al., 1980, N. latilimbatus Yuan in Zhang et al., 1980, and N. nangaoensis Yuan in Zhang et al., 1980, from below the boundary interval. This study recognizes that the differences between these species are the result of tectonic distortion and compaction of specimens and placed all five species into $N$. danzhaiensis. Most other differences in trilobite identification are probably the result of the two different approaches to identification procedures. Assignment of taxonomic names was done without reference to previously published taxonomic stratigraphic ranges. 
Another inconsistency in the taxon range above and below the FAD of $O$. indicus include Euarthricocephalus Ju, 1983, which was not seen in the quarry section below the FAD. However, the range analysis discussed above indicates that its absence may be due to the taxon's rarity in the section. Genera reported by Zhao et al. (2005a) and not identified in this study include: Arthricocephalus Bergeron, 1899, Bathynotus Hall, 1860, Chittidilla King, 1941, Eokaotaia Yuan \& Zhao, 1994, Kootenia Walcott, 1889, Oryctocephalites Resser, 1939, Paramgaspis Yuan \& Zhao in Yuan et al., 1997, Parashuiyuella, Qiannanagraulos Yuan \& Zhao in Yuan et al., 1997, and Yuehsienszella Zhang, 1957. These inconsistencies may be the result of the number of specimens collected, larger stratigraphic section collected (40 $\mathrm{m}$ above and below the FAD of $O$. indicus), preservation, tectonic distortion, and/or oversplitting of taxa.

FAD of Oryctocephalus indicus. - The first occurrence of Oryctocephalus indicus is presently being considered as the biohorizon to mark the base of the Cambrian Stage 5 (see Zhao et al. 2005a, Sundberg 2009, McCollum \& Sundberg 2010). This study demonstrates that this biohorizon (level FZX25) marks a significant change in trilobite faunas in southwestern China. The occurrence of oryctocephalids and other polymeroids above and below the FAD and the lack of lithologic changes at the FAD suggest that the appearance of $O$. indicus is not environmentally controlled. However, the carbon excursion (Lin 2011) just below the FAD and the abundant occurrence of Pagetia taijiangensis and Linnarssonia cf. constans beginning at this horizon does suggest that some aspect of the regional environment had changed. The presence of Linnarssonia constans in the lower Cambrian Redlichia chinensis-Kootenia gimmelfarbi Zone of Malyi Karatau in Kazakhstan (Holmer et al. 2001, Leonid Popov 2010, personal communication) suggests that the lineage migrated into South China due to some change in the environmental conditions.

The $20.5 \mathrm{~cm}$ relatively barren zone below the FAD of O. indicus (levels FZX 26-28) suggests that level FZX25 may not document the lowest occurrence of $O$. indicus. However, the lack of $O$. indicus below the relatively barren zone and the presence of other oryctocephalids suggest that if the FAD of $O$. indicus is not in level FZX25, then this level is considerably close to the actual FAD in the Kaili Formation. Analysis of range extentions suggests that O. indicus could potentially extend down to FZX29, approximately $30 \mathrm{~cm}$ below the FAD of $O$. indicus in the Wului Quary.

The results from here study confirm previously works (Yuan et al. 1997; Sundberg et al. 1999, 2010; Zhao et al. 2001a, 2001b, 2004, 2005a, 2007) that the FAD of O. indicus at Wuliu-Zengjiayan section is appropeate candidate for the GSSP of the Cambrian Stage 5 or Series 3.

\section{Systematic paleontology}

All illustrated specimens are from the Wuliu Quarry and are deposited in the Museum of College of Resource and Environment Engineering, Guizhou University (GK). Photographed specimens were coated with colloidal graphite or India ink (latex casts) and ammonium chloride sublimate. Material counts presented below are based on the number of positives or negatives, whichever is higher, of cranidia and pygidia counted as described above in the methods.

Suborder Eodiscina Kobayashi, 1939

Family Eodiscidae Raymond, 1913

\section{Genus Pagetia Walcott, 1916}

Type species. - Pagetia bootes Walcott, 1916.

Pagetia taijiangensis Yuan \& Zhao (in Yuan et al., 1997) Figure $8 \mathrm{~A}-\mathrm{Y}$

1997 Pagetia taijiangensis Yuan \& Zhao (in Yuan et al.); p. 499, pl. 1, figs 1-4.

2001a Pagetia sp. - Zhao et al., pl. 1, fig. 4.

2001b Pagetia taijiangensis Yuan \& Zhao (in Yuan et al., 1997). - Zhao et al., pl. 6, fig. 7.

2002 Pagetia taijiangensis Yuan \& Zhao (in Yuan et al., 1997). -Yuan et al., pp. 79, 230, pl. 2, figs 1-4, 6-15.

2002 Pagetia significans Etheridge, 1902. - Yuan et al., pp. 80, 230, pl. 4, figs 3-10, pl. 5, figs 1, 6-11, pl. 57, figs $1-2$.

2005a Pagetia taijiangensis Yuan \& Zhao (in Yuan et al., 1997). - Zhao et al., pl. 6, fig. 7.

2007 Pagetia taijiangensis Yuan \& Zhao (in Yuan et al., 1997). - Zhao et al., fig. 3k.

2009 Pagetia cf. P. significans Etheridge, 1902. - Lin \& Yuan, fig. 2.

2010b Pagetia danzhaiensis Zhang (in Zhang et al., 1980). Sundberg et al., fig. 1.

Material. - 4096 cranidia, 4871 pygidia, 26 complete or partial shields.

Emended diagnosis. - Pagetia with cranidia with poorly defined anterior border, shallow scrobicules, smooth surface, weak ocular ridges, and tapered glabella with occipital spine and shallow glabellar furrows. Pygidia elongated with anterior lateral corners occurring $1 / 2$ pleural field with to axis and flexing about $30^{\circ}$ posterio-laterally, shallow pleural furrows, axis with $4-5$ axial rings, weak axial nodes, sharply rounded terminal piece, and thin terminal spine; and smooth surface. 
Remarks. - Pagetia taijiangensis is the most common trilobite in the upper half of the quarry. Both $P$. taijiangensis and $P$. significans have been identified from this portion of the Kaili Formation (Yuan et al. 2002). Pagetia significans specimens from Australia (Jell 1975) are very similar to P. taijiangensis from the Kaili Formation. Pagetia taijiangensis differs from $P$. significans (based on specimens illustrated by Jell 1975) in the cranidia having a poorly defined anterior border (except internal molds, Fig. 8W), shallower scrobicules, smooth surface, and stronger ocular ridges. The pygidia differ in having the anterior lateral corners occurring closer to the axis and flexing at about $30^{\circ}$ instead of $45^{\circ}$, shallow pleural furrows, and smooth surface.

A few pygidia from the Kaili Formation have a very thin terminal spine (Fig. 8T, U), but this feature is commonly broken leaving only a small bump on the terminal segment of the pygidial axis. The third thoracic segment also has a very thin spine (Fig. 8V, Y), which is rarely preserved.

Pagetia taijiangensis differs from the type material of $P$. danzhaiensis Zhang in Zhang et al., 1980, the latter shows very few or absent (or preserved) scrobicules on the anterior border, a more rounded pygidium with granules and a rounded terminal piece (also see Yuan et al. 2002, pl. 3, figs 9, 10). Pagetia bilobata Lu \& Chien in Yin \& Lee, 1978, and $P$. salva Zhang in Zhang et al., 1980, differ from $P$. taijiangensis in a parallel sided glabella and rounded occipital "spine". However, Zhang (in Zhang et al. 1980, pl. 13, figs 9, 10) and Yuan et al. (2002, pl. 5, fig. 4) illustrate specimens of P. bilobata with a sharp occipital spine. If these specimens are correctly assigned, then the presence and absence of the occipital spine may be a preservation difference as can be seen in some of the specimens of $P$. taijiangensis illustrated by Yuan et al. (2002). Without further detailed study, Pagetia bilobata and $P$. salva are not included into $P$. taijiangensis.

Pagetia miaobanpoensis Yuan \& Huang (in Yuan et al., 2002) differs from $P$. taijiangensis in the glabella having a prominent furrow separating the frontal lobe from the remaining glabella and a pygidium with fewer axial rings and prominent axial ring nodes. A single specimen (Yuan et al. 2002, pl. 3, fig. 5) has a wide postaxial spine; other illustrated pygidia show breakage at the posterior lobe where a spine was attached, but not a large scar that would correspond to such a wide spine seen in the single specimen.

Occurrence. - Kaili Formation, Ovatoryctocara cf. granulata-Bathynotus holopygus and Oryctocephalus indicus zones: Wuliu Quarry level FZX1-29; Wuliu-Zengjiayan and Miaobanpo sections, China.

Order Redlichiida Richter, 1933

Suborder Redlichiina Moore (in Harrington et al., 1959)

Superfamily Redlichiacea Poulsen, 1927

Family Redlichiidae Poulsen, 1927

\section{Genus Redlichia (Redlichia) Cossmann, 1902}

Type species. - Hoeferia noetlingi Redlich, 1899.

\author{
Redlichia (Redlichia) takooensis longspina \\ Guo \& Zhao, 1998 \\ Figure 9A-C
}

1998 Redlichia (Redlichia) takooensis longspina Guo \& Zhao; p. 52, pl. 1, figs 3, 3a.

1999 Redlichia (Redlichia) takooensis longspina Guo \& Zhao, 1998. - Guo et al., pp. 159, 163, pl. 1, figs 1a, b, 2a, b, pl. 2, figs 3, 5-7.

2001a Redlichia (Redlichia) takooensis longspina Guo \& Zhao, 1998. - Zhao et al., pl. 1, fig. 11.

2002 Redlichia (Redlichia) takooensis longspina Guo \& Zhao, 1998. - Yuan et al., pp. 83, 231, pl. 6, figs 1-6.

2007 Redlichia (Redlichia) takooensis longspina Guo \& Zhao, 1998. - Zhao et al., fig. 4j.

2010b Redlichia taijiangensis Guo \& Zhao, 1998. - Sundberg et al., fig. 1.

Material. - 5 cranidia, 1 librigena, 6 partial shields.

Remarks. - Only a few specimens can be firmly established as this species. Diagnostic features include the presence of

Figure 8. Pagetia taijiangensis Yuan \& Zhao in Yuan et al., 1997, all figures $\times 11$. A - cranidium, partially exfoliated, GK B3 0003 , FZX20. $\cdot$ B - cranidium, partially exfoliated, GK B3 0004, FZX11. • C - cranidium, partially exfoliated, GK B3 0005, FZX20. • D - cranidium, partially exfoliated, GK B3 0006, FZX20. $\bullet$ E - cranidium, not exfoliated, GK B3 0007, FZX9. • F-cranidium, not exfoliated, GK B3 0008, FZX29. $\bullet$ - cranidium, exfoliated, GK B3 0009, FZX20. - H - cranidium not exfoliated, GK B3 0010, FZX18. • I - cranidium, partially exfoliated, GK B3 0011 , FZX28. - J - cranidium, partially exfoliated, GK B3 0012, FZX12. $\mathrm{K}$ - pygidium, not exfoliated, GK B3 0013, FZX17. $\bullet$ L - pygidium, not exfoliated, GK B3 0014, FZX9. • M - pygidium, partially exfoliated, GK B3 0015, FZX23. $・ \mathrm{~N}$ - pygidium, not exfoliated, GK B3 0016, FZX8. $\bullet$ - pygidium, not exfoliated, GK B3 0017, FZX17. • P - pygidium, partially exfoliated, GK B3 0018, FZX16. $\bullet$ - pygidium, exfoliated, GK B3 0019, FZX24. not exfoliated, GK B3 0020, FZX8. $\bullet$ S - pygidium, not exfoliated, GK B3 0021, FZX20. $\bullet$ - pygidium, exfoliated, arrow pointing to thin terminal spine, GK B3 0022, FZX8. $\bullet U$ - shield, not exfoliated, latex cast, arrow pointing to thin terminal spine, GK B3 0023, FZX9. $\bullet$ V - shield, not exfoliated, latex cast, arrow pointing to thin thoracic axial spine, GK B3 0024, FZX5. $\bullet$ W - shield, exfoliated, GK B3 0025, FZX20. $・$ X - shield, partially exfoliated, GK B3 0026, FZX11. • Y - shield, not exfoliated, latex cast, GK B3 0027, FZX17. 
Frederick A. Sundberg et al. • Trilobite biostratigraphy across the proposed GSSP for the Cambrian Stage 5

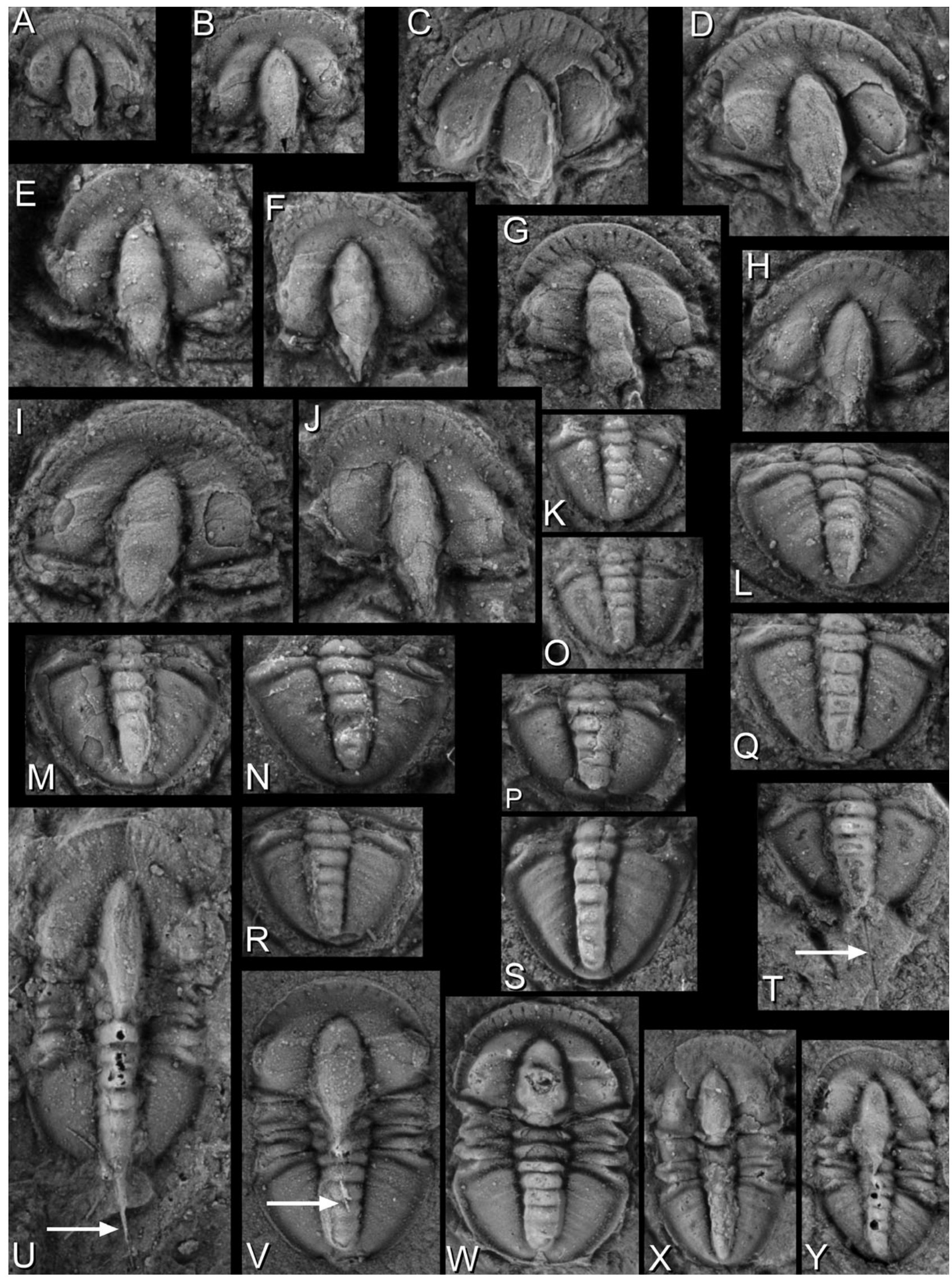




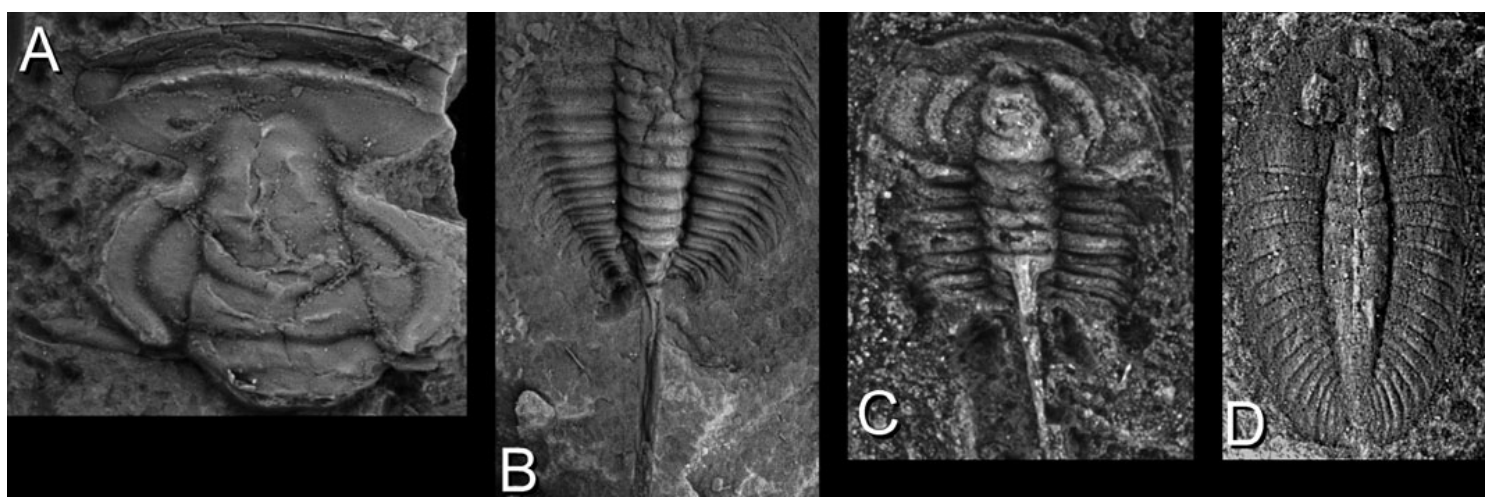

Figure 9. A-C - Redlichia (Redlichia) takooensis longspina Guo \& Zhao, 1998. • A - cranidium, partially exfoliated, GK B3 0028, × 7, FZX29. - B - thorax with terminal spine, exfoliated, GK B3 0029, × 5, FZX44. $\bullet$ C - partial shield, exfoliated, GK B3 0030, × 10, FZX32. D - Burlingia ovata Zhou \& Yuan in Zhang et al., 1980. D - complete shield, exfoliated, GK B3 0031, × 7, FZX29.

a prefrontal area, sharper acute angle between the anterior facial suture and the anterior border, and prominent spine on the thorax. The 12 specimens from the Wuliu Quarry have been assigned to this species, but most specimens are too incomplete or meraspids to allow specific identification. It is possible that some specimens may represent the co-occurring species Redlichia (Redlichia) taijiangensis Guo \& Zhao, 1998 (Yuan et al. 2002).

Occurrence. - Kaili Formation, Ovatoryctocara cf. granulata-Bathynotus holopygus Zone: Wuliu Quarry levels FZX29, 31-33, 35, 40, 44, 46; Wuliu-Zengjiayan section, China.

Uncertain order

Family Burlingiidae Walcott, 1908

\section{Genus Burlingia Walcott, 1908}

Type species. - Burlingia hectori Walcott, 1908.

\section{Burlingia ovata Zhou \& Yuan (in Zhang et al., 1980)} Figure 9D

1980 Burlingia ovata Zhou \& Yuan (in Zhang et al.); pp. 380, 381, pl. 110, fig. 1 .

2001b Burlingia ovata Zhou \& Yuan (in Zhang et al., 1980). - Zhao et al., pl. 7, fig. 4.

2002 Burlingia ovata Zhou \& Yuan (in Zhang et al., 1980). - Yuan et al., pp. 130, 131, 254, 255, pl. 38, figs 3-8, p. 39, figs $1-4$.

2005 Burlingia ovata Zhou \& Yuan (in Zhang et al., 1980). - Lin et al., fig. 3b.

2005a Burlingia ovata Zhou \& Yuan (in Zhang et al., 1980). - Zhao et al., pl. 7, fig. 4.

2005b Burlingia ovata Zhou \& Yuan (in Zhang et al., 1980). - Zhao et al., pl. 3, fig. 11.
Material. - 1 pygidium, 4 complete shield.

Remarks. - The difference between B. ovata and B. multisegmata Zhao et al. in Yuan et al., 2002, are the latter having longer palpebral lobes and 16 thoracic segments vs. 14 segments in B. ovata. Other differences mentioned by Yuan et al. (2002, p. 255) are based on the width of the shield, axial region, and glabella and strongly divergent anterior braches of facial sutures. These wider (tr.) features may be the result of tectonic deformation. The differences between B. ovata and B. primitiva Zhao et al. in Yuan et al., 2002 are the latter having shorter palpebral lobes, more conical glabella and 13-14 thoracic segments. Other differences mentioned by Yuan et al. (2002, p. 255) are based on the width (tr.) and shorter (sag.) shield and gently divergent anterior braches of facial sutures. These features also may be the result of tectonic deformation of the specimens. The stratigraphic ranges of $B$. ovata and B. multisegmenta overlap in the Miaobanpo section (Yuan et al. 2002).

Zhao et al. (2005a, p. 66, 2007, fig. 1) report the range of $B$. ovata as occurring only above the FAD of $O$. indicus. However in this study, $B$. ovata was found only below the FAD of $O$. indicus. This discrepancy in ranges is presently unexplained; it may be to the rarity of the species in the section.

Occurrence. - Kaili Formation, Ovatoryctocara cf. granulata-Bathynotus holopygus Zone: Wuliu Quarry levels FZX29, 31, 34; Oryctocephalus indicus Zone: WuliuZengjiayan and Miaobanpo sections, China.

Order Corynexochida Kobayashi, 1935

Family Dorypygidae Kobayashi, 1935

\section{Genus Olenoides Meek, 1877}

Type species. - Paradoxides (?) nevadensis Meek, 1870. 


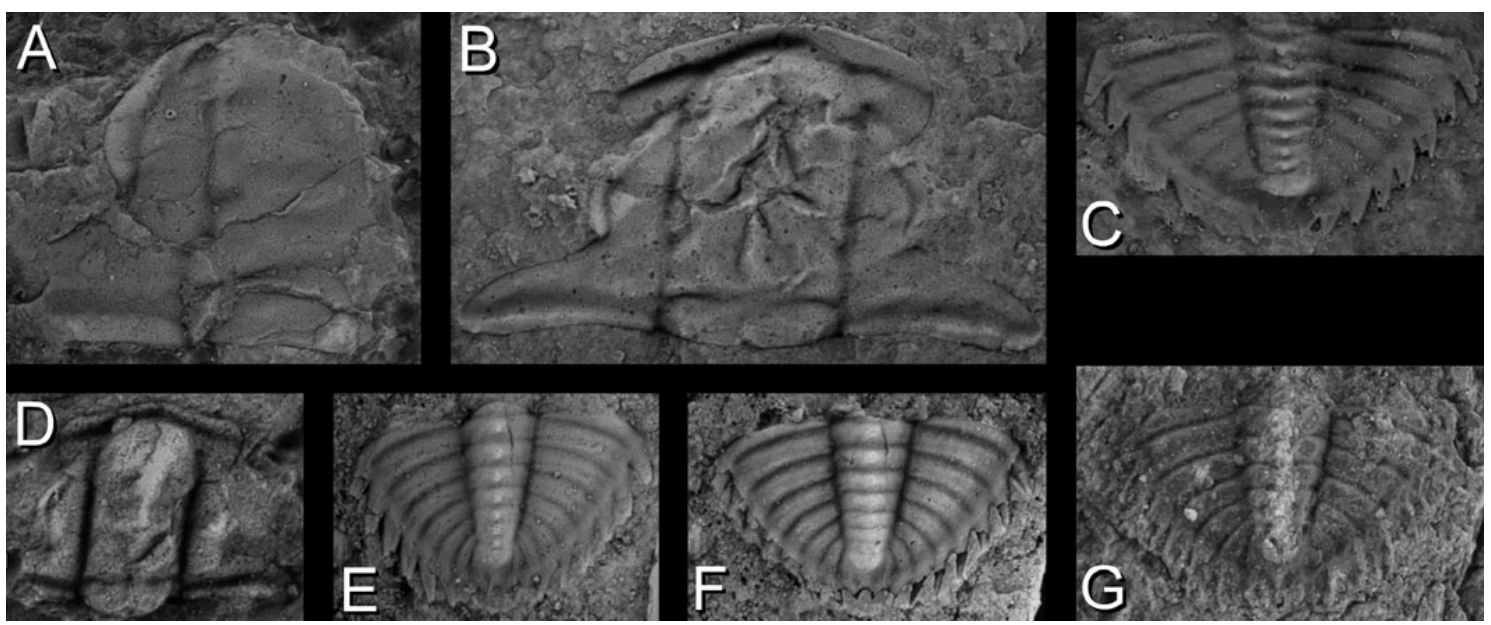

Figure 10. Olenoides hubeiensis (Sun, 1984). $\bullet$ - partial large cranidium, partially exfoliated, GK B3 0032, ×4, FZX31. • B - cranidium, exfoliated, GK B3 $0033, \times 5$, FZX46. $\bullet \mathrm{C}-$ pygidium, not exfoliated, latex cast, $\times 5$, GK B3 0034, FZX35. $\bullet \mathrm{D}$-cranidium, exfoliated, GK B3 0035, $\times 7$, FZX38. $\bullet \mathrm{E}, \mathrm{F}-$ pygidium, GK B3 0036, × 7, FZX31; E - latex cast showing axial nodes, F- exfoliated, most axial nodes absent. $\bullet \mathrm{G}$ - pygidium, calcite coated, GK B3 $0037, \times 7$, FZX38.

\section{Olenoides hubeiensis (Sun, 1984)}

Figures $10 \mathrm{~A}-\mathrm{G}$

1984 Fuchouia huberiensis Sun; p. 350, pl. 134, fig. 13.

1984 Kootenia sp. 1 Sun, pl. 1, figs 5, 6.

1984 Kootenia sp. 2 Sun, pl. 1, fig. 7.

1997 Mengzia sp. Yuan et al., p. 503, pl. 1, fig. 7.

1997 Olenoides abnormis Yuan \& Zhao (in Yuan et al.), pp. 501, 502, pl. 1, fig. 11, pl. 2, figs 11, 12.

1997 Olenoides octaspinus Yuan \& Zhao (in Yuan et al.), p. 502, pl. 1, figs 9, 10, pl. 2, fig. 10.

2002 Olenoides abnormis Yuan \& Zhao (in Yuan et al.). Yuan et al., pp. 92, 93, 233, pl. 10, figs 12-14.

2002 Olenoides hubeiensis (Sun, 1984). - Yuan et al., pp. 92, 93, 233, pl. 10, figs 1-11.

2002 Olenoides transversus Zhao \& Yuan (in Yuan et al.), pp. 93, 94, 233, pl. 11, figs 7, 8, not pl. 13, fig. 10 (=Olenoides paraptus).

2007 Olenoides hubeiensis (Sun, 1984). - Zhao et al., fig. $4 \mathrm{D}, \mathrm{E}$.

Material. - 4 cranidia, 16 pygidia.

Emended diagnosis. - Olenoides with cranidium with parallel sided glabella and prominent ocular ridges. Pygidium with six to seven axial rings, axial nodes, and seven to eight pairs of pleural spines.

Remarks. - The pygidia in the quarry samples have six to seven axial rings. It is very likely that $O$. abnormis Yuan \& Zhao in Yuan et al., 1997, is the same species with transverse elongation due to tectonic distortion. The two illustrated pygidia of Olenoides transversus Zhao \& Yuan in Yuan et al., 2002 (pl. 11, figs 7, 8; no holotype was designated for this species) are tectonically elongated (tr.) and have the same number of axial rings and pygidial spines as $O$. hubeiensis and are included in this species.

Occurrence. - Kaili Formation, Ovatoryctocara cf. granulata-Bathynotus holopygus Zone: Wuliu Quarry levels FZX31-32, 35, 36, 38, 40, 41, 43-46; Qinglinchong and Wuliu-Zengjiayan sections, China.

\section{Olenoides paraptus Zhao, Ahlberg \& Yuan, 1994c Figure $11 \mathrm{~A}-\mathrm{N}$}

1983 Kootenia jialaoensis Lu \& Chien, 1978. - Lu \& Qian, pp. 25, 26, pl. 3, figs 2, 3 .

1994c Olenoides paraptus Zhao et al.; pp. 370, 371, 374, 375, pl. 1, figs 1-4, 6-9.

1997 Olenoides jialaoensis (Lu \& Chien, 1978). - Yuan et al., p. 501, pl. 1, fig. 8 .

1999 Olenoides jialaoensis (Lu \& Chien, 1978). - Yuan et al., pl. 2, figs 12-14.

2001b Olenoides jialaoensis (Lu \& Chien, 1978). - Zhao et al., pl. 6, fig. 6.

2002 Olenoides paraptus Zhao et al., 1994c. - Yuan et al., pp. 91, 92, 232, pl. 11, figs $1-6$, pl. 12, figs $1-8$, pl. 13, figs 1-6.

2002 Olenoides transversus Zhao \& Yuan (in Yuan et al.), pp. 93, 94, 233, pl. 13, fig. 10, not pl. 11, figs 7,8 (= Olenoides hubeiensis).

2005a Olenoides jialaoensis (Lu \& Chien, 1978). - Zhao et al., pl. 6, fig. 6.

2005b Olenoides paraptus Zhao et al., 1994c. - Zhao et al., pl. 3 , fig. 3.

2007 Olenoides paraptus Zhao et al., 1994c. - Lin, fig. 1A.

2010b Olenoides transversus Zhao \& Yuan (in Yuan et al., 2002). - Sundberg et al., fig. 1. 
Material. - 83 cranidia, 60 pygidia, 7 partial or complete shields.

Emended diagnosis. -Olenoides with cranidium with anteriorly expanding glabella and moderate strength to weak ocular ridges. Pygidium with five axial rings, axial nodes, six pairs of pleural spines.

Remarks. - Olenoides paraptus is best recognized by the five pygidial axial rings, five strong interpleural furrows, and six pairs of pygidial spines. Olenoides jialaoensis (Lu \& Chien, 1978) in Yuan et al. (1997) differs in having a more rectangular shaped glabella but this could be the result of tectonic deformation. The type specimen of Kootenia jialaoensis Lu \& Chien, 1978, is a partial cranidium and does not have the features to characterize a species of Olenoides. The cranidium of $O$. transversus (Yuan et al., pl. 13, fig. 10; no holotype was designated for this species) is most likely a tectonically distorted specimen of $O$. paraptus and is included into this species.

Fragments composed of a thick exoskeleton with a granular surface similar to Olenoides paraptus are found at FZX20, 26, and 27. None of the fragments are large enough to allow specific identification. These occurrences are marked with question marks in Fig. 7. Zhao et al. (2007, fig. 1) report this taxon from the upper $8.5 \mathrm{~m}$ of the Ovatoryctocara cf. granulata-Bathynotus holopygus Zone, but no specimens below FZX25 were identified in this study.

Occurrence. - Kaili Formation, Ovatoryctocara cf. granulata-Bathynotus holopygus and Oryctocephalus indicus zones: Wuliu Quarry levels FZX1-19, ?20, 21, 23-25, ?26, ?27; Wuliu-Zengjiayan and Miaobanpo sections, China.

Family Oryctocephalidae Beecher, 1897

Remarks. - Most of the taxa assigned to this group are relatively easy to identify, although like the ptychopariids (see below), the identification can be questionable due to taphonomic problems, such as compression and tectonic deformation. In addition, the collapse of the frontal lobe due to the in situ hypostome obscures the presence and shape of the pits and furrows on the glabella.
Subfamily Oryctocephalinae Beecher, 1897

\section{Genus Oryctocephalus Walcott, 1886}

Type species. - Oryctocephalus primus Walcott, 1886.

Remarks. - Yuan et al. (2002) subdivided the genus into two subgenera, Oryctocephalus and Eoryctocephalus. The differences between the two subgenera are significant, but need to be tested with cladistic analysis. Eoryctocephalus has more primitive features than Oryctocephalus such as wider pleural lobes and fewer pygidial segments. These features may not be enough to separate the taxa.

\section{Oryctocephalus indicus (Reed, 1910)}

Figure 12A-L

1910 Zacanthoides indicus Reed; pp. 9, 10, pl. 1, fig. 15.

1910 Oryctocephalus cf. reynoldsi Reed, p. 12, pl. 1, figs 22,23 .

1934 Oryctocephalus orientalis Saito (in part), pp. 230, 231, pl. 25, fig. 21, not figs $17-20,22=$ O. orientalis Saito, 1934.

1934 Oryctocephalus kobayashii Saito, pp. 231, 232, pl. 25, figs 23-25.

1938 Oryctocephalus indicus (Reed, 1910). - Resser, p. 38.

1944 Oryctocephalus indicus (Reed, 1910). - Kobayashi, p. 33.

1967 Oryctocephalus indicus (Reed, 1910). - Kobayashi, p. 487, figs 7-11a, b.

1974b Oryctocephalus incurvus Lu \& Chien (in Lu et al.), p. 101 , pl. 39 , fig. 8 .

1980 Oryctocephalus cf. incurvus Lu \& Chien (in Lu et al., 1974a). - Zhang et al., p. 270, pl. 96, figs 13-15.

1983 Oryctocephalops incurvus (Lu \& Chien, 1974). - Lu \& Qian, p. 26, pl. 3, figs 6, 7.

1983 Oryctocephalops tongrenensis Lu \& Qian, p. 27, pl. 3, figs 4, 5 .

1997 Oryctocephalops tongrenensis Lu \& Qian, 1983. Yuan et al., pl. 4, figs 8, 9.

1997 Oryctocephalus indicus (Reed, 1910). - Jell \& Hughes, pp. 34, 35, figs 7a-c, pl. 5, figs 16-19.

1997 Oryctocephalus indicus (Reed, 1910). - Sundberg \& McCollum, pp. 1073-1077, figs 9.1-9.8, 9.10.

Figure 11. Olenoides paraptus Zhao, Ahlberg \& Yuan, 1994c. $\bullet$ A - cranidium, not exfoliated, GK B3 0038, ×5, FZX1. • B - cranidium, not exfoliated, GK B3 0039, × 5, FZX9. • C - cranidium, not exfoliated, GK B3 0040, × 3, FZX19. • D - cranidium, partially exfoliated, GK B3 0041, × 5, FZX9. $\bullet$ E - cranidium, not exfoliated, GK B3 0042, × 3, FZX23. $•$ F - cranidium, not exfoliated, latex cast, GK B3 0043, × 3, FZX10. $\bullet$ G - cranidium, partially exfoliated, $\times 3$, GK B3 0044, FZX11. $\bullet$ H, I - cranidium, not exfoliated, × 3, I - enlarged portion showing fine granules, $\times 6$, GK B3 0045 , FZX12. $\bullet \mathrm{J}$ - pygidium, not exfoliated, $\times 3$, GK B3 0046, FZX9. $\bullet$ K - pygidium, not exfoliated, $\times 3$, GK B3 0047, FZX4. $\bullet$ L - pygidium, not exfoliated, $\times 3$, GK B3 0048, FZX4. • M - shield, mostly exfoliated, $\times 2$, GK B3 0050, FZX7. • N - pygidium, not exfoliated, latex cast, $\times 3$, GK B3 0049, FZX7. 


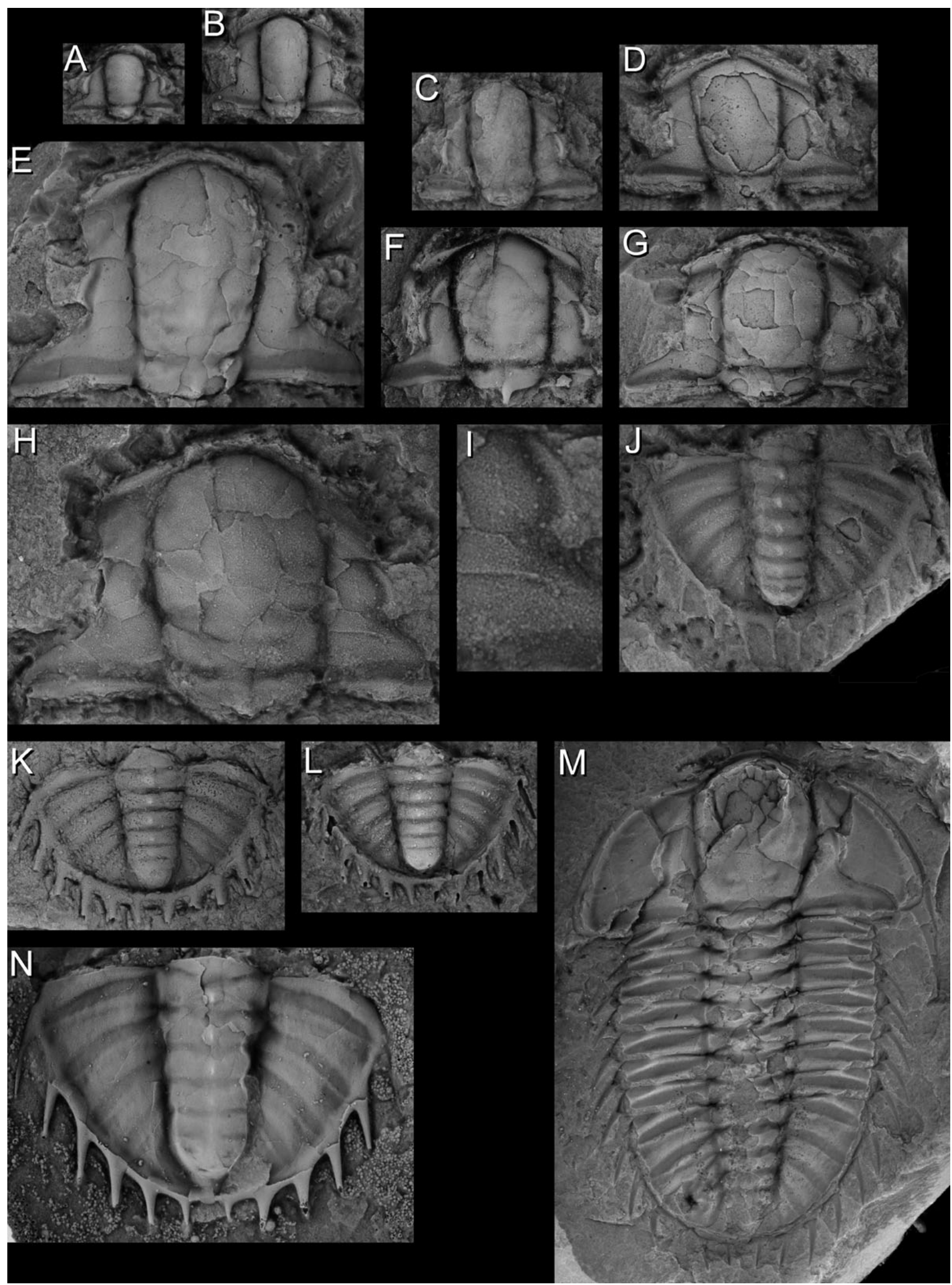




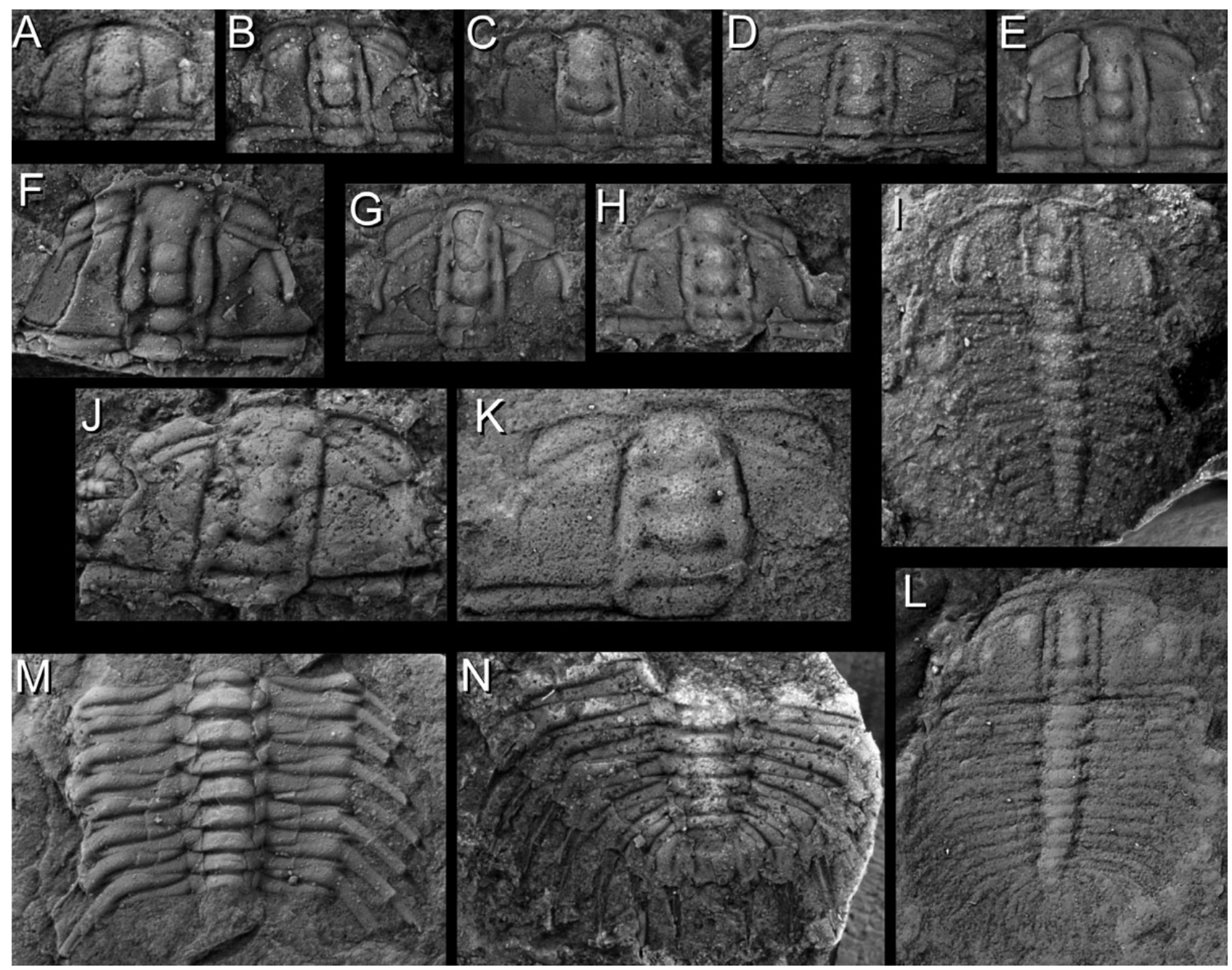

Figure 12. Oryctocephalus indicus (Reed, 1910), all figures $\times 7$ unless otherwise noted. $\cdot$ A - cranidium, exfoliated, GK B3 $0051, \times 10$, FZX2. - B - cranidium, partially exfoliated, GK B3 0052, FZX12. • C - cranidium, exfoliated, GK B3 0053, FZX14. • D - cranidium, exfoliated, GK B3 0054, FZX19. $\bullet$ E - cranidium, mostly exfoliated, GK B3 0055, FZX8. $\bullet$ F - cranidium, partially exfoliated, GK B3 0056, FZX11. $\bullet \mathrm{G}-$ cranidium, mostly exfoliated, with hypostome impression, GK B3 0057, FZX17. $\bullet \mathrm{H}$ - cranidium, exfoliated, GK B3 0058, FZX8. $\bullet$ - shield, not exfoliated, with hypostome impression, latex cast, GK B3 0059, FZX3. • J - cranidium, exfoliated, GK B3 0060, FZX25. K - partial cranidium, exfoliated, GK B3 0061 , FZX6. $\cdot \mathrm{L}$ - nearly complete shield, exfoliated, GK B3 0064, ×5, FZX16. $\bullet$ M - thoracic segments, calcite coated, GK B3 0062, FZX13. $\bullet$ - thoracic segments and pygidium, mostly exfoliated, GK B3 0063, FZX22.

1997 Oryctocephalus indicus (Reed, 1910). - Yuan et al., pl. 4, figs $1-6,8,9$.

1999 Oryctocephalus indicus (Reed, 1910). - Sundberg et al., pl. 1, fig. 3.

1999 Oryctocephalus indicus (Reed, 1910). - Yuan et al., pl. 1 , fig. 6 .

1999 Oryctocephalus indicus (Reed, 1910). - Zhao et al., pl. 4 , fig. 4.

2001 Oryctocephalus orientalis Saito, 1934. - Yuan et al., pl. 1 , fig. 2 .

2001 Oryctocephalus (O.) indicus (Reed, 1910). - Yuan et al., pl. 1, fig. 3.

2001a Oryctocephalus indicus (Reed, 1910). - Zhao et al., pl. 1 , figs 2,3 . 2001b Oryctocephalus indicus (Reed, 1910). - Zhao et al., pl. 6, figs 1,8 .

2002 Oryctocephalus (Oryctocephalus) indicus indicus (Reed, 1910). - Yuan et al., pp. 100, 101, 237, pl. 17, figs $1-9$, pl. 18 , figs $1-8$, pl. 19, figs $1-4$, pl. 20 , figs $4-9$, pl. 21, fig. 7, pl. 22, fig. 5, pl. 23, figs $1-4$, pl. 29, figs 6, 7 .

2002 Oryctocephalus (Oryctocephalus) indicus latus (Reed, 1910). - Yuan et al., pp. 101, 102, 237, pl. 20, figs 2,3 , pl. 21, figs $1-3,5,6$, pl. 22, fig. 2, 7, 8, pl. 28 , figs $9,10$.

2002 Oryctocephalus (Oryctocephalus) orientalis Saito, 1934. - Yuan et al., pp. 103, 238, pl. 22, figs 3-6, 9, 10 ?, pl. 28, figs 6-8. 
2003 Oryctocephalus indicus (Reed, 1910). - Sundberg \& McCollum, pp. 960, 962, pl. 8, figs 9, 12, 13.

2005 Oryctocephalus indicus (Reed, 1910). - Lin et al., fig. 3a.

2005a Oryctocephalus indicus (Reed, 1910). - Zhao et al., pl. 6 , fig. 1,8 .

2005b Oryctocephalus indicus (Reed, 1910). - Zhao et al., pl. 3, fig. 4.

2006 Oryctocephalus indicus (Reed, 1910). - Zhao et al., pp. 1178-1181, figs $1 \mathrm{a}-\mathrm{j}$.

2007 Oryctocephalus indicus (Reed, 1910). - Zhao et al., figs 5a-e.

2008 Oryctocephalus indicus (Reed, 1910). - Zhao et al., pl. 4, fig. 13.

2009 Oryctocephalus indicus (Reed). - Luo et al., pl. 9, figs 4-6a.

Material. - 53 cranidia, 6 pygidia, 18 partial or complete shields.

Diagnosis. - See Jell \& Hughes (1997) and Sundberg \& McCollum (1997).

Remarks. - The differences between $O$. (O.) indicus indicus and $O$. (O.) indicus latus are the result of tectonic distortion with the latter being transversely elongated. They also occur in the same horizons in the WuliuZengjiayan and Miaobanpo sections (Yuan et al. 2002). Specimens of $O$. orientalis Saito, 1934, illustrated by Yuan et al. (2002) fall within the morphological range of O. indicus.

Zhao et al. (2006) redefined the morphological range of $O$. indicus based primarily on the material from the Kaili Formation. In this redefinition, O. indicus was given a range of 1 to 3 transglabellar furrows. This was probably the primary justification for adding Oryctocephalus reticulatus (Lermontova, 1940) to their synonymy list. Korovnikov (2001, personal communication 2010) has also suggested that $O$. reticulatus is synonymous with $O$. indicus. The type material of Oryctocephalina reticulata Lermontova, 1940, is unlike subsequent material illustrated as Oryctocephalus reticulatus (Lermontova) by Tchernysheva (1962) and Shabanov et al. (2008a, b). The type material has a strongly curved anterior border opposed to the slightly curved anterior border of later illustrated material. The specimens later illustrated as Oryctocephalus reticulatus are very similar to $O$. indicus, but differ in having only the S1 transglabellar furrow.

To determine if $O$. indicus and $O$. reticulatus are separate species, a limited study of $O$. indicus from the Kaili Formation and the Emigrant Formation, Nevada, and $O$. reticulatus from the Kuonamka Formation, Siberia was done. All specimens were photographed or viewed under a microscope with low angle light. None of the specimens were whitened due to the humidity while the material was studied at Guizhou University (ammonium chloride sublimate dissolves too quickly in high humidity). Thus the results are biased against observing shallow transglabellar furrows. The study of the $O$. indicus from the Miaobanpo section indicates that the number of transglabellar furrows varies in the specimens. Well-preserved specimens $(n=57)$ in the mudstone show transglabellar furrows $100 \%$ of the cases for the SO and S1 positions; $96 \%$ for the S2, and $77 \%$ for the S3. In comparison, specimens $(n=68)$ also preserved in mudstone from a $30 \mathrm{~cm}$ interval from Split Mountain section, Nevada (Sundberg \& McCollum 2003) show transglabellar furrows $100 \%$ of the cases at the SO, S1, and S2 positions and $93 \%$ at the $\mathrm{S} 3$. Shale specimens $(n=100)$ from the same Split Mountain $30 \mathrm{~cm}$ interval illustrate that compaction has little influence on the number of transglabellar furrows with the furrows present $100 \%$ of the cases at the SO, S1, and S2 positions and $98 \%$ at the S3. Orytocephalus reticulatus shale specimens $(n=93)$ from two horizons in the Molodo River section show that the transglabellar furrows are present $100 \%$ of the cases at the $\mathrm{SO}$ and $\mathrm{S} 1$, and $41 \%$ at the S2, and only $3 \%$ at the $\mathrm{S} 3$. Most of the specimens of $O$. reticulatus that show furrows at the S2 and S3 positions have glabellar lengths less than $2.5 \mathrm{~mm}$. The disappearance of the furrows in larger specimens is probably an ontogenetic change. This indicates that $O$. reticulatus is not synonymous with $O$. indicus. Further study is being done on both taxa by Mark Webster (personal communication, 2010) using the material from this preliminary study and Elena Naimark (personal communication, 2010) using the large collections of $O$. reticulatus from Russia.

This variation in the number of transglabellar furrows in the Kaili specimens may be the result of: different species being present; morphological variation in the Chinese population (the same variation is seen in the coeval O. nyensis Palmer in Palmer \& Halley, 1979 from Nevada - Sundberg \& McCollum 1997) and/or tectonic distortion. Many of the specimens from the Kaili Formation are distorted. A specimen from FZX16 (Fig. 12L) is relatively large, and has perhaps only two transglabellar furrows, but the surface of the specimen is weathered. The lowest horizon (FZX25) has two well-preserved cranidia with all three transglabellar furrows (e.g., Fig. 12J).

Occurrence. - Oryctocephalus indicus Zone: Kaili Formation, Wuliu Quarry levels FZX1-4, 6-9, 11-25; WuliuZengjiayan and Miaobanpo sections, China; Emigrant Formation, Split Mountain section, Nevada, USA; Monola Formation, California and Nevada, USA; Maozhuangian Stage, Spiti, India; Mansanri Formation, Korea. 


\section{Oryctocephalus elongatus? (Zhao, Ahlberg \& Zhou,} 1997)

Figure 13A

1996 Oryctocephalina yui Zhao et al.; pl. 2, fig. C.

1997 Oryctocephalina elongatus Zhao, Ahlberg \& Zhou, pl. 1, figs 1, 5-7.

1997 Oryctocephalina elongatus guizhouensis Zhao, Ahlberg \& Zhou, pl. 1, fig. 2.

2001b Oryctocephalina elongata Zhao, Ahlberg \& Zhou, 1997. - Zhao et al., pl. 6, fig. 2.

2002 Oryctocephalus (Eoryctocephalus) yui Zhao \& Yuan (in Yuan et al.), pp. 104, 105, 239, 240, pl. 21, fig. 4, pl. 22, fig. 1, pl. 25, figs 1-8.

2005a Oryctocephalus (Eoryctocephalus) yui Zhao \& Yuan (in Yuan et al., 2002). - Zhao et al., pl. 6, fig. 2.

2005b Oryctocephalus (Eoryctocephalus) yui Zhao \& Yuan (in Yuan et al., 2002). - Zhao et al., pl. 3, fig. 7.

2010b Oryctocephalina yui Zhao \& Yuan (in Yuan et al., 2002). - Sundberg et al., fig. 1.

Material. - 1 pygidium.

Remarks. - The type species is Oryctocephalina renticulata is presently assigned to Oryctocephalus (Tchernysheva 1962, Savitsky et al. 1972, Shabanov et al. 2008a, b), thus Oryctocephalina elongatus guizhouensis Zhao, Ahlberg \& Zhou, 1997, is transfered to Oryctorcephalus.

A single pygidium from FZX4 is questionably assigned to this species due to the long, relatively flat pygidial spines. The first use of the name Oryctocephalina yui was by Zhao et al. (1996), however, the first description of $O$. yui was in Yuan et al. (2002). Oryctocephalina elongatus described in 1997 is the senior synonym.

It is possible that Oryctocephalus elongatus is tectonically elongated (sag.) where Oryctocephalus sinicus Zhao \& Yuan in Yuan et al., 2002 is tectonically widened (tr.). These two species may represent a single species, but more detailed work is needed to synonymize them. Both species are found in the same horizons in the Wuliu-Zengjiayan section and adjacent horizons in the Miaobanpo section (Yuan et al. 2002).

Occurrence. - Kaili Formation, Oryctocephalus indicus Zone: Wuliu Quarry level FZX4; Wuliu-Zengjiayan and Miaobanpo sections, China.

\section{Genus Curvoryctocephalus Zhao \& Yuan (in Yuan et al., 2002)}

Type species. - Curvoryctocephalus taijiangensis Zhao \& Yuan (in Yuan et al., 2002).

\section{Curvoryctocephalus taijiangensis Zhao \& Yuan} (in Yuan et al., 2002)

Figure 14A-H

2002 Curvoryctocephalus taijiangensis Zhao \& Yuan (in Yuan et al.), pp. 112, 244, pl. 26, figs 2-9.

2002 Curvoryctocephalus sinensis Zhao \& Yuan (in Yuan et al.), pp. 112, 113, 211, pl. 26, fig. 1 .

Material. - 9 cranidia, 2 complete shields.

Remarks. - This species is distinctive with a relatively long (sag.) anterior border and parallel to slightly expanding glabellar with undulatory glabellar furrows (when not distorted by compaction). Only two species have been defined in this genus, $C$. taijiangensis and $C$. sinensis Zhao \& Yuan in Yuan et al., 2002. Based on a limited number of samples from this study and those illustrated by Yuan et al. (2002), these two species are probably conspecific. Curvoryctocephalus sinensis longer (sag.) anterior border is probably due to its larger size specimen than those of $C$. taijiangensis. This increase in anterior border length is probably due to ontogenetic variation. Both $C$. taijiangensis and $C$. sinensis are reported from the same stratigraphic horizons in the Miaobanpo section (Yuan et al. 2002).

Occurrence. - Kaili Formation, Oryctocephalus indicus Zone: Wuliu Quarry levels FZX1-4, 11, 12, 14, 17; Wuliu-Zengjiayan and Miaobanpo sections, China.

\section{Genus Oryctocephalops Lermontova, 1940}

Type species. - Oryctocephalops frishenfeldi Lermontova, 1940.

\author{
Oryctocephalops guizhouensis Zhao \& Yuan \\ (in Yuan et al., 2002) \\ Figures 13B, C
}

1997 Oryctocephalops sp. Yuan et al.; pl. 3, fig. 5.

2001a Oryctocephalops guizhouensis Zhao \& Yuan (in Yuan et al., 2002). - Zhao et al., pl. 1, figs 5, 6.

2002 Oryctocephalops guizhouensis Zhao \& Yuan (in Yuan et al.); pp. 96, 235, pl. 15, figs 4-7, pl. 16, figs 2-7.

2007 Oryctocephalops guizhouensis Zhao \& Yuan (in Yuan et al., 2002). - Zhao et al., figs 4A, B.

Material. - 9 cranidia, 1 pygidium, 1 complete shield.

Remarks. - Distortion causes difficulty in separating cranidia of Protoryctocephalus wuxunensis, Oryctocephalops guizhouensis and Oryctocephalites taijiangensis 
Zhao \& Yuan in Yuan et al., 2002. The palpebral lobes of Oryctocephalops guizhouensis are relatively shorter than the other two species. The pygidia of the latter two species are better defined from the thorax and with pygidial and thoracic spines about half the length of Oryctocephalites taijiangensis. The status of Oryctocephalops ellipsoidalis Zhao \& Yuan in Yuan et al., 2002, cannot be established due to only one specimen illustrated by Yuan et al. (2002, pl. 16, fig. 1) and the limited number of specimens of O. guizhouensis found during this study and illustrated by Yuan et al. (2002, pl. 15, figs 4-7, pl. 16, figs 2-7).

Occurrence. - Kaili Formation, Ovatoryctocara cf. granulata-Bathynotus holopygus Zone: Wuliu Quarry levels FZX32, 36; Wuliu-Zengjiayan section, China.

\section{Genus Protoryctocephalus Zhou (in Lu et al., 1974b)}

Type species. - Protoryctocephalus wuxunensis Zhou (in Lu et al., 1974b).

\section{Protoryctocephalus wuxunensis Zhou \\ (in Lu et al., 1974b) \\ Figure 13F-M}

1974a Protoryctocephalus wuxunensis Zhou (in Lu et al.), p. 93 , pl. 3, fig. 4 .

1974b Protoryctocephalus wuxunensis Zhou (in Lu et al., 1974b). - Zhou (in Lu et al.), p. 95, pl. 36, fig. 11.

1978 Protoryctocephalus wuxunensis Zhou (in Lu et al., 1974b). - Zhou (in Yin \& Lee), p. 440, pl. 156, fig. 1.

1980 Protoryctocephalus wuxunensis Zhou (in Lu et al., 1974b). - Zhou (in Zhang et al.), p. 270, pl. 91, fig. 1.

1997 Oryctocephalops sp. in Yuan et al., pl. 3, figs 1, 2.

2001 Protoryctocephalus wuxunensis Zhou (in Lu et al., 1974b). - Yuan et al., pl. 1, fig. 6.

2002 Protoryctocephalus wuxunensis Zhou (in Lu et al., 1974b). - Yuan et al., pp. 94, 95, 234, pl. 14, figs 1, 2.

2002 Protoryctocephalus elongatus Zhao \& Yuan (in Yuan et al.), pp. 95, 96, 234, pl. 14, fig. 8, pl. 16, figs 8, 9 .

Material. - 22 cranidia, 21 pygidia, 10 complete or partial shields.

Emended diagnosis. -Protoryctocephalus with cranidium with SO and S1 transglabellar furrow.

Remarks. - The biggest difficulty in the specific identification of this taxon is the compaction of the frontal lobe as the result of compression onto the hypostoma. Protoryctocephalus wuxunensis is probably the same species as $P$. elongatus Zhao \& Yuan in Yuan et al., 2002, with the latter being tectonically stretched (Fig. 13K, L vs. Fig. 13G). Protoryctocephalus balangensis Zhao \& Yuan in Yuan et al., 2002, differs from $P$. wuxunensis in having more than one transglabellar furrow. As with $O$. indicus, the number of furrows may be the result of tectonic distortion and compaction. In the samples studied here, most specimens have only one obvious transglabellar furrow. Only P. balangensis has been previously reported from the WuliuZengjiayan section (Yuan et al. 2002). Protoryctocephalus wuxunensis has not been previously reported in faunal lists from either the Wuliu-Zengjiayan or Miaobanpo sections (Yuan et al. 2002).

Occurrence. - Ovatoryctocara cf. granulata-Bathynotus holopygus Zone: Wuliu Quarry levels FZX29-32, 33-37, 39-41, 44-46, China.

\section{Protoryctocephalus balangensis Zhao \& Yuan (in Yuan et al., 2002)}

Figure 13N

2002 Protoryctocephalus balangensis Zhao \& Yuan (in Yuan et al.); pp. 94, 95, 234, pl. 14, figs 3-7, pl. 15, figs 1, 2.

Material. - 1 complete shield.

Remarks. - The specimen from FZX45 clearly show three transglabellar furrows and is assigned to this species.

Occurrence. - Kaili Formation, Ovatoryctocara cf. granulata-Bathynotus holopygus Zone: Wuliu Quarry level FZX45; Wuliu-Zengjiayan and Miaobanpo sections, China.

Subfamily Oryctocarinae Hupé, 1953

Genus Euarthricocephalus Ju, 1983

Type species. - Euarthricocephalus laterilobatus Ju, 1983.

\section{Euarthricocephalus taijiangensis Zhou \& Yuan} (in Yuan et al., 2002)

Figure $15 \mathrm{~F}-\mathrm{L}$

1997 Euarthricocephalus sp. 1, Yuan et al., pl. 3, figs 9, 10.

1999 Microryctocara sp., Sundberg et al., pl. 1 fig. 2.

2001b Microryctocara sp., Zhao et al., pl. 6, figs 5.

2002 Euarthricocephalus (Euarthricocephalus) taijiangensis Zhao \& Yuan (in Yuan et al.); pp. 118, 248, pl. 33, figs 2, 3, pl. 34, figs 2-9, pl. 35, figs 2, 3 .

2005a Euarthricocephalus taijiangensis Zhao \& Yuan (in Yuan et al., 2002). - Zhao et al., pl. 6, fig. 5. 


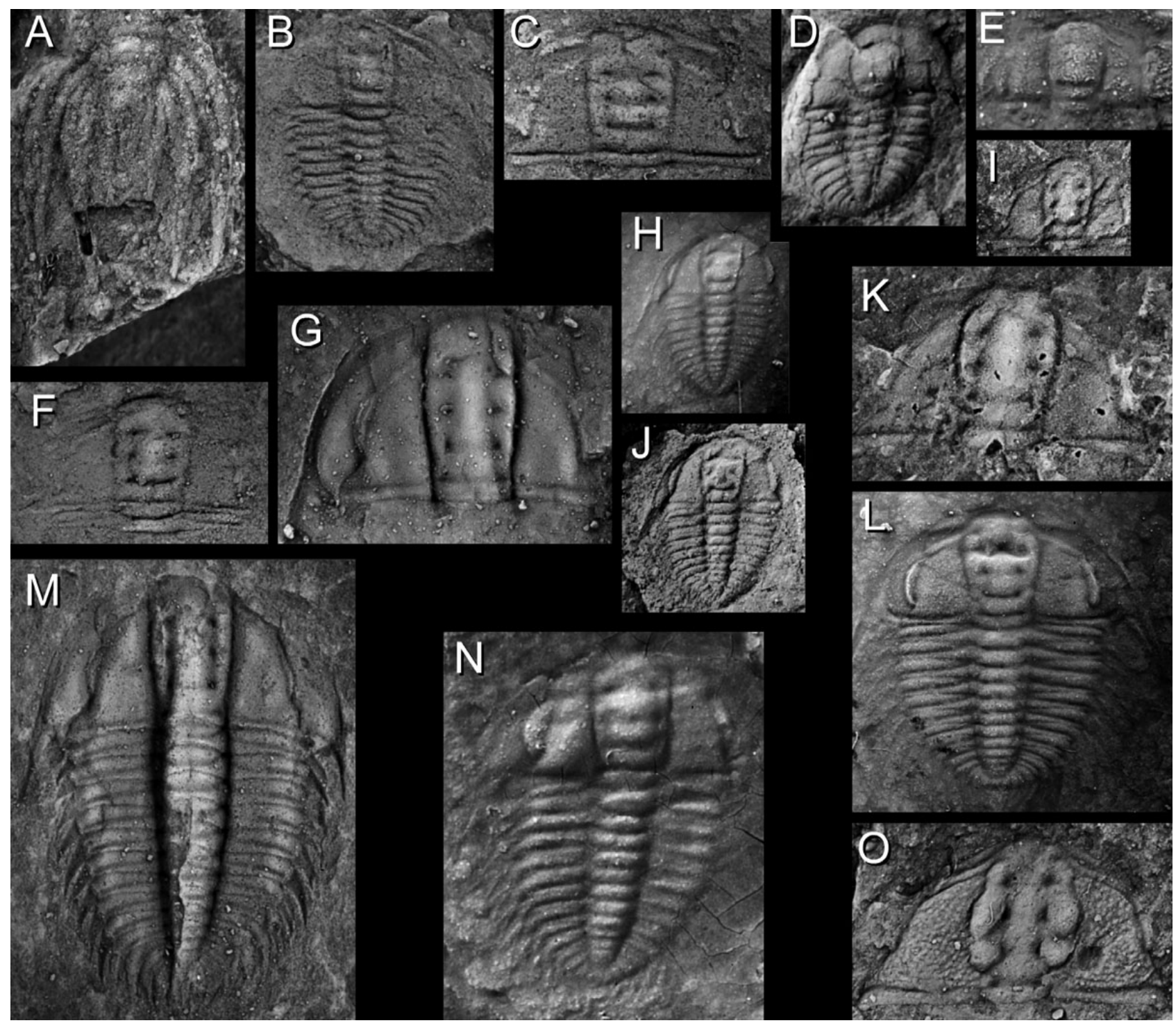

Figure 13. A-Oryctocephalus elongates? (Zhao, Alberg \& Zhou, 1997), cranidium, calcite coated, GK B3 0070, $\times 8$, FZX4. $\bullet$ B, C - Oryctocephalops guizhouensis Zhao \& Yuan in Yuan et al., 2002; B - partial shield, calcite coated, GK B3 0065, × 8, FZX36, C - cranidium, exfoliated, GK B3 0066, × 8, FZX32. D, E-Metabalangia yupingensis Qian \& Yuan in Zhang et al., 1980; D - shield, exfoliated, GK B3 0072, × 10, FZX22, E - cranidium, not exfoliated, latex cast, GK B3 0071, $\times 12$, FZX19. $\bullet$ F-M - Protoryctocephalus wuxunensis Zhou in Lu et al., 1974b, all $\times 8$. $\bullet$ F - cranidium with thoracic segment, exfoliated, GK B3 0073, FZX44. $\bullet \mathrm{G}$ - cranidium and librigena, exfoliated, GK B3 0075, FZX44. • H, J - shield, not exfoliated, latex cast, GK B3 0077, FZX45; J - shield, exfoliated. $\bullet$ I - cranidium, exfoliated, GK B3 0078, FZX45. $\bullet$ K - cranidium, exfoliated, GK B3 0074, FZX30 • L - shield, not exfoliated, latex cast, GK B3 0076, FZX29. • M - shield, exfoliated, GK B3 0079, FZX44. • N - Protoryctocephalus balangensis Zhao \& Yuan in Yuan et al., 2002 shield, not exfoliated, latex cast, GK B3 0068, × 12, FZX45. • O - Metarthricocephalus spinosus Zhou \& Yuan in Yuan et al., 2002, cranidium, exfoliated, GK B3 0069, × 8, FZX8

2005b Euarthricocephalus taijiangensis Zhao \& Yuan (in Yuan et al., 2002). - Zhao et al., pl. 3, fig. 10.

Material. - 11 cranidia, 6 pygidia, 8 partial or complete shields.

Remarks. - Euarthricocephalus taijiangensis specimens are better preserved and more numerous than the similar E. typicalis Zhao \& Yuan in Yuan et al., 2002. The illustrated specimen of E. typicalis (Yuan et al.2002, pl. 34, fig. 1) is distorted and relatively small and illustrates three transglabellar furrows and more slit shaped glabellar pits. The specimens of E. taijiangensis from the Wuliu Quarry do not have the slit shaped pits or three transglabellar furrows. In addition, E. typicalis occurs in the Ovatoryctocara cf. granulata-Bathynotus holopygus Zone in the Wuliu-Zengjiayan section (Yuan et al. 2002).

Euarthricocephalus (Microryctocara) similis Zhao \& Yuan in Yuan et al., 2002 and Euarthricocephalus (Euarthricocephalus) ligulatus Zhao \& Yuan in Yuan 

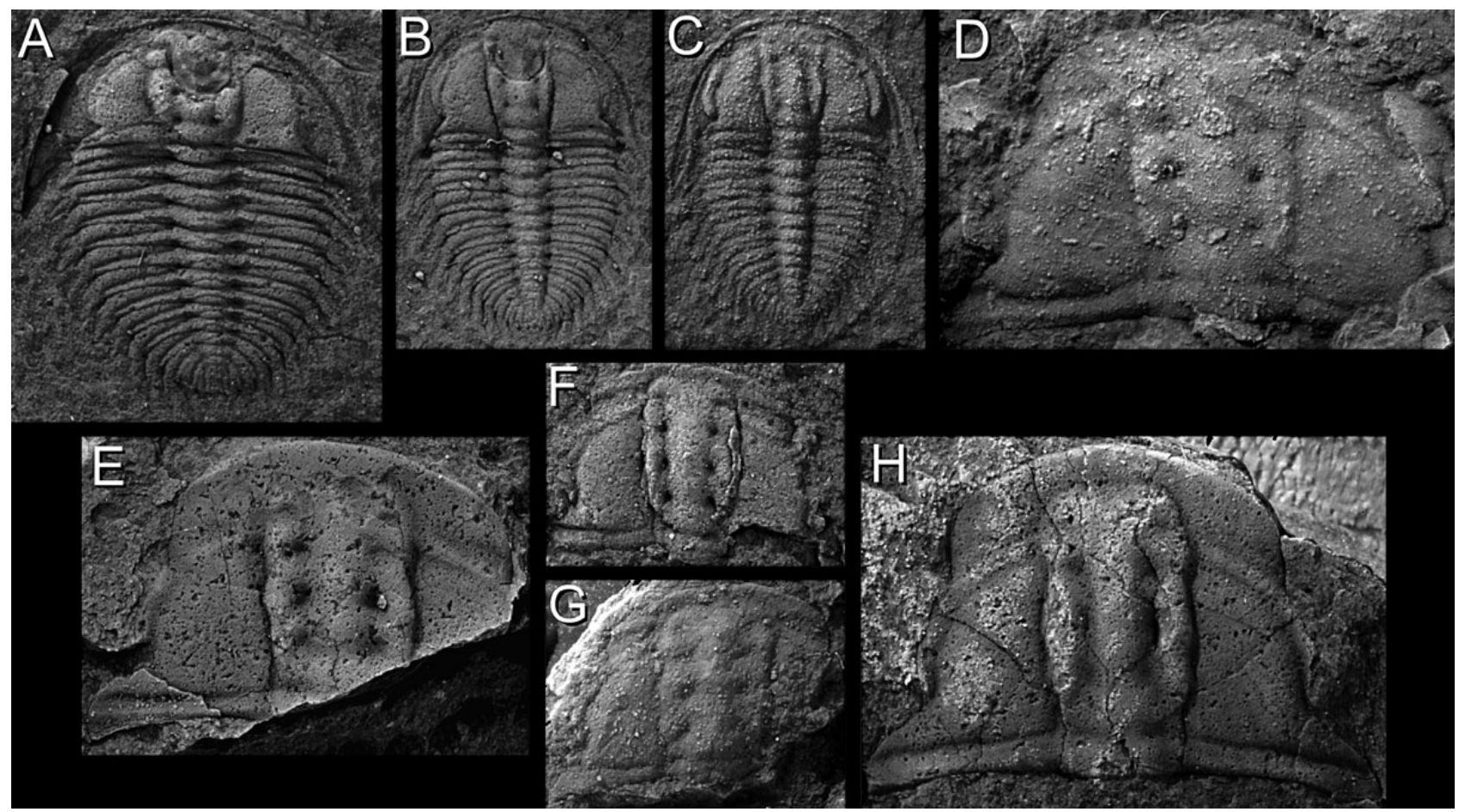

Figure 14. Curvoryctocephalus taijiangensis Zhao \& Yuan in Yuan et al., 2002, all figures $\times 7$ unless otherwise noted. $\bullet$ A - complete shield, exfoliated, with hypostome impression, GK B3 0080, FZX12. • B, C - complete shield; B - exfoliated, with hypostome impression, GK B3 0081, C - not exfoliated, latex cast, GK B3 0082, FZX4. • D - cranidium, not exfoliated, latex cast, GK B3 0083, FZX3. • E - partial cranidium, mostly exfoliated, GK B3 0084, × 5, FZX17. • F - damaged cranidium, exfoliated, GK B3 0085, FZX1. • G - partial cranidium, exfoliated, GK B3 0086, FZX17. • H - cranidium, exfoliated, GK B3 0087, FZX21.

et al., 2002 differ from E. taijiangensis in having three transglabellar furrows and slit shaped glabellar pits.

Euarthricocephalus ligulatus has a more parallel sided glabella with stronger developed longitudal furrows and probably represents a different species. This species co-occurs in the same horizons as E. taijiangensis in the Miaobanpo section (Yuan et al. 2002).

Occurrence. - Kaili Formation, Oryctocephalus indicus Zone: Wuliu Quarry levels FZX1-4, 7, 8, 11-14, 17, 18, 21; Wuliu-Zengjiayan and Miaobanpo sections, China.

\section{Genus Metabalangia Qian \& Yuan (in Zhang et al., 1980)}

Type species. - Metabalangia yupingensis Qian \& Yuan (in Zhang et al., 1980).

\section{Metabalangia yupingensis Qian \& Yuan (in Zhang et al., 1980) \\ Figure 13D, E}

1980 Metabalangia yupingensis Qian \& Yuan (in Zhang et al.); p. 283, pl. 96, figs 9, 10 .
2002 Metabalangia yupingensis Qian \& Yuan (in Zhang et al., 1980). - Yuan et al., pp. 127, 253, pl. 35, figs 4-8.

2002 Metabalangia transversa Zhao \& Yuan (in Yuan et al.), pp. 128, 253, pl. 36, figs 1-12, pl. 38, figs 9, 10.

2005a Metabalangia yupingensis Qian \& Yuan (in Zhang et al., 1980). - Zhao et al., pl. 7, fig. 1.

2005b Metabalangia yupingensis Qian \& Yuan (in Zhang et al., 1980). - Zhao et al., pl. 3, fig. 6.

2010 b Oryctocephaloides convexus Zhao \& Yuan (in Yuan et al., 2002). - Sundberg et al., fig. 1.

Material. - 2 cranidia, 1 complete shield.

Diagnosis. - See the emended generic diagnosis of Yuan et al. (2002, p. 252). The only two species named for the genus are here synonymized.

Remarks. - The poorly preserved complete shield has only 3 to 4 thoracic segments. Metabalangia transversa Zhao \& Yuan in Yuan et al., 2002 (Fig. 13D) is very similar to M. yupingensis, but differs in having 4 to 5 thoracic segments. The number of thoracic segments may be an ontogenetic change. The other differences cited by Yuan et al. (2002) do not appear to be consistent and may be the result of deformation. The two species occur together in the same 
horizons at the Wuliu-Zengjiayan and Miaobanpo sections (Yuan et al. 2002), suggesting that they are conspecific.

Occurrence. - Kaili Formation, Oryctocephalus indicus Zone: Wuliu Quarry level FZX10, 19, 22; Wuliu-Zengjiayan and Miaobanpo sections, China.

\section{Genus Metarthricocephalus Zhao \& Yuan (in Yuan et al., 2002)}

Type species. - Metarthricocephalus spinosus Zhao \& Yuan (in Yuan et al., 2002).

\section{Metarthricocephalus spinosus Zhao \& Yuan (in Yuan et al., 2002)}

Figure 13O

2001b Oryctocephalid in Zhao et al., pl. 6, fig. 3.

2002 Metarthricocephalus spinosus Zhao \& Yuan (in Yuan et al.); pp. 115, 246, pl. 28, fig. 1, pl. 29, fig. 8, pl. 32, figs 1-9, pl. 33, fig. 1 .

2005a Metarthricocephalus spinosus Zhao \& Yuan (in Yuan et al., 2002). - Zhao et al., pl. 6, fig. 3.

2005b Metarthricocephalus spinosus Zhao \& Yuan (in Yuan et al., 2002). - Zhao et al., pl. 3, fig. 8.

Material. - 1 cranidium.

Occurrence. - Kaili Formation, Oryctocephalus indicus Zone: Wuliu Quarry level FZX8; Wuliu-Zengjiayan and Jinyinshan sections, China.

\section{Genus Ovatoryctocara Tchernysheva, 1962}

Type species. - Oryctocara ovata Tchernysheva, 1960.

\section{Ovatoryctocara cf. granulata Tchernysheva, 1962} Figure 15A-E

1997 ?Ovatoryctocara spp. Yuan et al., pl. 3, figs 11, 12.

2001a Ovatoryctocara granulata Tchernysheva, 1962. Zhao et al., pl. 1, figs 8, 9.

2001 Ovatoryctocara granulata Tchernysheva, 1962. Yuan et al., pl. 1, fig. 5.

2002 Ovatoryctocara granulata Tchernysheva, 1962. Yuan et al., pp. 125, 252, pl. 29, figs 4, 5.

2002 ?Ovatoryctocara sp. Yuan et al., pp. 125, 252, pl. 31, figs 7,8 .

2002 Ovatoryctocara sp. Yuan et al., pp. 125, 252, pl. 31, fig. 9.

2002 not Ovatoryctocara granulata Tchernysheva, 1962.Yuan et al., pp. 125, 252, pl. 31, figs 10-13 = Ovatoryctocara yaxiensis Yuan et al., 2009.
2007 Ovatoryctocara granulata Tchernysheva, 1962. Zhao et al., fig. 4I.

2009 Ovatoryctocara granulata Tchernysheva, 1962. Yuan et al., p. 216, figs 2a, b, 3c.

Material. - 1 cranidium, 3 pygidia, 8 complete shields.

Remarks. - Some specimens previously reported as Ovatoryctocara granulata Tchernysheva, 1962 from the Kaili Formation (Yuan et al. 2001, 2002, 2009; Zhao et al. 2001a, 2007) differ from the type material (Naimark et al. 2011) in having a longer (exsag.) posterior area of the fixigena, shorter (exsag.) palpebral lobe placed more anteriorly, longitudinal glabellar furrows connecting the glabellar furrows, and a more prominent S3 transglabellar furrow. As a result, the specimens previously reported from the "Ovatoryctocara granulata-Bathynotus holopygus Zone" are assigned to $O$. cf. granulata.

Specimens of Ovatoryctocara spp. illustrated by Yuan et al. (1997, pl. 3, figs 11, 12; re-illustrated in Yuan et al. 2002, pl. 31, figs 7, 8) are either too poorly preserved or too small to accuately assign to $O$. cf. granulata. The specimen illustrated by Yuan et al. (2002, pl. 31, fig. 9) can be assigned to this species.

Ovatoryctocara yaxiensis Yuan et al., 2009, from the Aoxi Formation differs from $O$. cf. granulata primarily in it more posterior placed palpebral lobes. The glabellar shape and presence of transglabellar furrows are also present in $O$. cf. granulata specimens from the Kaili Formation (Fig. 15C). Ovatoryctocara cf. granulata differs from O. doliiformis Shabanov \& Korovnikov in Shabanov et al., 2008 b, in having smaller granuals on the cranidia, longitudinal furrows connecting the glabellar furrows, narrower (tr.) width of the librigena between the palpebral lobes and glabella, wider pygidial axis, and fewer pygidial segments.

Occurrence. - Kaili Formation, Ovatoryctocara cf. granulata-Bathynotus holopygus Zone: Wuliu Quarry levels FZX29, 31, 34, 36, 37, 42, 43, 45; Wuliu-Zengjiayan and Miaobanpo sections, China.

Order Ptychopariida Swinnerton, 1915

Superfamily Ptychoparioidae Matthew, 1887

Remarks. - Revision of the ptychopariid families is out of the scope of this paper, thus the species are listed alphabetically.

\section{Genus Balangcunaspis Yuan \& Zhao (in Yuan et al., 1997)}

Type species. - Paraantagmus (Balangcunaspis) subcylindricus Yuan \& Zhao (in Yuan et al., 1997). 

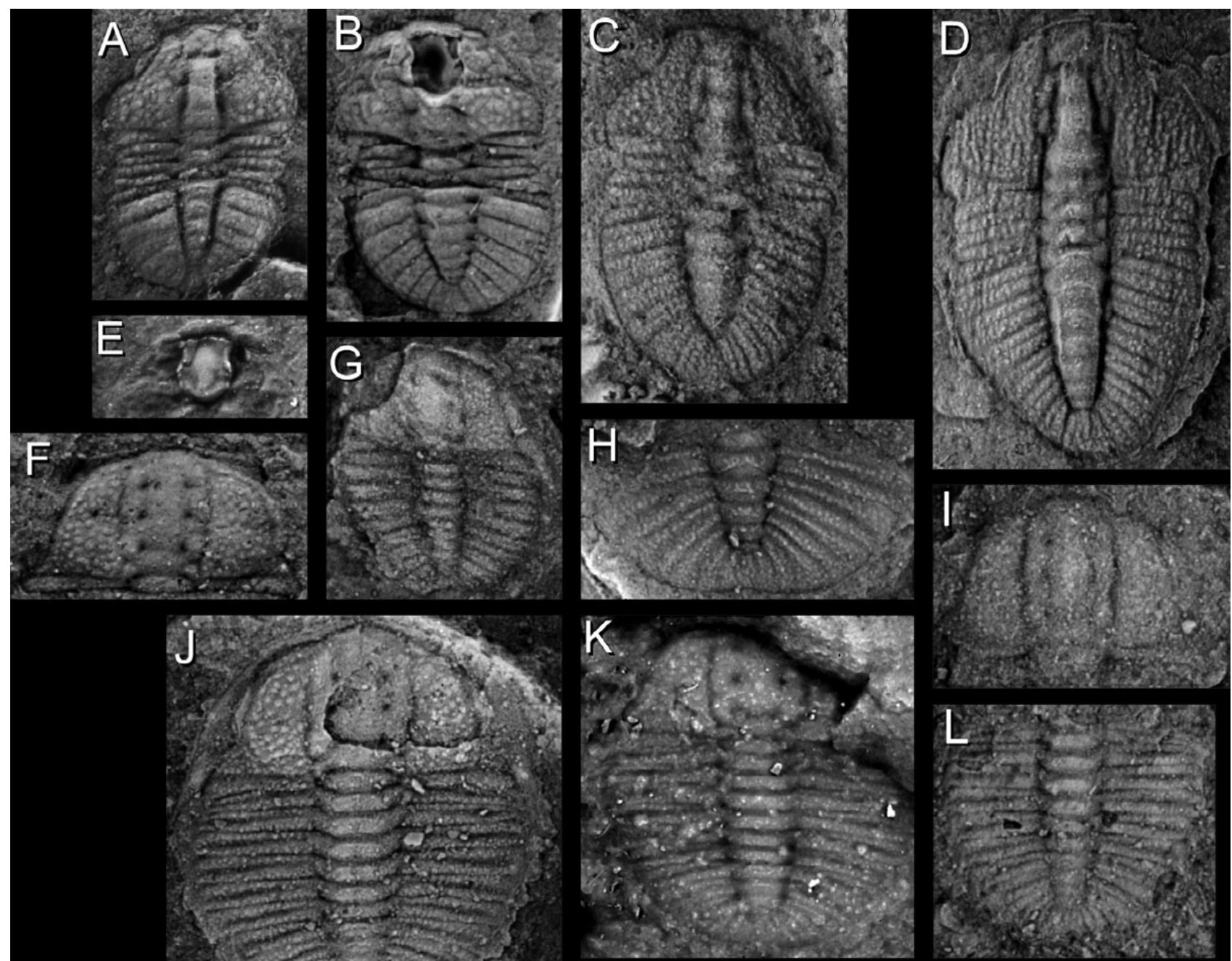

Figure 15. A-E - Ovatoryctocara cf. granulata Tchernysheva, 1962, all figures $\times 12$. • A - partial shield, exfoliated, GK B3 0088 , FZX29. - B, E - shield, exfoliated, GK B3 0089, FZX45; B - shield, exfoliated, E - hypostome, latex cast. $\bullet$ C - nearly complete shield, not exfoliated, latex cast, GK B3 0090, FZX34. D - nearly complete shield, not exfoliated, latex cast, GK B3 0091, FZX42. • F-L - Euarthricocephalus taijiangensis Zhou \& Yuan in Yuan et al., 2002, all figures $\times 12$. $\bullet$ F - cranidium, exfoliated, GK B3 0092, FZX4. • G - partial shield, partially exfoliated, GK B3 0093 , FZX18. $\cdot$ H - pygidium, exfoliated, GK B3 0094, FZX13. • I - cranidium, exfoliated, GK B3 0095, FZX4. • J - shield, partially exfoliated, GK B3 0096, FZX11. - K - partial shield, not exfoliated, latex cast GK B3 0097, FZX7. $\bullet$ - thorax and pygidium, partially exfoliated, GK B3 0098, FZX17.

Remarks. - The two subgenera assigned to this genus by Yuan \& Zhao (in Yuan et al. 1997, 2002), Balangcunaspis and Taijiangia, are distinctly different and should be considered different genera. Balangcunaspis has palpebral lobes that are longer, short (exsag.) posterior areas of the fixigena and pygidium with the anterolateral margins adjacent to the posterior end of the axis. Taijiangia Yuan \& Zhao in Yuan et al., 2002 (pp. 262, 263), has palpebral lobes that are shorter, a posterior area of the fixigena that is longer (exsag.), and the pygidial anterolateral margins adjacent to the anterior of the axis. Balangcunaspis is found in the Ovatoryctocara cf. granulata-Bathynotus holopygus Zone at the Wuliu-Zengjiayan section, where as Taijiangia is found in the basal beds of the overlying Oryctocephalus indicus Zone at the Miaobanpo section (Yuan et al. 2002).

\section{Balangcunaspis subcylindricus Yuan \& Zhao} (in Yuan et al., 1997)

Figure 16A-P

1980 Protohedinidae gen. et sp. undet. Yuan (in Zhang et al.), p. 362, pl. 102, figs 10-12.

1997 Paraantagmus (Balangcunaspis) subcylindricus Yuan \& Zhao (in Yuan et al.); p. 508, pl. 5, figs 6, 7. 


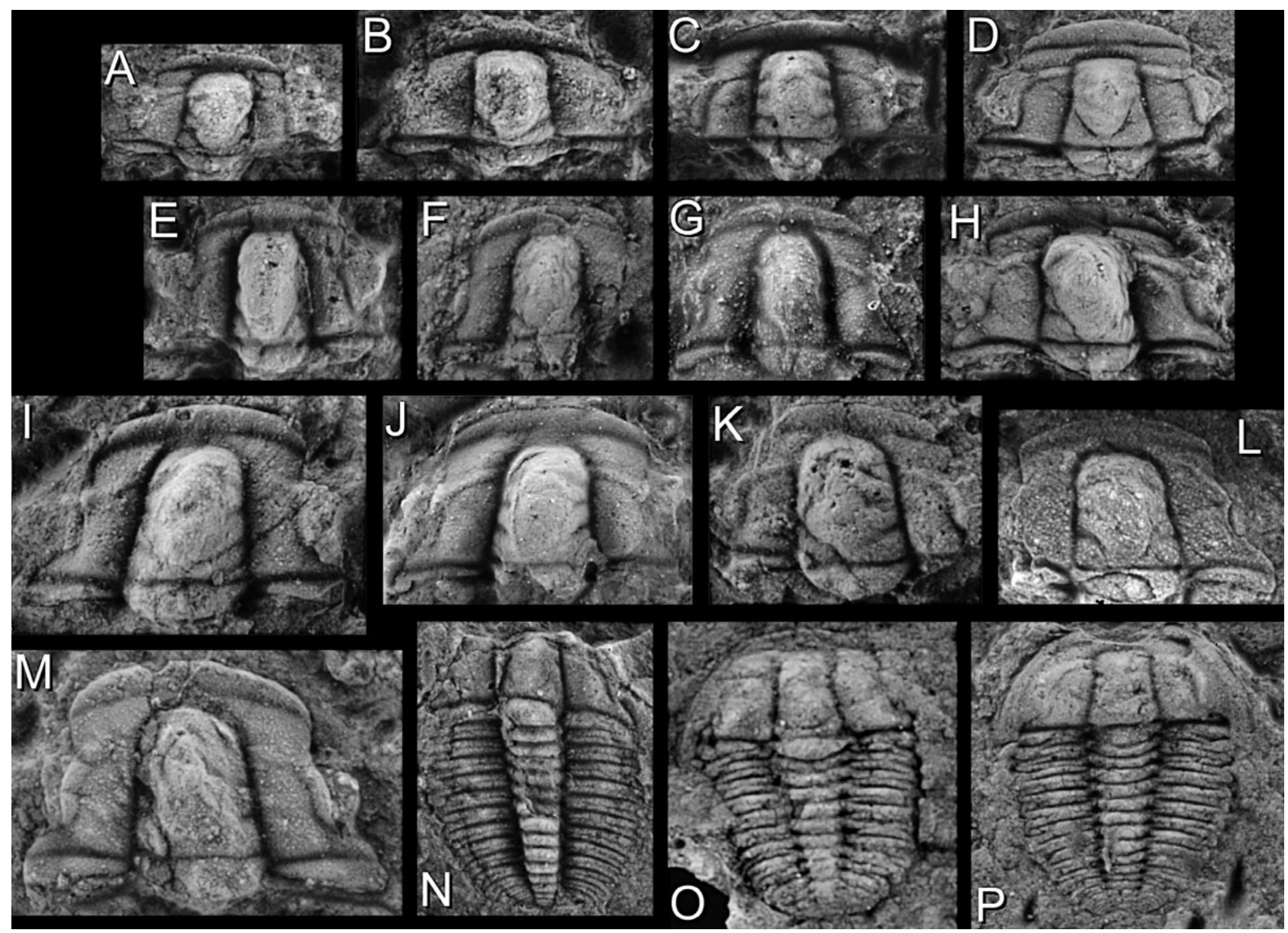

Figure 16. Balangcunaspis subcylindricus Yuan \& Zhao in Yuan et al., 1997, all figures $\times 12$. • A - partial cranidium, exfoliated, GK B3 $0099, \mathrm{FZX} 40$. - B - cranidium, exfoliated, GK B3 0100, FZX40. • C - partial cranidium, exfoliated, GK B3 0101, FZX29. • D - cranidium, exfoliated, GK B3 0102 , FZX28. $\bullet$ E - cranidium, exfoliated, GK B3 0103, FZX40 • F-damaged cranidium, exfoliated, GK B3 0104, FZX45. $\bullet$ - cranidium, not exfoliated, GK B3 0105, latex cast, FZX46. $\bullet \mathrm{H}$ - cranidium, exfoliated, GK B3 0106, FZX34. $\bullet$ I - cranidium, exfoliated, GK B3 0107, FZX46. $\bullet$ J - cranidium, exfoliated, GK B3 0108, FZX30. $\bullet$ - cranidium, exfoliated, GK B3 0109, FZX46. $\bullet$ - partial cranidium, exfoliated, GK B3 0110, FZX44. • M - cranidium, exfoliated, GK B3 0111, FZX46. • N - partial shield, exfoliated, GK B3 0112, FZX34. • - partial shield, exfoliated, GK B3 0113, FZX34. P - partial shield, exfoliated, GK B3 0114, FZX46.

1997 Balangcunaspis (Balangcunaspis) transversus Yuan \& Zhao (in Yuan et al.), p. 508, pl. 5, figs 4, 5.

1999 Balangcunaspis transversus Yuan \& Zhao (in Yuan et al., 1997). - Yuan et al., p. 27, pl. 1, fig. 1.

2002 Balangcunaspis (Balangcunaspis) subcylindricus Yuan \& Zhao (in Yuan et al., 1997). - Yuan et al., pp. 148, 149, 262, pl. 43, figs 7-12.

2002 Balangcunaspis (Balangcunaspis) transversus Yuan \& Zhao (in Yuan et al., 1997). - Yuan et al., pp. 149, 262, pl. 43, figs 1-6.

2010b Balangcunaspis transversus Yuan \& Zhao (in Yuan et al., 1997). - Sundberg et al., fig. 1.

Material. - 147 cranidia, 14 pygidia, 8 partial or complete shields.

Emended diagnosis. - Balangcunaspis with palpebral lobes nearly one and a half as long as posterior area of the fixigena $(150 \%)$; ocular ridges directed moderately posterio-laterally, of moderate strength; glabellar length approximately $80-85 \%$ of cranidial length; preglabellar field length nearly absent in front of glabella; anterior border slightly convex, flat to upturned; facial sutures slightly divergent anterior of palpebral lobes, very strongly divergent (approx. 90 $)$ from the posterior end of the palpebral lobes.

Remarks. - The difference between B. subcylindricus and B. transversus Yuan \& Zhao in Yuan et al., 1997, can easily be explained due to specimen distortion. Balangcunaspis subcylindricus is sagittally elongated (e.g., Fig. 16E-G) whereas B. transversus is transversely elongated (e.g., Fig. 16B-D). Both species have been reported to occur together in the Wuliu-Zengjiayan section (Yuan et al. 2002). 
Cranidia with a relatively small frontal area (Fig. 16J, L, M) and at times almost no preglabellar field (Fig. 16I, K) and long palpebral lobes belong only to a limited number of genera from the Kaili Formation, i.e., Balangcunaspis Yuan \& Zhao in Yuan et al., 1997, Nangaoia Zhou in Lu et al., 1974a, and Parashuiyuella Yuan \& Zhao in Yuan et al., 1997. In both Nangaoia and Parashuiyuella the fixigena at the center of the palpebral lobes is less than half the width of the glabella at the position, where as Balangcunaspis has the width nearly equal or slightly greater than half of the width of the glabella. The glabella of Balangcunaspis is more quadrate than tapered, although this is a dangerous character to use based on the specimen distortion. Balangcunaspis subcylindricus is represented by mostly small specimens.

Both B. subcylindricus and B. transverses have been recorded only from in the Ovatoryctocara cf. granulata-Bathynotus holopygus by Zhao et al. (2005a, p. 66); but also from the Oryctocephalus indicus Zone by Zhao et al. (2007, fig. 1).

Occurrence. - Kaili Formation, Ovatoryctocara cf. granulata-Bathynotus holopygus Zone: Wuliu Quarry levels FZX26-36, 38-46; Ovatoryctocara cf. granulataBathynotus holopygus and Oryctocephalus indicus zones: Wuliu-Zengjiayan section, China.

\section{Genus Danzhaiaspis Yuan \& Zhou (in Zhang et al., 1980)}

Type species. - Danzhaiaspis quadratus Yuan \& Zhou (in Zhang et al., 1980).

\section{Danzhaiaspis quadratus Yuan \& Zhou (in Zhang et al., 1980)}

Figure 17A-O

1980 Danzhaiaspis quadratus Yuan \& Zhou (in Zhang et al.); pp. 355, 356, pl. 125, figs 1-5.

1980 Danzhaiaspis latilimbatus Yuan (in Zhang et al.), p. 356, pl. 125, fig. 6 .

1980 Danzhaiaspis brevicus Yuan (in Zhang et al.), pp. 356, 357, pl. 125, fig. 7-9.

1980 Danzhaiaspis niuchangensis Zhou (in Zhang et al.), p. 357, pl. 124, fig. 6 .

1980 Danzhaiaspis? sanwanensis Yuan (in Zhang et al.), pp. 357, 358, pl. 125, fig. 10, 11.

1999 Danzhaiaspis quadratus Yuan \& Zhou (in Zhang et al., 1980). - Yuan et al., pl. 1, fig. 8.

2002 Danzhaiaspis quadratus Yuan \& Zhou (in Zhang et al., 1980). - Yuan et al., pp. 202, 281, pl. 64, figs 1-8, pl. 67, figs 7-9.

2002 Danzhaiaspis elongatus Yuan \& Zhao (in Yuan et al.), pp. 202, 203, 281, pl. 54, figs 11, pl. 61, figs 3-8, pl. 65 , fig. 10 , pl. 67, fig. 3 .

2002 Danzhaiaspis brevis Yuan (in Zhang et al.), pp. 203, 204, 281, pl. 64, fig. 4.

2002 Danzhaiaspis rarus Yuan \& Zhao (in Yuan et al.), pp. 204, 281, 282, pl. 61, fig. 9 .

2010b Kutsingocephalus qiannanensis Yuan \& Zhou (in Yuan et al., 2002). - Sundberg et al., fig. 1.

not 2010b Danzhaiaspis quadratus Yuan \& Zhou (in Zhang et al., 1980). - Sundberg et al., fig. 1 = Miabanpoia angustilimbata (Yuan in Zhang et al., 1980).

Material. - 57 cranidia, 3 pygidia, 4 partial or complete shields.

Emended diagnosis. - Danzhaiaspis with the palpebral lobes longer than the posterior portion of the fixigena (150\%); ocular ridges slightly to moderately directed posterio-laterally; glabellar length approximately $65-70 \%$ of cranidial length; fixigena narrower than glabella at center of palpebral lobes; anterior border approximately $100 \%$ of preglabellar field, flat to very slightly convex, slightly to moderately upturned; facial sutures moderately divergent anterior of palpebral lobes, strongly divergent (approx. $90^{\circ}$ ) from the posterior end of palpebral lobes. Pygidium transversely elongated with anterior lateral corners located adjacent to nearly the end of the axis, and well developed border widening laterally. Fine granules on the glabella and librigena occur on the latex casts of the betterpreserved specimens (Fig. 17F, K).

Remarks. - This species is difficult to identify due to its general cranidial characteristics similar to Xingrenaspis xingrenensis. Danzhaiaspis quadratus differs in the length ratio of the preglabellar area and the anterior border being nearly equal as opposed to the preglabellar area being twice as long; the anterior border is upturned to level, possibly as the result of compaction; and the palpebral lobe length is nearly $150 \%$ the length of the posterior area of the fixigena.

The differences of the various species included to D. quadratus are relatively minor and can be contributed to tectonic distortion. In addition, stratigraphic evidence supporting the synonymy of $D$. quadratus and D. elongatus Yuan \& Zhao in Yuan et al., 2002, is that the two species occur together in the Miaobanpo section (Yuan et al. 2002). In the Wuliu-Zengjiayan section, the different species occur at different levels, one directly above the other in the ascending order of $D$. quadratus, D. brevis Yuan in Zhang et al., 1980, D. elongatus and D. rarus Yuan \& Zhao in Yuan et al., 2002 (Yuan et al. 2002).

The cranidia of this species is very similar to compressed specimens of $M$. angustilimbata, but differs in a more latterly projected ocular ridge, which is difficult to determine in the deformed specimens from the quarry. The 

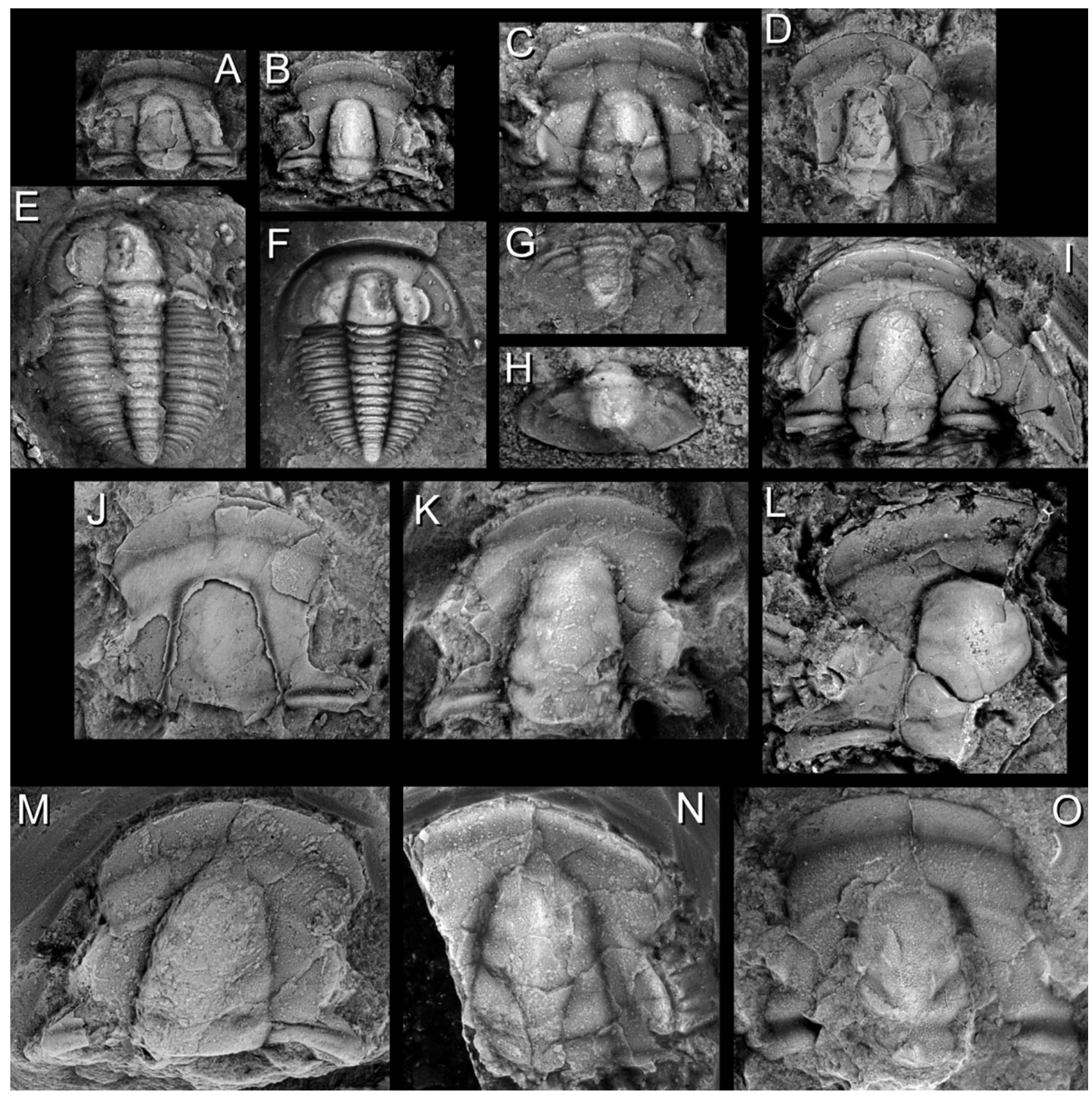

Figure 17. Danzhaiaspis quadratus Yuan \& Zhou in Zhang et al., 1980, all figures $\times 5$, unless otherwise noted. $\bullet$ A - cranidium, partially exfoliated, GK B3 0115, FZX17. • B - cranidium, not exfoliated, GK B3 0116, FZX4. • C - cranidium, not exfoliated, latex cast, GK B3 0117 , FZX15. -D - cranidium, mostly exfoliated GK B3 0118, FZX24. $\bullet$ E - partial shield, not exfoliated, GK B3 0120, latex cast, FZX6. $\bullet$ F - shield, exfoliated, GK B3 0121, FZX20. • G - pygidium, partially exfoliated, latex cast, GK B3 0122, FZX20. $\bullet$ H - pygidium, not exfoliated, latex cast, GK B3 0123 , FZX9. -I - cranidium and librigena, partially exfoliated, GK B3 0124, FZX3.・ J - partial cranidium, partially exfoliated, GK B3 0119, FZX13. K - mostly complete cranidium, not exfoliated, GK B3 0128, FZX1 • L - partial, crushed cranidium, exfoliated, GK B3 0127, FZX9. $\bullet$ M - cranidium, not exfoliated, GK B3 0128, FZX24. • N - partial cranidium, not exfoliated, GK B3 0129, FZX12, × 4.・O - cranidium, not exfoliated, GK B3 0125, latex cast, FZX20.

pygidium is the most diagnostic character to distinguish the two species. Danzhaiaspis quadratus has a wide relatively flat pygidial margin that widens significantly laterally and a similar doublure. A shield from FZX20 (Fig. 17F) has a pygidium that indicates that this specimen is Danzhaiaspis quadratus and not $M$. angustilimbata even though the cranidia are very similar. This indicates the importance of having associated sclerites in addition to cranidia.

Occurrence. - Kaili Formation, Oryctocephalus indicus 


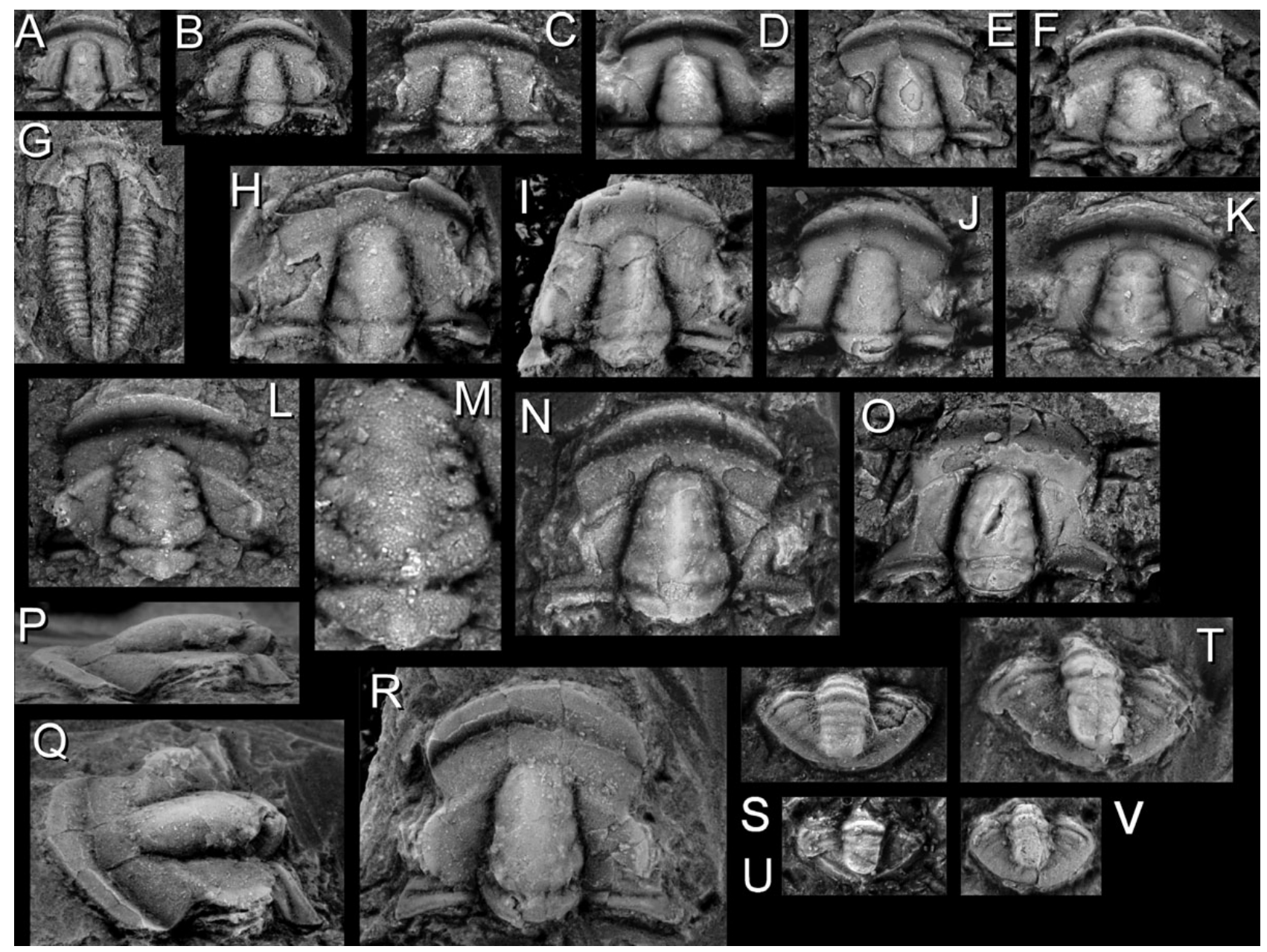

Figure 18. Miabanpoia angustilimbata (Yuan in Zhang et al., 1980), all figures $\times 5$ unless otherwise noted. $\bullet$ A - cranidium, not exfoliated, GK B3 0130, FZX9. • B - cranidium, not exfoliated, GK B3 0131, FZX11. • C - cranidium, not exfoliated, GK B3 0132, FZX13. • D - cranidium, not exfoliated, GK B3 0133, latex cast, FZX13. • E - partial cranidium, not exfoliated, GK B3 0134, FZX13.・F - cranidium, not exfoliated, GK B3 0135, FZX11. $\cdot \mathrm{G}$ - shield, poorly preserved internal mold illustrating pygidium, GK B3 0136, FZX21. $\bullet$ H - cranidium, partially exfoliated, GK B3 0137 , FZX12. I - partially crushed cranidium, not exfoliated, GK B3 0138, FZX24. $\mathbf{J}$ - cranidium, not exfoliated, GK B3 0139, FZX13. $\bullet$ K - cranidium, not exfoliated, GK B3 0140, FZX9. $\bullet$ L, M - cranidium, partially exfoliated, GK B3 0141, latex cast, fig. M showing granular ornamentation, $\times 10$, FZX9. - N - cranidium, partially exfoliated, GK B3 0142, FZX11. - O - damaged cranidium, partially exfoliated, GK B3 0143 , FZX9. - P-R - cranidium with crushed anterior border, not exfoliated, GK B3 0164, FZX24. - S - pygidium, partially exfoliated, GK B3 0145 , FZX9. - T - damaged pygidium, not exfoliated, GK B3 0146, FZX9. • U - damaged pygidium, not exfoliated, GK B3 0147, latex cast, FZX9. $・$ V - pygidium, not exfoliated, GK B3 0148, FZX14.

Zone: Wuliu Quarry levels FZX1-6, 9-17, 19-22, 24, 25; Wuliu-Zengjiayan and Miaobanpo sections, China.

\section{Genus Miabanpoia Yuan \& Zhao (in Yuan et al., 2002)}

Type species. - Miabanpoia typica Yuan \& Zhao (in Yuan et al., 2002) [= Miabanpoia angustilimbata (Yuan in Zhang et al., 1980)].

Remarks. - The differences between M. typica, M. triangulata Yuan \& Zhao in Yuan et al., 2002, and M. angustilimbata are minor and could easily be due to tectonic distor- tion; the three specimens occur together in the Miaobanpo section. Miabanpoia angustilimbata has priority.

\section{Miabanpoia angustilimbata (Yuan in Zhang et al., 1980)} Figure 18A-V

1980 Meitania angustilimbata Yuan (in Zhang et al.); p. 349, pl. 119, figs 21, 22.

2002 Danzhaiaspis brevis Yuan (in Zhang et al., 1980).Yuan et al., pp. 203, 204, 281, 282, pl. 62, fig. 4.

2002 Miabanpoia typica Yuan \& Zhao (in Yuan et al.), pp. 205, 283, pl. 68 , fig. 7. 
2002 Miabanpoia angustilimbata (Yuan in Zhang et al., 1980). - Yuan et al., pp. 205, 206, 283, pl. 66, figs 1-4.

2002 Miabanpoia triangulata Yuan \& Zhao (in Yuan et al.), pp. 206, 207, 283, pl. 63, fig. 11, pl. 65, figs 5-7, pl. 66, figs 5-10, pl. 67, figs 5, 6, pl. 68, figs 2-6.

2010b Danzhalaspis quadratus Yuan \& Zhou (in Zhang et al., 1980). - Sundberg et al., fig. 1 .

Material. - 348 cranidia, 6 pygidia, 5 partial or complete shields.

Emended diagnosis. - Miabanpoia with palpebral lobes nearly twice to twice as long as the posterior area of the fixigena (180-200\%); ocular ridges moderately strong posterio-laterally; glabellar length approximately 68-73\% of cranidial length; anterior border approximately $100-150 \%$ of preglabellar field; anterior border slightly convex to flat (could be influenced by compaction), strongly upturned, slightly tapering laterally; facial sutures moderately divergent anterior of palpebral lobes, very strongly divergent (approx. $90^{\circ}$ ) from the posterior end of palpebral lobes. Pygidium transversely elongated with anterior lateral corners located about the mid-length of the pygidium; doublure narrow at posterior margin, nearly uniform to the anterior margin; pleural furrows prominent, interpleural furrows moderately developed; axis with 4 rings, width about $1 / 2$ pleural field width, rounded terminal piece that nearly reaches the posterior border. Granular exoskeleton is present in latex casts (Fig. 18M).

Remarks. - The strongly upturned anterior border is one of the most distinct features of this species, along with the palpebral lobes being nearly twice as long as the posterior area of the fixigena. The difference in the pygidium is the nearly uniform width of the pygidial border and the underlying doublure. Many of the pygidia illustrated by Yuan et al. (2002) appear to have wider borders.

Yuan et al. (2002) assigned a single pygidium to Meitania suni (Lu, 1945) illustrated in Zhang et al. (1980, pl. 119 , fig. 15 ) to $M$. angustilimbata; however, this pygidium is not well enough preserved to determine its taxonomic affinity. A moderately preserved specimen of Danzhaiaspis brevis Yuan in Zhang et al., 1980, illustrated in Yuan et al. (2002, pl. 62, fig. 4) has a cranidium and pygidium very similar to $M$. angustilimbata and is thus considered a specimen belonging to the latter species. Specimens illustrated by Yuan (in Zhang et al. 1980) of D. brevis and D. ?xingrenensis Yuan \& Zhou in Zhang et al., 1980, are not assigned to $M$. angustilimbata, but rather Danzhaiaspis quadratus.

Occurrence. - Kaili Formation, Oryctocephalus indicus Zone: Wuliu Quarry levels FZX1-25; Wuliu-Zengjiayan and Miaobanpo sections, China.

\section{Genus Nangaoia Zhou (in Lu et al., 1974a)}

Type species. - Nangaoia megaceps Zhou (in Lu et al., 1974a).

Remarks. - Three subgenera have been recognized in $\mathrm{Na}$ ngaoia (Yuan et al. 1997), Nangaoia, Shilengshuia Zhou \& Yin in Yin et al., 1978, and Gedongaspis Yuan \& Zhao in Yuan et al., 1997. Yuan et al. (2002, p. 263) elevated Gedongaspis to generic level. Gedongaspis granulosa Yuan \& Zhao in Yuan et al., 1997 (type species) and G. oblonga Yuan \& Zhao in Yuan et al., 1997, occur together (Yuan et al. 2002) implies one species with a variation in the density of granules. However, the pygidia of the two species are different in the strength of the interplural furrows, border width and location of the anterior lateral corners relative to the axis. Nangaoia (Nangaoia) triangularis Yuan \& Zhao in Yuan et al., 2002 (pl. 42, figs 3,4 ), have a pygidium similar to Xingrenaspis with a wide border narrowing posterior of the axis. The post cranidial material of Nangaoia (Shilengshuia) is unknown, thus a comparison cannot be made; however, the cranidial features of this subgenus differs from $N$. (Nangaoia) in having a more tapered glabella, narrower (tr.) fixigena and convergent anterior branches of the facial sutures. However, N. (N.) triangularis (Yuan et al. 2002, pl. 42, fig. 2) illustrates the same features, but with wider fixigena.

\section{Subgenus Nangaoia (Shilengshuia) Zhou \& Yin (in Yin \& Lee, 1978)}

Type species. - Shilengshuia jiubaensis Zhou \& Yin (in Yin \& Lee, 1978).

\author{
Nangaoia (Shilengshuia) conica Yuan \& Zhao \\ (in Yuan et al., 2002) \\ Figure 19A-I, J?
}

2002 ?Nangaoia (Nangaoia) triangularis Yuan \& Zhao (in Yuan et al.); pp. 146, 147, 260, pl. 42, figs 2-4.

2002 Nangaoia (Shilengshuia) conica Yuan \& Zhao (in Yuan et al.), pp. 147, 261, pl. 42, figs 5, 6, 8-10.

2010b Gedongaspis granulosa Yuan \& Zhao (in Yuan et al., 1997). - Sundberg et al., fig. 1.

2010b Nangaoia triangularis Yuan \& Zhao (in Yuan et al., 2002). - Sundberg et al., fig. 1.

Material. - 35 cranidia.

Emended diagnosis. - Nangaoia with relatively large glabella extending nearly to the anterior border, palpebral lobes of moderate length, narrow fixigenae, scattered 

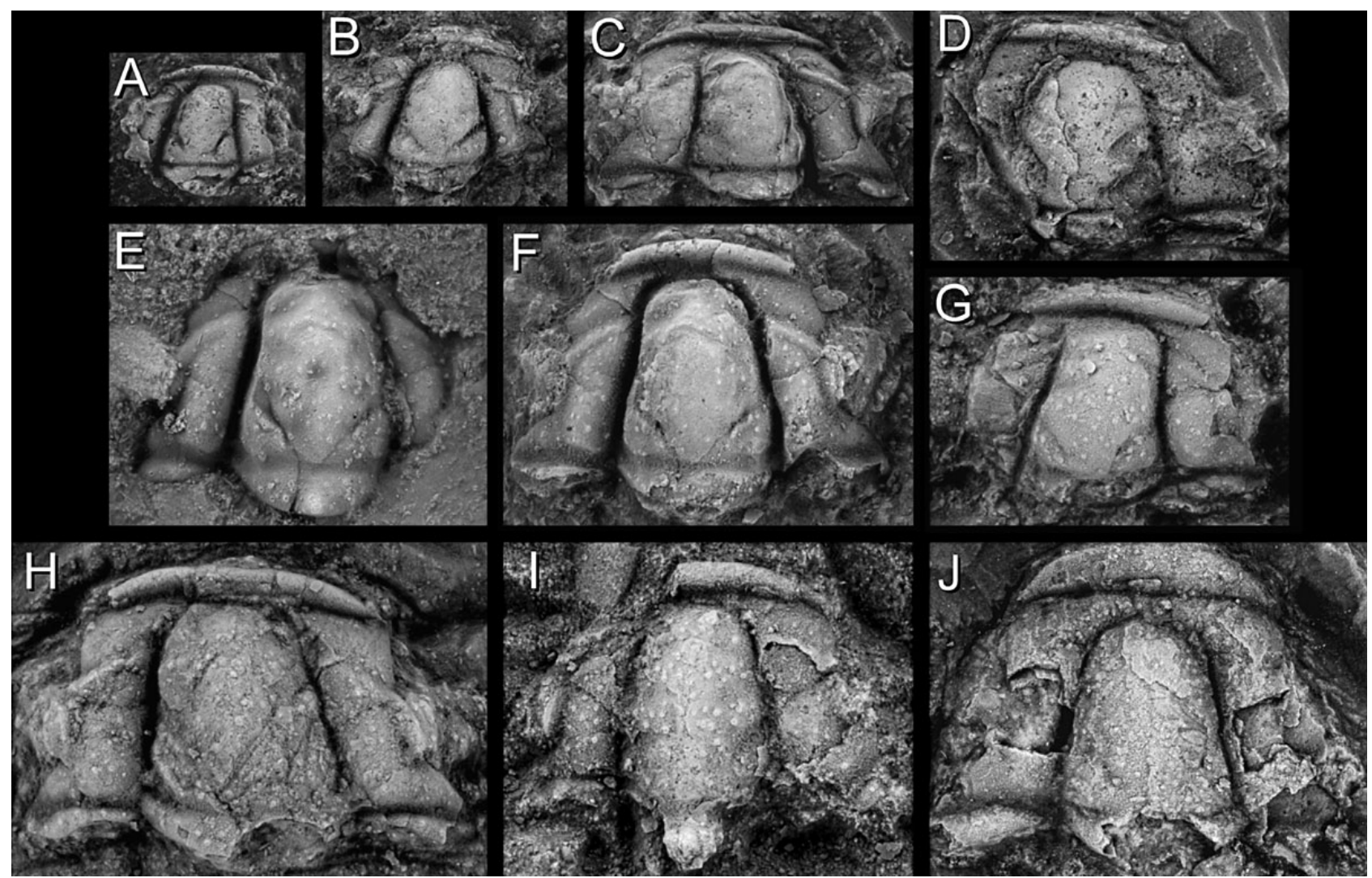

Figure 19. A-I, J? - Nangaoia (Shilengshuia) conica Yuan \& Zhao in Yuan et al., 2002, all figures $\times 7$ unless otherwise noted. $\bullet$ A - cranidium, partially exfoliated, GK B3 0149, FZX18. • B - damaged cranidium, partially exfoliated, GK B3 0150, FZX22. • C - cranidium, mostly exfoliated, GK B3 0151, FZX8. • D - damaged cranidium, partially exfoliated, GK B3 0152, FZX7.•E - partial cranidium showing occipital node, exfoliated, GK B3 0153, latex cast, FZX8. $\bullet$ F - cranidium, exfoliated, GK B3 0154, FZX8. • G - cranidium, partially exfoliated, GK B3 0155, FZX4. • H - cranidium, not exfoliated, GK B3 0156, FZX19. • I - partial cranidium, partially exfoliated, GK B3 0157, FZX16. • J - cranidium questionably assigned to the species, partially exfoliated, GK B3 0158, FZX9, × 3 .

granules on the cranidia, and anterior border that is convex, upturned and slightly curved.

Remarks. - Nangaoia (S.) conica and N. (N.) triangularis in Yuan et al., 2002 (pl. 42) appears to be quite different, especially in the curvature of the anterior border and the tapering of the glabella. However, it is unsure if the $N$. (N.) triangularis form may be more the result of tectonic deformation given that almost all specimens looked laterally compressed. It is possible that $N$. (S.) conica in pl. 42, fig. 8 (Yuan et al. 2002) could be a highly distorted specimen of $N$. (N.) triangularis. The specimens of $N$. (N.) triangularis are questionably assigned to $N$. (S.) conica until more data on the two taxa can be accumulated to show that they are different taxa.

A single large specimen (Fig. 19J, level FZX9) illustrates a more tapered glabella, presence of a preglabellar area, more convergent anterior portion of the facial suture, and an anterior border that is longer (sag.) and more tapered than in the other specimens. However, these features are also present in some specimens of $N$. (S.) conica (Yuan et al. 2002, pl. 42, figs 8, 10). This larger specimen is questionably assigned to the species.

Occurrence. - Kaili Formation, Oryctocephalus indicus Zone: Wuliu Quarry levels FZX1, 3, 4, 7, 8, 10, 13-16, 18-22, 28, 29; Wuliu-Zengjiayan and Miaobanpo sections, China.

\section{Genus Nangaops Yuan \& Sun (in Zhang et al., 1980)}

Type species. - Nangaops elongatus Yuan \& Sun (in Zhang et al., 1980), "Middle" Cambrian, Chongyang, Hubei, China; [= to Elrathina danzhaiensis Zhou (in Lu et al., 1974a)].

Remarks. - According to Yuan et al. (2002), the genus was originally named in a manuscript Yuan \& Sun (M.S. 1978). However, the first published description of Nangaops is in Zhang et al. (1980, pp. 317, 436). If the synonymy presented below is correct, $N$. elongatus is a junior synonym of N. danzhaiensis. 


\section{Nangaops danzhaiensis (Zhou in Lu et al., 1974a) Figure 20A-X}

1974a Elrathina danzhaiensis Zhou (in Lu et al.); p. 99, pl. 38, fig. 11.

1978 Nangaops danzhaiensis (Zhou in Lu et al., 1974a). Zhou (in Yin \& Lee), p. 471, pl. 162, fig. 12.

1980 Nangaops elongatus Yuan \& Sun (in Zhang et al.), pp. 317, 318, fig. 88, pl. 106, figs 1-3.

1980 Nangaops latilimbatus Yuan (in Zhang et al.), p. 318, pl. 106, figs 4-6.

1980 Nangaops danzhaiensis (Zhou in Lu et al., 1974a). Yuan (in Zhang et al.), pp. 318, 319, pl. 106, fig. 7.

1980 Nangaops brevicus Yuan \& Sun (in Zhang et al.), p. 319 , fig. 89 , pl. 106 , figs $8-11$.

1980 Nangaops rara Yuan (in Zhang et al.), pp. 319, 320, pl. 106, fig. 12.

1980 Nangaops nangaoensis Yuan (in Zhang et al.), p. 320, pl. 106, figs 13-17.

1983 Nangaops yuhangensis Ju, p. 84, pl. 27, fig. 3.

1984 Nangaops elongatus Yuan \& Sun (in Zhang et al., 1980). - Sun, pp. 354, 355, pl. 134, figs 1, 2.

1984 Nangaops brevicus Yuan \& Sun (in Zhang et al., 1980). - Sun, p. 355, pl. 133, figs 7, 8, pl. 134, figs 3,4 .

1984 Nangaops danzhaiensis (Zhou in Lu et al., 1974a). Sun, p. 355, pl. 134, figs 5, 6 .

1997 Nangaops brevicus Yuan \& Sun (in Zhang et al., 1980). - Yuan et al., pl. 5, fig. 13.

1999 Nangaops elongatus Yuan \& Sun (in Zhang et al., 1980). - Yuan et al., pl. 1, fig. 2.

2002 Nangaops elongatus Yuan \& Sun (in Zhang et al., 1980). - Yuan et al., p. 193, pl. 60, figs 9-11.

2002 Nangaops brevis Yuan \& Sun (in Zhang et al., 1980). - Yuan et al., p. 194, pl. 60, figs 2-4, 6-8.

2002 Nangaops danzhaiensis (Zhou in Lu et al., 1974a). Yuan et al., p. 194, pl. 60, figs 1, 5.

2010a Nangaops brevis Yuan \& Sun (in Zhang et al., 1980). - Sundberg et al., p. 24.

2010b Nangaops brevis Yuan \& Sun (in Zhang et al., 1980). - Sundberg et al., fig. 1.

2010b Eosoptychoparia conica Yuan (in Zhang et al., 1980). - Sundberg et al., fig. 1.

Material. - 130 cranidia, 36 pygidia, 11 partial or complete shields.

Emended diagnosis. - Nangaops with short palpebral lobes; ocular ridges that project at nearly $90^{\circ}$ from the glabella; posterior portion of the fixigena exsagittally long; preglabellar area about $25 \%$ of cranidial length; convergent anterior branches of the facial sutures, divergent posterior branches of the facial sutures at nearly $45^{\circ}$; and anterior border relatively short (sag.) and slightly convex.
Remarks. - The type specimens of Nangaops elongatus, type species, are clearly tectonically distorted, being elongated sagittally. The distortion of the specimens from the $\mathrm{Wu}-$ liu Quarry falls within the range of the previously named species of Nangaops. Nangaops brevis is transversely elongated, $N$. danzhaiensis appears to have proper dimensions, $N$. nangaoensis has been sagittally elongated and $N$. rara Yuan in Zhang et al., 1980, and N. latilimbatus are similar to $N$. brevis. Whereas most of the species have a tapering glabella, $N$. elongatus has a more parallel sided glabella; this again can be the result of the tectonic stretching. In addition, Zhao et al. (2001a, fig. 4; 2005a, fig. 7) list N. brevicus (= $N$. brevis), $N$. danzhaiensis, $N$. latilimbatus, and/or $N$. nangaoensis from the same horizons within 3 meters below the FAD of Oryctocephalus indicus. These co-occurrences suggest that the different species are just different tectonic distortions and/or morphological variations of a single species.

Sundberg et al. (2010a, b) assigned several specimens of $N$. danzhaiensis (listed as $N$. brevis) to Eosoptychoparia conica Yuan (in Zhang et al., 1980), because of the elongated cranidia and more parallel-sided glabella. However, based on the anterior border, convergent anterior facial sutures, short palpebral lobes, and lack of a pygidium similar to E. conica, these specimens are regarded here in as sagittally elongated specimens of $N$. danzhaiensis. These specimens were also found in the same horizons as $N$. danzhaiensis.

Occurrence. - Kaili Formation, Ovatoryctocara cf. granulata-Bathynotus holopygus Zone: Wuliu Quarry levels FZX29-46; Wuliu-Zengjiayan and Miaobanpo sections, China.

\section{Genus Probowmania Kobayashi, 1935}

Type species. - Ptychoparia ligea Walcott, 1905.

Remarks. - Yuan et al. (1997, 2002) placed three genera into subernera of Probowmania, Probowmania, Mufushania Lin, 1965, and Gunnia Gatehouse, 1968. Peng et al. (2009, pp. 49, 59) discussed the subgenera Gunnia and Mufushania and re-elevated them to generic rank. The differences between Probowmania and Mufushania listed by Peng et al. (2001) are inconsistent in the samples from the Wuliu Quarry and those illustrated by Yuan et al. (1997, 2002). Thus Probowmania is retained and Mufushania is considered a junior synonym.

\section{Probowmania nankingensis Lin, 1965}

Figure 21A-T

1965 Probowmania (Mufushania) nankingensis Lin; pp. 554, 555, 558, 559, pl. 1, fig. 6-11. 

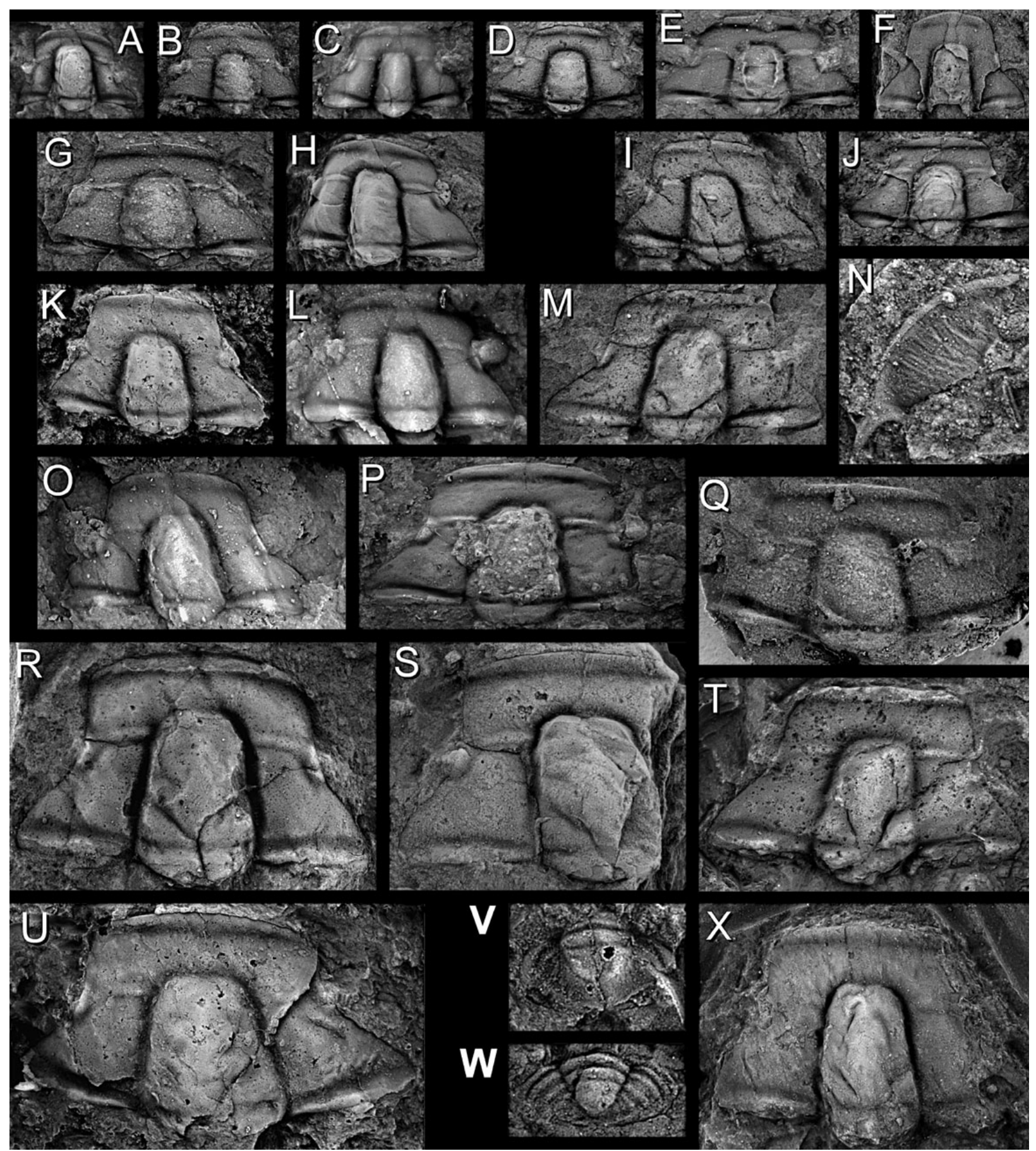

Figure 20. Nangaops danzhaiensis (Zhou in Lu et al., 1974a), all figures $\times 5$ unless otherwise noted. $\bullet$ A - cranidium, exfoliated, GK B3 0159 , FZX30. -B - cranidium, exfoliated, GK B3 0160, latex cast, FZX31. •C - cranidium, not exfoliated, GK B3 0161, latex cast, FZX31. D - cranidium, exfoliated, GK B3 0162, FZX31. E - cranidium, partially exfoliated, GK B3 0163, latex cast, FZX44. • F - cranidium, partially exfoliated, GK B3 0164 , FZX43. - G - cranidium, calcite coated, GK B3 0165, FZX41. $\bullet$ H - deformed cranidium, exfoliated, GK B3 0166, FZX30. • I - cranidium, exfoliated, GK B3 0167, FZX40. • J - cranidium, partially exfoliated, GK B3 0168, FZX45. $\bullet \mathrm{K}$ - cranidium, exfoliated, GK B3 0169, FZX45. $\bullet$ L - cranidium, not exfoliated, GK B3 0170, latex cast, FZX31. • M - cranidium, exfoliated, GK B3 0171, latex cast, FZX35. • N - librigena, exfoliated, GK B3 0172, FZX45, $\times$ 7.5. $\bullet$ O - cranidium, not exfoliated, GK B3 0173, latex cast, FZX41. $\bullet$ P - damaged cranidium, not exfoliated, GK B3 0174, latex cast, FZX44. -Q - cranidium, not exfoliated, granular surface possibly due to calcite coating, GK B3 0175, latex cast, FZX46. $\bullet$ - cranidium, exfoliated, GK B3 0176, FZX32. $\bullet$ S - cranidium, exfoliated, GK B3 0177, FZX31. $\mathrm{T}$ - cranidium, exfoliated, GK B3 0178, FZX46. • U - cranidium, exfoliated, GK B3 0179, FZX31. $\bullet$ V - damaged pygidium, exfoliated, GK B3 0180, FZX31, × 10. $\bullet$ W - pygidium, exfoliated, GK B3 0181, FZX35, × 10. $\bullet$ X - cranidium, exfoliated, GK B3 0182, FZX45. 
1965 Probowmania (Mufushania) changi Lin, pp. 555, 559, pl. 1, fig. 12-17.

1983 Mufushania changi Lin, 1965. - Qiu et al., p. 68, pl. 22, figs 9 .

1983 Mufushania nankingensis Lin, 1965. - Qiu et al., p. 68 , pl. 22, fig. 10 .

1988 Mufushania changi Lin, 1965. - Zhu et al., p. 38, pl. 1, figs 3, 4 .

1988 Mufushania nankingensis Lin, 1965. - Zhu et al., p. 38, pl. 1, fig. 6 .

1989 Mufushania nankingensis Lin, 1965. - Xie, pl. 1, fig. 1, pl. 3, fig. 2.

1997 Probowmania (Probowmania) balangensis Yuan \& Zhao (in Yuan et al.), pp. 509, 510, pl. 6, fig. 2.

1997 Probowmania (Gunnia) sp. Yuan \& Zhao (in Yuan et al.), p. 510, pl. 6, fig. 3 .

1999 Xingrenaspis (?) quadratus Yuan \& Zhao (in Zhang et al., 1980). - Yuan et al., p. 2, fig. 18-21.

2001 Mufushania nankingensis Lin, 1965. - Peng et al., p. 238, pl. 1, figs 1-7, pl. 2, figs 1-3, 5-10.

2002 Probowmania (Probowmania) balangensis Yuan \& Zhao (in Yuan et al., 1997). - Yuan et al., p. 155, pl. 44, figs 1-6, 11.

2002 Probowmania (Mufushania) nankingensis Lin, 1965. - Yuan et al., p. 157, pl. 44, figs 7-10.

2002 Probowmania (Gunnia?) himalaica (Reed). - Yuan et al., pp. 158, 159, pl. 44, fig. 12, 13, pl. 45, figs 2, 3.

2002 ?Probowmania (Gunnia?) quadrata (Yuan \& Zhou in Zhang et al., 1980). - Yuan et al., p. 159, pl. 47, fig. $10-13$, pl. 57 , fig. 7.

Material. - 19 cranidia, 33 partial or complete shields.

Emended diagnosis. - Probowmania with palpebral lobes twice as long as the posterior area of the fixigena (200\%); ocular ridges directed slightly posterior-laterally and strong; glabellar length approximately $66 \%$ of cranidial length; preglabellar field length longer than anterior border (150\%); anterior border convex, level, slightly tapering at lateral margins; facial sutures divergent anterior of palpebral lobes, very strongly divergent (approx. 90 ) from the posterior end of palpebral lobes. Pygidium transversely elongated with anterior lateral corners located about the mid-length of the pygidium; doublure narrow at posterior margin, slightly wider at anterior margin; pleural furrows prominent, interpleural furrows weaker; pygidial axis with 3 rings, width about $2 / 3$ pleural field width; rounded terminal piece that nearly reaches the anterior border. Well-preserved specimens illustrate a fine granular texture on the dorsal surface of the exoskeleton (Fig. 21F, I).

Remarks. - This species has a relatively truncate glabella with long palpebral lobes and strong ocular ridges directed nearly straight outwards. It is most similar to Parashuiyella Yuan \& Zhao in Yuan et al., 1997, but differs in having a narrower anterior border, more segments in the pygidium, wider preglabellar area and wider fixigena. This species is also similar to Kaotaia Lu 1962, but differs in its stronger ocular ridges, longer palpebral lobes, elongated, less rectangular pygidium, less pronounced doublure on the thoracic segments and pygidium, and less tapered shield. Specimens of Kaotaia magna (Lu, 1945) are similar, but the anterior border is less convex and possibly upturned. Kaotaia typically includes a medial swelling in the preglabellar field, but is not always apparent on some specimens. Some specimens of Probowmania also have these swellings (Fig. 21F, K, P), but it cannot be established if they are the result of tectonic distortion and/or compaction.

Illustrated specimens of Probowmania (Probowmania) balangensis Yuan \& Zhao in Yuan et al., 1997 (pl. 6, fig. 2, Yuan et al. 2002, pl. 44, figs 1-6, 11) fall within the morphological range of the specimens of species found in the quarry section and the specimens of Probowmania (Mufushania) nankinensis illustrated by Peng et al. (2001, pl. 1, figs 1-7, pl. 2, figs 1-3, 5-10) and Yuan et al. (2002, pl. 44, figs 1-10). These two species also occur in the same horizons in the Wuliu-Zengjiayan section (Yuan et al. 2002).

The type specimens of Ptychoparia? himalaica Reed, 1910, illustrated as Shantungaspis himalaica (Reed) in Jell \& Hughes (1997, pl. 11, figs 1-4, fig. 4 is the lectotype), are similar to Probowmania balangensis, but differ in the more rectangular glabella. If this shape of the glabella is reliable in the tectonically distorted specimens, then S. himalaica is a different species. Peng et al. (2009) placed $S$. himalaica into Douposiella Lu \& Chang in Lu et al., 1974a. If the specimens preserved in limestone illustrated by Peng

Figure 21. Probowmania nankingensis Lin, 1965, all figures $\times 7$ except figures Q-T which are $\times 15$. $\bullet$ A - damaged cranidium, partially exfoliated, GK B3 0183, FZX46. • B - cranidium, exfoliated, GK B3 0184, FZX45. • C - cranidium, mostly exfoliated, GK B3 0185, FZX45. • D - partial shield, not exfoliated, GK B3 0186, latex cast, FZX44. • E - cranidium, covered with calcite layer, GK B3 0187, FZX35. • F - cranidium with librigenae and two thoracic segments, mostly exfoliated, GK B3 0188, FZX43. $\bullet \mathrm{G}$ - damaged cranidium, not exfoliated, GK B3 0189, FZX42. • H - partial shield, exfoliated, GK B3 0190, FZX39. • I - shield, not exfoliated, GK B3 0191, latex cast, FZX46. • J - partial cranidium, partially exfoliated, GK B3 0193, FZX41. - K - partial shield, partially exfoliated, GK B3 0193, FZX42.・L - shield, calcite coated, GK B3 0194, FZX34. • M - partial shield, not exfoliated, GK B3 0195, latex cast, FZX35. • N - nearly complete shield, not exfoliated, GK B3 0196, latex cast, FZX41. • O - shield, not exfoliated, GK B3 0197, latex cast, FZX40. • P - shield, partially exfoliated, GK B3 0198, latex cast, FZX41. • Q - partial pygidium, exfoliated, GK B3 0199, FZX46. • R - crushed pygidium, exfoliated, GK B3 0200, FZX46. • S - pygidium, partially exfoliated, GK B3 0201, FZX37. • T - pygidium, not exfoliated, GK B3 0202, latex cast, FZX45. 


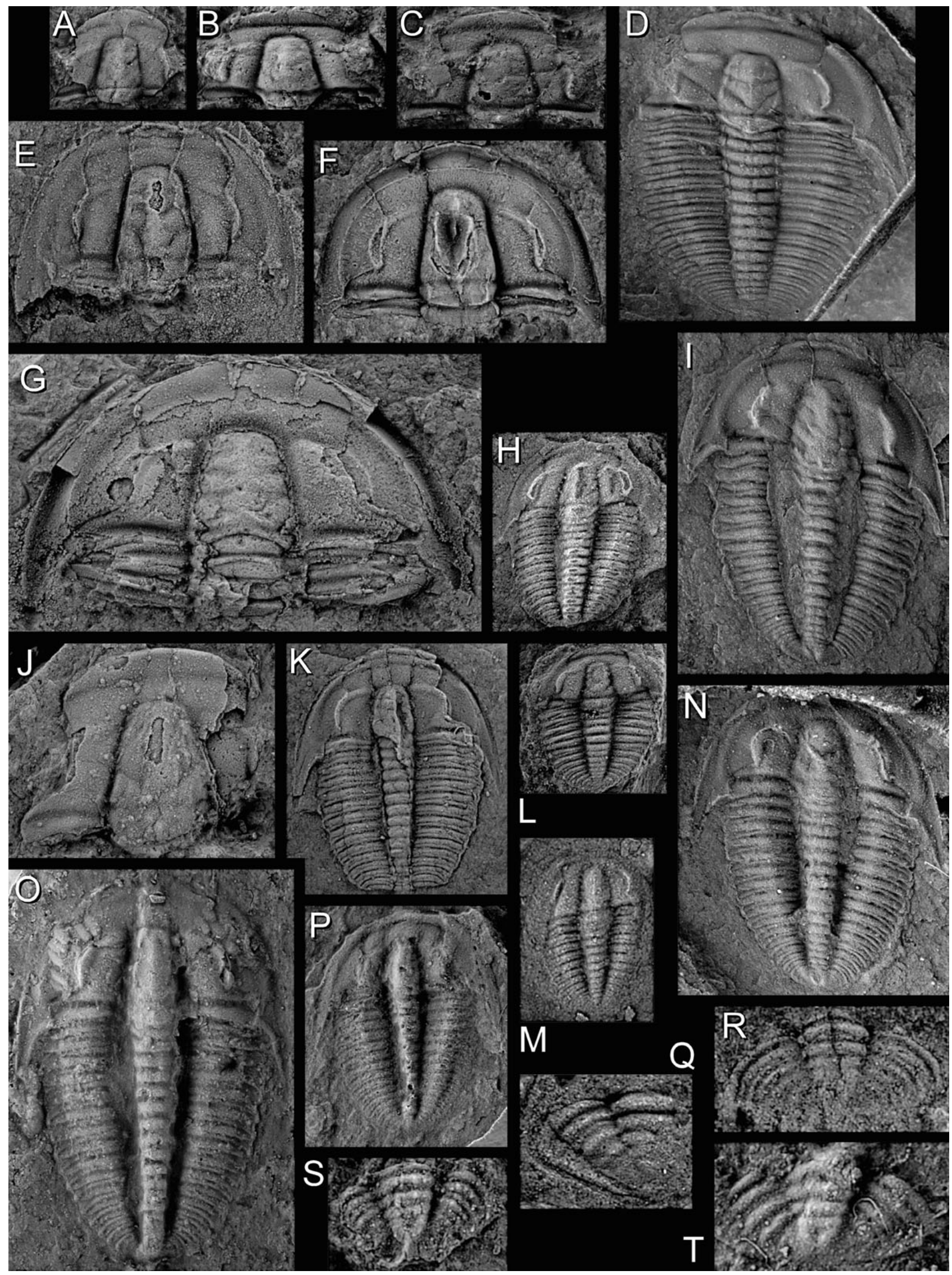


et al. (2009, fig. 29) are conspecific, then Douposiella himalaica is a distinct genus from Probowmania in its glabellar outline, rounded termination of the posterior area of the fixigena, and narrow (tr.) genal area of the librigena. However, the specimens of Probowmania himalaica illustrated by Yuan et al. (2002, pl. 11, figs 12, 13, pl. 45, figs 2,3) could be tectonically stretched representatives of $P$. nankinensis and are thus included into this species.

Probowmania (Gunnia?) quadrata Yuan \& Zhou in Zhang et al., 1980, illustrated by Yuan et al. (2002) is questionably assigned to $P$. nankinensis. It has a wider fixigena and more quadrate glabella, although these could be the result of tectonic distortion. Probowmania quadrata occurs stratigraphically above $P$. nankinensis in the upper portion of the $O$. indicus Zone (=O. orientalis Zone of Yuan et al. 2002). Xingrenaspis quadratus Yuan \& Zhou in Zhang et al., 1980 (pl. 109, figs 14-19) has upturned anterior borders, narrower palpebral lobes, and weaker ocular ridges and is not considered conspecific with $P$. nankinensis.

Occurrence. - Kaili Formation, Ovatoryctocara cf. granulata-Bathynotus holopygus Zone: Wuliu Quarry levels FZX31, 32, 35, 36, 40, 41, 43-46; Wuliu-Zengjiayan and Miaobanpo sections, China.

\section{Genus Xingrenaspis Yuan \& Zhou (in Zhang et al., 1980)}

Type species. - Xingrenaspis xingrenensis Yuan \& Zhou (in Zhang et al., 1980).

Remarks. - Peng et al. (2009, pp. 63-65) synonymized the type species with $X$. hoboi (Resser \& Endo in Endo \& Resser 1937). This reassignment of the type species to $X$. hoboi we consider an error, see discussion below.

\section{Xingrenaspis xingrenensis Yuan \& Zhou (in Zhang et al., 1980) \\ Figure 22A-Y}

1980 ?Wuxunaspis subquadrata Yuan (in Zhang et al.); p. 325 , fig. 92 , pl. 107 , fig. 16 .
1980 Xingrenaspis xingrenensis Yuan \& Zhou (in Zhang et al.), pp. 330, 331, fig. 94, pl. 108, figs 19, 20, pl. 109, figs 1-12, pl. 110, figs 5, 6 .

1980 Xingrenaspis quadratus Yuan \& Zhou (in Zhang et al.), p. 331, pl. 109, figs 14-16.

1980 Xingrenaspis rectangularis Yuan \& Zhou (in Zhang et al.), p. 331, pl. 109, figs 13.

1980 Xingrenaspis jialaoensis Yuan \& Zhou (in Zhang et al.), p. 332, pl. 108, fig. 14.

1980 Xingrenaspis elongatus Yuan \& Zhou (in Zhang et al.), pp. 332, 333, pl. 109, figs 17-19.

1983 ?Xingrenaspis politus Lu \& Qian, p. 39, pl. 4, fig. 11.

1997 ?Xingrenaspis dardapurensis (Reed, 1934). - Jell \& Hughes, pp. 66, 67 (see for further synonymy of this species), pl. 18, figs 4-11, pl. 26, figs 1-11, not pl. 19, figs $1,2$.

2002 Xingrenaspis xingrenensis Yuan \& Zhou (in Zhang et al., 1980). - Yuan et al., pp. 186, 274, pl. 45, fig. 10, pl. 46, figs 5-7, pl. 47, fig. 6, pl. 48, figs 1-10, pl. 49, figs $2-7$.

2002 ?Xingrenaspis primus Yuan \& Zhao (in Yuan et al.), pp. 187, 274, pl. 47, fig. 7.

2002 ?Xingrenaspis politus Lu \& Qian, 1983. - Yuan et al., pp. 187,274 , pl. 45 , fig. 12 , pl. 47 , figs $3-5$, pl. 49 , figs 8,9 .

2002 Xingrenaspis rectangularis Yuan \& Zhou (in Zhang et al., 1980). - Yuan et al., pp. 188, 275, pl. 46, figs $1-4$.

2002 ?Xingrenaspis granulosa Yuan \& Zhao (in Yuan et al.), pp. 188, 275, pl. 57, fig. 10.

2009 Xingrenaspis hoboi (Resser \& Endo in Endo \& Resser, 1937). - Peng et al., pp. 65, 66, fig. 42.1-42.5.

2010b Douposiella guizhouensis Yuan \& Zhou (in Yuan et al., 2002). - Sundberg et al., fig. 1.

Material. - 489 cranidia, 54 pygidia, 11 partial or complete shields.

Emended diagnosis. - Xingrenaspis has palpebral lobes slightly shorter than the posterior area of the fixigena (85-95\%); ocular ridges directed moderately posterior laterally; glabellar length approximately $70 \%$ of cranidial length; anterior border approximately $60-75 \%$ of preglabellar field, slightly convex (could be influenced

Figure 22. Xingrenaspis xingrenensis Yuan \& Zhou in Zhang et al., 1980, all figures $\times 5$ unless otherwise noted. $\bullet$ A - cranidium, exfoliated, GK B3 0203, FZX11, × 10.・B - cranidium, not exfoliated, GK B3 0204, latex cast, FZX10.・C - cranidium, exfoliated, GK B3 0205, FZX16. • D - cranidium, not exfoliated, GK B3 0206, FZX13.• E - cranidium, not exfoliated, GK B3 0207, latex cast, FZX13. • F - cranidium, partially exfoliated, GK B3 0208, FZX11. • G - cranidium, mostly exfoliated, GK B3 0209, FZX13. $\bullet \mathrm{H}$ - cranidium, exfoliated, GK B3 0210, FZX16. • I - cranidium, partially exfoliated, GK B3 0211, FZX6. • J - cranidium, partially exfoliated, GK B3 0212, FZX13.・K - cranidium, exfoliated, GK B3 0213, FZX6. • L, M - cranidium, not exfoliated, GK B3 0214, latex cast, FZX2; M - closeup showing fine granules, $\times 10$. $\bullet \mathrm{N}$ - cranidium, exfoliated, GK B3 0215, FZX9. $\bullet$ O - cranidium, not exfoliated, GK B3 0216, FZX15. • P - cranidium, not exfoliated, GK B3 0217, FZX16. • Q - cranidium, not exfoliated, GK B3 0218, FZX16; latex cast. - R - shield, not exfoliated, GK B3 0219, latex cast, FZX6. $\bullet \mathrm{S}$ - cranidium, not exfoliated, GK B3 0220, FZX2. $\bullet$ T - shield, exfoliated, internal mold, GK B3 0223, FZX3. • U - cranidium, not exfoliated, GK B3 0221, FZX9.・V - pygidium, not exfoliated, GK B3 0222, latex cast, FZX9. • W - pygidium, not exfoliated, GK B3 0224, FZX9. • X - pygidium, partially exfoliated, GK B3 0225, FZX9. • Y - pygidium, not exfoliated, GK B3 0226 , FZX15. 


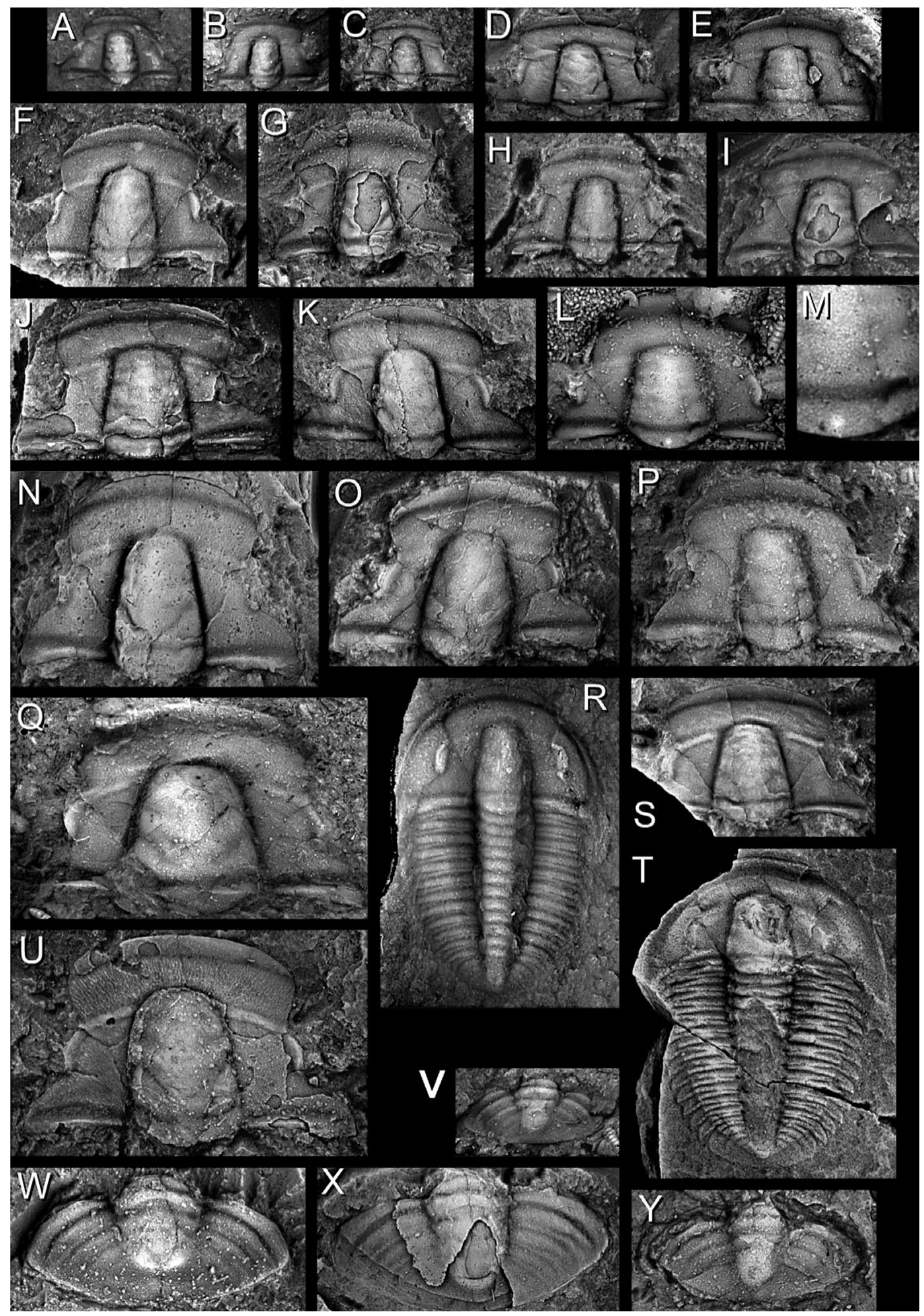


by compaction), level to upturned, slightly tapering laterally; facial sutures moderately divergent anterior of palpebral lobes, strongly divergent (approximately $45^{\circ}$ ) from the posterior end of the palpebral lobes. Pygidium transversely elongated with anterior lateral corners located about the mid-length of the pygidium and doublure narrow at posterior margin, but nearly $1 / 3$ to $1 / 2$ of the anterior margin.

Remarks. - Because of the distortion, the relative length/width ratio of the cranidium and glabella varies considerably, ranging in morphology between $X$. rectangularis Yuan \& Zhou in Zhang et al., 1980, to X. quadratus, to X. elongatus Yuan \& Zhou in Zhang et al., 1980. Included in this range of morphologies is X. jialaoensis Yuan \& Zhou in Zhang et al., 1980. These species are probably synonymous with $X$. xingrenensis. The anterior border ranges from very slightly to moderately concave and can be level to upturned. These features could also be the result of tectonic distortion and lithologic compaction of the mudstones. The anterior border furrow is also variable. In several specimens it is well defined, although shallow. Other specimens with more upturned anterior borders have furrows that are very shallow.

Peng et al. (2009) synonymized $X$. xingrenensis with $X$. hoboi, however the two species differ. Based on the illustration of the type material in Zhang \& Jell (1987, pl. 83, figs 4-6, 6 is lectotype), $X$. hoboi differs from the type material of $X$. xingrenensis and the material found in the Wuliu Quarry in having longer palpebral lobes that have anterior and posterior ends aligning exsagittally and a stronger curvature; ocular ridges that are stronger and directly nearly at $90^{\circ}$ to the glabella; posterior facial sutures that are more divergent; and pleural lobes and pygidium with a narrower doublure and the anterior-lateral corners nearly parallel with the anterior margin of the pygidium. However, the specimens illustrated by Peng et al. (2009, fig. 42.1-42.5) as $X$. hoboi match the characteristics of the type and quarry material of $X$. xingrenensis and are reassigned here.

Xingrenaspis brevicus Yuan \& Zhou in Zhang et al., 1980, and X. curvus Yuan \& Zhou in Zhang et al., 1980 are very similar species and may represent a single taxon. These species are preserved in limestone and differ from the specimens of $X$. xingrenensis in having a more strongly curved anterior border and wider preglabellar area. In contrast, X. primus Yuan \& Zhao in Yuan et al., 2002, and X. politus Lu \& Qian, 1983 are preserved in shale and their strongly curved anterior border and wider preglabellar areas may be the result of tectonics. These two species are questionably included here to $X$. xingrenensis.

Xingrenaspis dardapurensis (Reed, 1934) is questionably assigned to this species because the specimens from India are strongly tectonically deformed and lack pygidia. The cranidia of Xingrenaspis dardapurensis illustrated by
Jell \& Hughes (1997) are very similar to X. xingrenensis with the exception of the specimen illustrated in plate 19 , figures 1 and 2 (Jell \& Hughes 1997), which has a very conical shaped glabella. If $X$. dardapurensis is the same species as that from the Kaili Formation, then it would be the senior synonym.

Zhang \& Jell (1987, pp. 72, 73) placed several species named by Yuan \& Zhou (in Zhang et al., 1980) into synonymy with $X$. hoboi. However, many of the specimens of Yuan \& Zhou (in Zhang et al., 1980) are poorly preserved and/or internal moulds with limonite coatings preventing accurate taxonomic determination (based on personal observation by FAS of the type specimens). Of those species listed by Zhang \& Jell (1987), Eosoptychoparia intermedia Yuan in Zhang et al., 1980, E. guizhouensis Yuan in Zhang et al., 1980, E. conica, Onchocephalus? sanwanensis Yuan in Zhang et al., 1980, Pachyapsis (Danzhaina) lilia Yuan in Zhang et al., 1980, P. (D.) sp. Yuan in Zhang et al., 1980, Wuxunaspis deltoidea Yuan in Zhang et al., 1980, W.? deflecta Yuan in Zhang et al., 1980, W.? guizhouensis Yuan in Zhang et al., 1980, Ptychoparia? nitida Yuan in Zhang et al., 1980, Elrathiella kailiensis Zhou in Zhang et al., 1980, and Elrathiella? bella Yuan in Zhang et al., 1980 are not included in the above synonymy for Xingrenaspis xingrenensis.

Zhang \& Jell (1987) and Peng et al. (2009) placed Eosoptychoparia conica and E. intermedia into X. hoboi. If the specimens of E. conica and E. intermedia illustrated by Yuan et al. (2002, pl. 52, figs 1-9, pl. 53, fig. 7-9, pl. 54, fig. 10) are conspecific with the type material, differences in the pygidium shape and absence of a wide marginal border would indicate that these species do not belong in Xingrenaspis. This does not, however, state that E. conica, E. intermedia, and E. guizhouensis are different species. These and E. lilia (Yuan in Zhang et al., 1980), E. mesembrina Yuan \& Zhao in Yuan et al., 2002, and E. typica (Yuan in Zhang et al., 1980) may be conspecific.

Onchocephalus? sanwanensis (Zhang et al. 1980, pl. 102, figs 3,20) differs from $X$. xingrenensis in have longer palpebral lobes, ocular ridges nearly 90 degrees to the glabellar axis and a relatively narrow posterior area of the fixigena. Ptychoparia? nitida (Zhang et al., 1980, pl. 107, fig. 17) differs from $X$. xingrenensis in its more hour-glass shaped glabella. Wuxunaspis deltoidea (Zhang et al., 1980, pl. 107, figs 10-12), W.? deflecta (Zhang et al., 1980, pl. 107, figs 13, 14), and W.? guizhouensis (Zhang et al., 1980, pl. 107, fig. 15) generally have longer palpebral lobes and a narrower, parallel sided posterior area of the fixigena. Other sclerites of these taxa are unknown. Wuxunaspis subquadrata Yuan in Zhang et al., 1980 is questionably assigned to $X$. xingrenensis based on its overall shape, but the material is poorly preserved and has deeper glabellar furrows. Elrathiella kailiensis (Zhang et al., 1980, pl. 118, figs 7,8) and Elrathiella? bella (Zhang et 
al., 1980, pl. 118, figs 9-12) are also not included into $X$. xingrenensis due to their longer and wider palpebral lobes and narrower (exsag.) posterior area of the fixigena.

Xingrenaspis shyamalae and $X$. parthiva, both named by Peng et al. (2009), are two closely related species, but are not Xingrenaspis based on the pygidia having a short bluntly rounded axis with only two segments, stronger interpleural furrows [similar to Alokistocaridae as revised by Sundberg 1999 (= Ehmaniellidae Sundberg, 1994)], and narrow margins and matching narrow doublure.

Occurrence. - Kaili Formation, Ovatoryctocara cf. granulata-Bathynotus holopygus to Oryctocephalus indicus zones: Wuliu Quarry levels FZX32, 25-1; Wuliu-Zengjiayan and Miaobanpo sections, China. Parahio Formation, Oryctocephalites salteri Zone: Parahio River section, India.

\section{Acknowledgments}

A special thanks to Peng Jin, Yang Xinglian, Yin Leming, and Tai Tongshu and our local Balang villagers Liu Feng, Liu Zefu, Liu Zebiao, Wan Kai, Zhang Leilei, and Tai Gulong for their help with the field work. Pete Scholten assisted in the counting of trilobite and brachiopod specimens. Elena Naimark and Anna Zyłinska provided valuable comments to this paper. This research was supported, in part, by grants form the National Natural Science Foundations of China (40672018), the Ministry of Technology and Science of China (2006C13806401), the Foundation of Chinese Committee of Stratigraphy, the Foundation of International Cooperation of Guizhou and Technology (Gui:[2010]7001), the Foundation of Paleontological Museum of Shenzhen, Xianhu Botanical Garden, special Science and Technology Foundation of Guizhou (Gui. Sci. Ji 2007-4004), and International cooperation of Guizhou Science and Technology (G[2008]700110, G[2010]7001) to Zhao and the Project-Oriented Hundred Talents Programme (KZCX2-YW-BR-23) of the Chinese Academy of Sciences to Lin.

\section{References}

BABCOCK, L.E. \& Robison, R.A. 1988. Taxonomy and Paleobiology of some Middle Cambrian Scenella (Cnidaria) and Hyolithids (Mollusca) from western North America. University of Kansas Paleontological Contributions, Paper 121, $1-22$.

BEECHER, C.E. 1897. Outline of a natural classification of the trilobites. American Journal of Science, Series 4(3), 89-106, 181-207.

Bergeron, J. 1899. Etude de quelques trilobites de China. Bulletin de la Société Géologique de France, $3^{\text {rd }}$ series 27, 499-519.

Cossmann, M. 1902. Rectifications de la nomenclature. Revue de Critique Paléozoologie 6, 1-52.
Endo, R. \& Resser, C.E. 1937. Sinian and Cambrian formations and fossils of southern Manchuria. Manchurian Science Museum Bulletin 1, 1-474.

ETHERIDGe, R. JR. 1902. Official contributions to the palaeontology of South Australia. No. 13, Evidence of further Cambrian trilobites. South Australian Parliamentary Papers, 3-4.

Gaines, R.R., Mering, J.A., Zhao, Y.-L. \& Peng, J. In press. Stratigraphic and Microfacies Analysis of the Kaili Formation, a Candidate GSSP for the Cambrian Series 2-Series 3 Boundary. Palaeogeography, Palaeoclimatology, Palaeoecology.

Gatehouse, C.G. 1986. Early Middle Cambrian trilobites of the Litchfield area, Northern Territories. Bulletin of the Bureau of Mineral Resouces Geology and Geophysics 80, 45-64.

Goryansky, V.I. \& KonEVA, S.P. 1983. Nizhnekembriyskie bezzamkovye brakhiopody khrebta Malyi Karatau (Iuzhnyi Kazakhstan) [Lower Cambrian inarticulate brachiopods of the Malyi Karatau Range (southern Kazakhstan)]. Akademiya Nauk SSSR, Sibirskoe otdelenie, Institut Geologii i Geofiziki (IGIG), Trudy 541, 128-138.

Guo, Q.-J., Strauss, H., Lui, C.-Q., Zhao, Y.-L., Pi, D.-H., Fu, P.-Q, ZHU, L.-J. \& YANG, R.-D. 2005. Carbon and oxygen isotopic composition of Lower to Middle Cambrian sediments at Taijiang, Guizhou Province, China. Geological Magazine 142, 723-733. DOI 10.1017/S0016756805001202

Guo, Q.-J., Strauss, H., Lui, C.-Q., ZhaO, Y.-L., Yang, X.-L., Peng, J. \& YANG, H. 2010. A negative carbon isotope excursion defines the boundary from Cambrian Series 2 to Cambrian Series 3 on the Yangtze Platform, South China. Palaeogeography, Palaeoclimatology, Palaeoecology 285, 143-151. DOI 10.1016/j.palaeo.2009.11.005

Guo, Q.-J. \& Zнао, Y.-L. 1998. The Redlichia of Kaili Formation in the south-east region of Guizhou. Journal of Guizhou University of Technology 27(1), 51-55.

Guo, Q.-J., ZhaO, Y.-L. \& Yuan, J.-L. 1999. The restudy of Redlichia from the lower part of the Kaili Formation in Kaili area, Guizhou Province. Acta Palaeontologica Sinica 38 (Supplement), 157-164.

Hall, J. 1860. Annual report of the New York State Cabinet of Natural History 13, 1-118.

Harrington, H.J., Henningsmoen, G., Howell, B.F., JaAnusson, V., Lochman-Balk, C., Moore, R.C., Poulsen, C., Rasetti, F., Richter, E., Richter, R., Schmidt, H., Sdzuy, K., Struve, W., Størmer, L., Stubblefield, C.J., Tripp, R., Weller, J.M. \& Whittington, H.B. 1959. Arthropoda 1. In Moore, R.C. (ed.) Treatise on invertebrate paleontology. Part O. 560 pp. Geological Society of America \& University of Kansas, Lawrence, Kansas.

Holmer, L.E., Popov, L.E., Koneva, S.P. \& Bassett, M.G. 2001. Cambrian-early Ordovician brachiopods from Malyi Karatau, the western Balkhash Region, and northern Tien Shan, Central Asia. Special Papers in Palaeontology 65, 1-180.

Huang, Y.-H. \& DAI, X.-C. 1998. A view of Scenella in the Kaili fauna at Taijiang of Guizhou. Journal of Guizhou University of Technology 27, 56-61. [in Chinese with English summary]

Huang, Y.-H., Wang, H.-Y., ZhaO, Y.-L. \& DaI, X.-C. 1994. 
Brachiopods from Early-Middle Cambrian Kaili Formation in Taijiang, Guizhou. Acta Palaeontologica Sinica 33, 335-344. [in Chinese with English summary]

Hupé, P. 1953. Classe des trilobites, 44-246. In Piveteau, J. (ed.) Traité de Paléontologie. Masson, Paris.

JeLL, P.A. 1975. Australian Middle Cambrian eodiscoids with a review of the superfamily. Palaeontographica, Abteilung A 150, 1-97.

Jell, P.A. \& Hughes, N.C. 1997. Himalayan Cambrian trilobites. Special Papers in Palaeontology 58, 1-113.

Ju, T.-Y. 1983. Early Cambrian trilobites from the Hotang and Dachenling Formations of Zhejiang. Acta Palaeontologica Sinica 22, 628-636. [in Chinese]

KING, W.B.R. 1941. The Cambrian fauna of the Salt Range of India. Records of the Geological Survey of India 75, 1-15.

Kobayashi, T. 1935. The Cambro-Ordovician formations and faunas of South Chosen. Palaeontology, part 3: Cambrian faunas of South Chosen with special study on the Cambrian trilobite genera and families. Journal of the Faculty of Science, Imperial University of Tokyo, Section II 4(2), 49-344.

Kobayashi, T. 1939. On the agnostids (Part 1). Journal of the Faculty of Science, Imperial University of Tokyo, Section II 5(5), 69-198.

Kobayashi, T. 1944. On the eodiscids. Journal of the Faculty of Science, Tokyo University, Section 2(7), 1-74.

Kobayashi, T. 1967. The Cambro-Ordovician formations and faunas of South Korea, Part X Stratigraphy of the Chosen Group in Korea and South Manchuria and its relation to the Cambro-Ordovician formations of other areas. Journal of the Faculty of Science, Tokyo University, Section 2(16), 381-535.

Koneva, S.P. 1979. Stenotekoidy i bezzamkovye brakhiopody nizhnego i nizov srednego kembriia Tsentralnogo Kazakhstana. [Stenotecoids and inarticulate brachiopods from the Lower and lower Middle Cambrian of Central Kazakhstan.] 123 pp. Nauka, Alma-Ata.

Korovnikov, I.V. 2001. Lower and Middle Cambrian boundary and trilobites from northeast Siberia platform. Palaeoworld 13, 270-275.

Lermontova, E.V. 1940. Arthropoda, 112-157. In Vologdin, A. (ed.) Atlas of the Leading Forms of Fossil Faunas of the USSR. Cambrian. State Editorial Office, Geological Literature, Moscow \& Leningrad.

LiN, T. 1965. A Cambrian trilobite fauna from Mufushan, Nanking. Acta Palaeontologica Sinica 13, 552-559. [in Chinese with English summary]

LiN, J.-P. 2007. Preservation of the gastrointestinal system in Olenoides (Trilobita) from the Kaili Biota (Cambrian) of Guizhou, China. Memoirs of the Association of Australasian Palaeontologists 33, 179-189.

Lin, J.-P. 2008. From a Fossil Assemblage to a Paleoecological Community: Time, Organism and Environment based on the Kaili Lagerstätte (Cambrian), South China and Coeval Deposits of Exceptional Preservation. 416 pp. VDM Verlag Dr. Müller, Saarbrücken.

Lin, J.-P. 2009. Review of the depositional environment of the Kaili Formation (Cambrian Series 2-3 boundary interval:
China). Memoirs of the Association of Australasian Palaeontologists 37, 131-149.

LiN, J.-P. 2010. Preliminary study of a negative carbon isotopic excursion in the middle Kaili Formation (Cambrian series 2-3) at the Miaopanbo section, Guizhou, China, 15. In FATKA, O. \& BudiL, P. (eds) The $15^{\text {th }}$ Field Conference of the Cambrian Stage Subdivision Working Group, International Subcommission on Cambrian Stratigraphy. Abstracts and Excursion Guide, Prague, Czech Republic and south-eastern Germany. 107 pp. Czech Geological Survey, Prague.

LiN, J.-P. 2011. Confirmation of a negative carbon istopic excursion in the middle Kaili Formation (Cambrian Series 2-3), Guizhou, China, 290. In Hollingsworth, J.S., Sundberg, F.A. \& Foster, J.R. (eds) Cambrian Stratigraphy and Paleontology of Northern Arizona and Southern Nevada. Museum of Northern Arizona Bulletin 67.

Lin, J.-P. \& Yuan, J.-L. 2009. Reassessment of the mode of life of Pagetia Walcott, 1916 (Trilobita: Eodiscidae) based on a cluster of intact exuviae from the Kaili Formation (Cambrian) of Guizhou, China. Lethaia 42, 67-73.

Lin, J.-P., YuAn, J.-L., WANG, Y. \& ZhaO, Y.-L. 2005. Introduction to the type section of the Kaili Formation, Danzhai, Guizhou Province, China, 55-61. In PeNG, S.-C., BABCOCK, L.E. \& ZHu, M.-Y. (eds) Cambrian System of China and Korea - Guide to Field Excursions. University of Science and Technology of China Press, Hefei.

Lin, J.-P., ZhaO, Y.-L., Rahman, I.A., XiaO, S.-H. \& Wang, Y. 2010. Bioturbation in Burgess Shale-type Lagerstätten - Case study of trace fossil-body fossil association from the Kaili Biota (Cambrian Series 3), Guizhou, China. Palaeogeography, Palaeoclimatology, Palaeoecology 292, 245-256. DOI 10.1016/j.palaeo.2010.03.048

Lu, Y.-H. 1945. Early Middle Cambrian faunas from Meitan. Bulletin of the Geological Society of China 25, 185-199.

Lu, Y.-H. \& CHIEN, Y.-Y. 1983. In Lu, Y.-H. \& Qian, Y.-Y. 1983. Cambro-Ordovician trilobites from eastern Guizhou. Palaeontologica Cathayana 1, 1-105.

Lu, Y.-H., Zhang, W.-T., Qian, Y.-Y., Zhu, Z.-L., Lin, H.-L, Zhou, Z.-Y., QiAn, Y., Zhang, S.-G. \& Wu, H.-J. 1974a. Cambrian trilobites, 82-107. In NANJING InSTITUE OF GEOLOGY AND Palaeontology, Academia Sinica (ed.) Handbook of Stratigraphy and Palaeontology, Southwest China. Science Press, Beijing. [in Chinese]

Lu, Y.-H., Zhu, Z.-L., Qian, Y.-Y., Lin, H.-L., Zhou, Z.-Y. \& YUAN, K.-X. 1974b. Bio-environmental control hypothesis and its application to the Cambrian biostratigraphy and palaeozoogeography. Memoir, Nanjing Institute of Geology and Palaeontology, Academia Sinica 5, 27-116. [in Chinese]

Luo, H.-L., Hu, S.-X., Hou, S.-G., Gao, H.-G., Zhand, Q. \& LI, W.-C. 2009. Cambrian stratigraphy and trilobites from southeastern Yunnan, China. 252 pp. Yunnan Science and Technology Press, Kunming. [in Chinese with English summary]

MaO, J.-R., Zhao, Y.-L. \& Huang, Y.-H. 1993. Some Cambrian monoplacophorans from Taijiang, Guizhou. Acta Micropalaeontologica Sinica 10, 99-104. [in Chinese with English summary] 
Maо, J.-R., Zhaо, Y.-L. \& Yu, P. 1994. Noncalcareous algae of Kaili Fauna of Taijiang, Guizhou. Acta Palaeontologica Sinica 33, 345-349. [in Chinese with English summary]

MaO, J.-R., Zhao, Y.-L., Yu, P. \& Qian, Y. 1992. Some Middle Cambrian Hyolithids from Taijiang, Guizhou. Acta Micropalaeontologica Sinica 9, 257-265. [in Chinese with English summary]

MatThew, G.F. 1887. Illustrations of the fauna of the St. John Group. 4. Part 1. Description of a new species of Paradoxides (Paradoxides regina). Part 2. The smaller trilobites with eyes (Ptychopariidae and Ellipsocephalidae). Transactions of the Royal Society of Canada 5(4), 123-166.

McCollum, L.B. \& Sundberg, F.A. 2010. Status of the stage 5 series 3 boundary from the Lower-Middle Cambrian Working Group, 20. In FATKA, O. \& BudIL, P. (eds) The $15^{\text {th }}$ Field Conference of the Cambrian Stage Subdivision Working Group, International Subcommission on Cambrian Stratigraphy. Abstracts and Excursion Guide, Prague, Czech Republic and south-eastern Germany. 107 pp. Czech Geological Survey, Prague.

MeEk, F.B. 1870. Descriptions of fossils collected by the U.S. Geological Survey, under charge of Clarence King. Proceedings of the Academy of Natural Sciences of Philadelphia, $2^{\text {nd }}$ series $14,56-64$.

Meek, F.B. 1877. Palaeontology. United States Geological Exploration of the Fortieth Parallel. Clarence King, Geologist-in-charge 4(1), 1-197.

Naimark, E., Shabanov, Y. \& Korovnikov, I. 2011. Cambrian trilobite Ovatoryctocara Tchernysheva, 1962 from Siberia. Bulletin of Geosciences 86(3), 405-422. DOI 10.3140/bull.geosci.1272

Palmer, A.R. \& Halley, R.B. 1979. Physical stratigraphy and trilobite biostratigraphy of the Carrara Formation (Lower and Middle Cambrian) in the southern Great Basin. United States Geological Survey, Professional Paper 1047, 1-131.

Peng, S.-C., Hughes, N.C., Heim, N.A., Sell, B.K., Zhu, X.-J., Myrow, P.M. \& Parcha, S.K. 2009. Cambrian trilobites from the Parahio and Zanskar Valleys, Indian Himalaya. Journal of Paleontology 83, Supplement 6, Memoir 71, $1-95$.

Peng, S.-C., Lin, T.-R., Van Iten, H., Zhu, M.-Y. \& Lin, H.-L. 2001. Primitive ptychoparioids from southern Anhui Province, South China. Acta Palaeontologica Sinica 40 (Supplement), 236-242.

Poulsen, C. 1927. The Cambrian, Ozarkian and Canadian faunas of northwest Greenland. Meddelelser om Grønland 70, 233-343.

Qıu, H.-G., Lu, Y.-H., Zнu, Z.-L., Bı, D.-C., Lin, T.-R., Zноu, Z.-Y., Zhang, Q.-Z., Qian, Y.-Y., Ju, T.-Y., Han, N.-R. \& WiE, X.-Z. 1983. Trilobita, 28-254. In NANJing Institute of Geology and Mineral Resources (ed.) Palaeontological Atlas of East China 1. 657 pp. Geological Publishing House, Beijing. [in Chinese]

RAYMOND, P.E. 1913. On the genera of the Eodiscidae. The Ottawa Naturalist 27, 101-106.

RedLich, K. 1899. The Cambrian faunas of the eastern Salt-
Range. Memoirs of the Geological Survey of India, Palaeontologia Indica, New Series 1, 1-13.

REED, F.R.C. 1910. The Cambrian Fossils of Spiti. Memoirs of the Geological Survey of India, Palaeontologia Indica, Series 15, 7(1), 1-70.

ReED, F.R.C. 1934. Cambrian and Ordovician fossils from Kashmir. Memoirs of the Geological Survey of India, Palaeontologa Indica, New Series 21(2), 1-38.

RESSER, C.E. 1938. Fourth contribution to nomenclature of Cambrian fossils. Smithsonian Miscellaneous Collections 97(10), $1-43$.

Resser, C.E. 1939. The Ptarmigania strata of the Norther Wasatch Mountains. Smithsonian Miscellaneous Collections 98, 1-72.

Richter, R. 1933. Crustacea (Paläontologie) 2, 840-863. Handwürterbuch der Naturwissenschaften. $2^{\text {nd }}$ edition. Gustav Fischer, Jena.

Runnegar, B. \& Jell, P.A. 1976. Australian Middle Cambrian mollusks and their bearing on early molluscan evolution. Alcheringa 1, 109-138. DOI 10.1080/03115517608619064

SAITo, K. 1934. Older Cambrian Trilobita and Conchostraca from north-western Korea. Japanese Journal of Geology and Geography 11, 211-237.

Savitsky, V.E., Evtushenko, V.M., Egorova, L.I., KontoRovitch, A.E. \& Shabanov, Y.Y. 1972. Kembriy Sibirskoy platformy (Yudomo-Olenekskiy tip razreza. Kuonamskiy kompleks otlozheniy) [Cambrian of the Siberian Platform (Yudoma-Olenek section type. Kuonamka assemblage of sediments)]. Trudy Sibirskogo nauchno-issledovatel'skogo instituta geologii, geofiziki i mineral'nogo syr'ya 130, 1-199.

SEILACHER, A. 1955. Spuren und fazies im Unterkambrium, 11-143. In Schinderwolf, O.H. \& SeIlacher, A. Beitrage zur Kenntnis des Cambriums in der Salt Range (Pakistan). Akademie der Wissenschaften und der Literatur, Mainz, mathematisch-naturwissenschaftliche Klasse, Abhandlungen 10.

Shabanov, Y.Y., Korovnikov, I.V., Pereladov, V.S. \& FefoLov, A.F. 2008a. Excursion 1a. The traditional Lower-Middle Cambrian boundary in the Kuonamka Formation of the Molodo River section (the southeastern slope of the Olenek Uplift of the Siberian Platform) proposed as a candidate for GSSP of the lower boundary of the Middle Cambrian and its basal (Molodian) stage, defined by the FAD of Ovatoryctocara granulata, 8-59. In The Cambrian System of the Siberian Platform. Part 2: North-East of the Siberian Platform, XIII. International Field Conference Cambrian Stage Subdivision Working Group. Moscow \& Novosibirsk.

Shabanov, Y.Y., Korovnikov, I.V., Pereladov, V.S., PaK, K.L. \& Fefelov, A.F. 2008b. Kuonamka Formation section on Molodo River - a candidate for global stratotype of the lower boundary of the Middle Cambrian (East of the Siberian Platform). Cambrian Sections of the Siberian Platform - candidates for statotypes of subdivisions of the International Stratigraphical scheme (stratigraphy and paleontology), 59-70. In Materials for $13^{\text {th }}$ International Field Conference of the Cambrian Stage Subdivision Working Group. SB RAN, Novosibirsk. 
Sun, Z.-H. 1984. Trilobita, 328-421, 753-773. In Regional GeOLogical Survey Team of Hubei (ed.) The Palaeontological atlas of Hubei Province. Hubei Science and Technology Press, Wuhan. [in Chinese]

Sundberg, F.A. 1994. Corynexochida and Ptychopariida (Trilobita, Arthropoda) of the Ehmaniella Zone (Middle Cambrian), Utah and Nevada. Contributions in Science, Los Angeles County Museum of Natural History 446, 1-137.

SundBerg, F.A. 1999. Redescription of Alokistocare subcoronatum (Hall and Whitfield, 1877), the type species of Alokistocare, and the status of Alokistocaridae, Resser, 1938b (Ptychopariida: Trilobita, Middle Cambrian). Journal of Paleontology 73, 1126-1143.

SundBerg, F.A. 2009. Placement of the Stage 5, Series 3 GSSP (approximately the "Lower-Middle" Cambrian Boundary): an update. International Conference on the Cambrian Explosion, Abstract Volume, 90-91.

SundBerg, F.A. \& McCollum, L.B. 1997. Oryctocephalids (Corynexochida: Trilobita) of the Lower-Middle Cambrian Boundary Interval from California and Nevada. Journal of Paleontology 71, 1065-1090.

SundBerg, F.A. \& McCollum, L.B. 2003. Early and Mid Cambrian trilobites from the outer-shelf deposits of Nevada and California, USA. Palaeontology 46, 945-986.

DOI 10.1111/1475-4983.00328

Sundberg, F.A., Yuan, J.-L., McCollum, L.B. \& Zhao, Y.-L. 1999. Correlation of the Lower-Middle Cambrian boundary of South China and western North America. Acta Palaeontologica Sinica 38 (Supplement), 102-107.

SundBerg, F.A., ZhaO, Y.-L., YuAn, J.-L. \& Lin, J.-P. 2010a. Summary of recent quarrying across the proposed GSSP for Stage 5 (Cambrian) at the Wuliu-Zengjianyan section, Guizhou, China, 24. In FAtKa, O. \& Budil, P. (eds) The $15^{\text {th }}$ Field Conference of the Cambrian Stage Subdivision Working Group, International Subcommission on Cambrian Stratigraphy. Abstracts and Excursion Guide, Prague, Czech Republic and south-eastern Germany. 107 pp. Czech Geological Survey, Prague.

Sundberg, F.A., Zhao, Y.-L., Yuan, J.-L. \& Lin, J.-P. 2010 b. Summary of recent quarrying across the proposed GSSP for Stage 5 (Cambrian) at the Wuliu-Zengjianyan section, Guizhou, China. Journal of Stratigraphy 34(3), 289-292.

Swinnerton, H.H. 1915. Suggestions for a revised classification of trilobites. Geological Magazine (New Series) 6(2), 487-496, 538-545. DOI 10.1017/S0016756800203634

TChernysheva, N.E. 1960. Trilobita, 17-194. In OrLov, Y.A. (ed.) Fundamentals of Paleontology vol. 8, Arthropoda, trilobites, and crustaceans. Akademiya Nauk SSSR, Moscow.

TChernysheva, N.Y. 1962. Cambrian trilobites of the Family Oryctocephalidae, 3-64. In SHvedov, N.A. (ed.) Problems of oil and gas occurrence in the Soviet Arctic, palaeontology and biostratigraphy 3. Trudy Nauchno-issledovatel'skogo instituta geologii arktiki (NIIGA). 127 pp. Leningrad.

WaLcotT, C.D. 1886. Second contribution to the studies on the Cambrian fauna of North America. Bulletin of the United States Geological Survey 30, 1-369.
WaLcotT, C.D. 1889. Description of new genera and species of fossils from the Middle Cambrian. Proceedings of the Unites States National Museum 11, 441-446.

Walcott, C.D. 1905. Cambrian faunas of China. Proceedings of the United States National Museum 30(1458), 563-595. DOI 10.5479/si.00963801.1458.563

Walcott, C.D. 1908. Cambrian trilobites. Smithsonian Miscellaneous Collections 53(2), 13-52.

WalcotT, C.D. 1916. Cambrian geology and paleontology of Cambrian trilobites. Smithsonian Miscellaneous Collections 64(5), 303-456.

WalcotT, C.D. 1919. Cambrian Geology and Paleontology IV, no. 5 - Middle Cambrian algae. Smithsonian Miscellaneous Collections 67(5), 217-260.

WANG, Y., Yu, Y.-Y., Peng, J. \& WANG, P.-L. 2006. Discussion on the sequence stratigraphy and sea-level changes of the Kaili Formation at Balang, Taijiang, Guizhou. Journal of Stratigraphy 30, 34-43.

XIE, Z.-Q. 1989. Cambrian, 27-38. In BuREau of Geology and Mineral Resources of Jiangsu Province (ed.) Memoir on Geology of Nanjing-Zhenjiang Mountains. Jiangsu Science and Technology Press, Nanjing. [in Chinese with English abstract]

YANG, R.-D., ZU, L.-J. \& WANG, S.-J. 2003. Negative carbon isotopic excursion on the Lower/Middle Cambrian boundary of Kaili Formation, Taijiang County, Guizhou Province, China: Implications for mass extinction and stratigraphic division and correlation. Science in China Series D: Earth Sciences 46, 872-881. DOI 10.1360/01yd0416

Yin, G.-Z. \& LeE, S.-J. 1978. Trilobita, 385-594, 798-829. In Stratigraphical and Palaeontological Working Group of Guizhou Province (ed.) Palaeontological Atlas of Southwest China, Guizhou Volume 1. Cambrian-Devonian. 843 pp. Geological Publishing House, Beijing. [in Chinese]

Yin, L.-M., ZhaO, Y.-L., YANG, R.-D. \& Peng, J. 2010. Acritarchs from the Early-Middle Cambrian Kaili Formation in the Wuliu-Zengjianya section, east Guizhou Province, China. Acta Palaeontologica Sinica 49, 164-173.

YUAN, J.-L., Lin, J.-P., ZHAO, Y.-L. \& PENG, J. 2011. Zonation of the Balang and Wuxun ('Tsinghsutung') formations and the lowermost part of the Kaili Formation (Cambrian stage 4) based on oryctocephalid trilobites in Guizhou, South China, 314-315. In Hollingsworth, J.S., SundBerg, F.A. \& Foster, J.R. (eds) Cambrian Stratigraphy and Paleontology of Northern Arizona and Southern Nevada. Museum of Northern Arizona Bulletin 67.

Yuan, J.-L. \& Zhao, Y.-L. 1994. On Kaotaia. Acta Palaeontologica Sinica 33, 281-294.

YuAN, J.-L., ZHAO, Y.-L. \& GuO, Q.-J. 1999. On the Kaili Formation. Acta Palaeontologica Sinica 38 (Supplement), 15-27. [in Chinese]

YuAN, J.-L., ZhaO, Y.-L. \& LI, Y. 2001. Biostratigraphy of oryctocephalid trilobites. Acta Palaeontologica Sinica 40 (Supplement), 143-156.

YuAn, J.-L., ZhaO, Y.-L., Li, Y. \& HuAnG, Y.-Z. 2002. Trilobite fauna of the Kaili Formation (uppermost Lower Cambrian-lower Middle Cambrian) from southeastern Guizhou, 
South China. 422 pp. Shanghai Science and Technology Press, Shanghai. [in Chinese with English summary]

Yuan, J.-L., Zhao, Y.-L., PenG, J., Zhu, X.-J. \& Lin, J.-P. 2009. Cambrian trilobite Ovatoryctocara granulata Tchernysheva, 1962 and its biostratigraphic significance. Progress in Natural Science 19, 213-221. DOI 10.1016/j.pnsc.2008.08.002

YuAn, J.-L., ZhaO, Y.-L., WANG, Z.-Z., Zhou, Z., \& Chen, X.-Y. 1997. A preliminary study on Lower-Middle Cambrian boundary and trilobite fauna at Balang, Taijiang, Guizhou, South China. Acta Palaeontologica Sinica 36(4), 494-524. [in Chinese with English abstract]

Zhang, W.-T. 1957. Preliminary note on the Lower and Middle Cambrian stratigraphy of Poshan, Central Shantung. Acta Palaeontologica Sinica 5, 13-32.

Zhang, W.-T. \& JeLL, P.A. 1987. Cambrian trilobites of North China. Chinese Cambrian trilobites housed in the Smithsonian Institution. 322 pp. Science Press, Beijing.

Zhang, W.-T., Lu, Y.-H., Zhu, Z.-L., Qian, Y.-Y., Lin, H.-L., Zhou, Z.-Y., Zhang, S.-G. \& YuAn, J.-L. 1980. Cambrian trilobite faunas of Southwestern China. 497 pp. Science Press, Beijing. [in Chinese with English summary]

Zhang, Z.-H., Shen, J.-W, Gong, X.-Y., Zhao, Y.-L., Mao, J.-R. \& YAN, C.-H. 1996. A preliminary discussion on preservation condition of Kaili Fauna, Middle Cambrian, Taijiang, Guizhou. Acta Palaeontologica Sinica 35, 607-621. [in Chinese with English summary]

Zhao, Y.-L., AhlBerg, P. \& YuAn, J.-L. 1994c. A new species of trilobite Olenoides from Middle Cambrian of Taijiang, Guizhou. Acta Palaeontologica Sinica 33(3), 367-375. [in Chinese with English summary]

Zhao, Y.-L., AhlBerg, P. \& Zhou, Z. 1997. The Oryctocephalina in Kaili Formation, Guizhou. Journal of Guizhou University of Technology 26(5), 32-36.

ZhaO, Y.-L., Huang, Y.-Z., Gong, X.-Y. \& DaI, X.-C. 1990. Bathynotus from Kaili Formation (Lower-Middle Cambrian) of Kaili area, Guizhou. Acta Palaeontologica Sinica 29, 43-53. [in Chinese with English summary]

ZhaO, Y.-L., Qian, Y. \& Li, X.-S. 1994b. Wiwaxia from EarlyMiddle Cambrian Kaili Formation in Taijiang, Guizhou. Acta Palaeontologica Sinica 33, 359-366. [in Chinese with English summary]

Zhao, Y.-L., Yu, Y.-Y., Yuan, J.-L., Yang, X.-L. \& Guo, Q.-J. 2001b. Cambrian stratigraphy at Balang, Guizhou Province, China: candidate section for a global unnamed series and stratotype section for the Taijiangian Stage, 189-208. In PENG, S.-C., BАвСоск, L.E. \& Zнu, M.-Y. (eds) Cambrian system of South China. University of Science and Technology Press, Hefei.

Zhao, Y.-L., Yuan, J.-L., Huang, Y.-Z., MaO, J.-R., Qian, Y., Zhang, Z.-H. \& Gong, X.-Y. 1994a. Middle Cambrian Kaili Fauna in Taijiang, Guizhou. Acta Palaeontologica Sinica 33(3), 263-271. [in Chinese with English summary]

Zhao, Y.-L., Yuan, J.-L., McCollum, L.B., Sundberg, F.A., YANG, R.-D., Guo, Q.-J., Zhu, L.-J. \& YANG, X.-L. 2001a. A potential GSSP for the Lower and Middle Cambrian boundary near Balang Village, Taijiang County, Guizhou Province,
China. Acta Palaeontologica Sinica 40 (Supplement), 130-142.

Zhao, Y.-L., Yuan, J.-L., Peng, S.-C., Babcock, L.E., Peng, J., Guo, Q.-J., Lin, J.-P., TAI, T.-S., YANG, R.-D. \& WANG, Y.-X. 2008. A new section of Kaili Formation (Cambrian) and a biostratigraphic study of the boundary interval across the undefined Cambrian Series 2 and Series 3 at Jianshan, Jianhe County, China with a discussion of global correlation based on the first appearance datum of Oryctocephalus indicus (Reed, 1910). Progress in Natural Science 18, 1549-1556.

DOI 10.1016/j.pnsc.2008.05.020

Zhao, Y.-L., Yuan, J.-L., Peng, S.-C., Babcock, L.E., Peng, J., Lin, J.-P., Guo, Q.-J. \& Wang, Y.-X. 2007. New data on the Wuliu-Zengjiayan section (Balang, South China), GSSP candidate for the base of Cambrian Series 3. Memoirs of the Association of Australasian Palaeontologists 33, 57-65.

Zhao, Y.-L., Yuan, J.-L., Peng, S.-C., Guo, Q.-J., Zhu, L.-J., Peng, J. \& Wang, P.-L. 2004. Propsal and prospects for the global Lower-Middle Cambrian boundary. Progress in Natural Science 14(12), 1034-1039.

DOI 10.1080/10020070412331344771

Zhao, Y.-L., Yuan, J.-L., Peng, S.-C., Yan, X.-L., Peng, J., Lin, J.-P. \& Guo, Q.-J. 2006. A restudy of Oryctocephalus indicus (Reed, 1910). Progress in Natural Science 16, 1177-1182.

Zhao, Y.-L., Yuan, J.-L., Peng, J. \& Yang, Y.-N. 2011. The FADs of trilobite species for the international Cambrian stage 3 , stage 4 and stage 5 in Guizhou Province China, 316. In Hollingsworth, J.S., Sundberg, F.A. \& Foster, J.R. (eds) Cambrian Stratigraphy and Paleontology of Northern Arizona and Southern Nevada. Museum of Northern Arizona Bulletin 67.

Zhao, Y.-L., Yuan, J.-L., Sundberg, F.A., Babcock, L.E., Peng, J., Guo, Q.-J., Yin, L.-M., YAnG, X.-N., Lin, J.-P., Yang, R.-D., WANG, C.-J. \& TAI, T.-S. 2010. Proposed Global Standard Stratotype-section and point for the base of the Guizhouan Series and Wuliuan Stage (provisional Cambrian Series 3 and Stages 5), 29. In FAtKa, O. \& Budil, P. (eds) The $15^{\text {th }}$ Field Conference of the Cambrian Stage Subdivision Working Group, International Subcommission on Cambrian Stratigraphy. Abstracts and Excursion Guide, Prague, Czech Republic and south-eastern Germany. 107 pp. Czech Geological Survey, Prague.

Zhao, Y.-L., Yuan, J.-L., Zhu, M.-Y., Babcock, L.E., Peng, J., WANG, Y., YANG, X.-L., GuO, Q.-J., YANG, R.-D. \& TAI, T.-S. 2005a. Balang Section, Guizhou, China: Stratotype section for the Taijiangian Stage and candidate for GSSP of an unnamed Cambrian series, 62-83. In PeNG, S.-C., B АBCOCK, L.E. \& ZHU, M.-Y. (eds) Cambrian System of China and Korea, Guide to Field Excursions. University of Science and Technology of China Press, Hefei.

Zhao, Y.-L., Yuan, J.-L., Zhu, M.-Y., Babcock, L.E., Peng, J., WANG, Y., YANG, X.-L., GuO, Q.-J., YANG, R.-D. \& TAI, T.-S. 2005b. Kaili Biota: a taphonomic window on diversification of Metazoans from the basal Middle Cambrian: Guizhou, China. Acta Geologica Sinica 79, 751-765. DOI 10.1111/j.1755-6724.2005.tb00928.x 
Zhao, Y.-L., Yuan, J.-L., Zhu, L.-J., Chen, X-Y., Zhou, P.-K. \& Zноu, Z. 1996. The division of the Lower-Middle Cambrian boundary in China. Journal of Guizhou Institute of Technology 25(4), 15-20.

Zhao, Y.-L., Yuan, J.-L., Zhu, M.-Y., Yang, R.-D., Guo, Q.-J., Qian, Y., Huang, Y.-Z. \& PAN, Y. 1999. A progress report on research on the early Middle Cambrian, Kaili Biota, Guizhou, PRC. Acta Palaeontologica Sinica 38 (Supplement), 1-14.

Zhou, Z.-Y., Yuan, J.-L., Zhang, Z.-H., Wu, X.-R. \& Yin, G.-Z. 1980. Division and correlation of Cambrian stratigraphy in Guizhou Province, China. Journal of Stratigraphy 4(4), 273-281. [in Chinese with English summary]
Zhu, M.-Y., Erdtmann, B.D. \& Zhao, Y.-L. 1999. Taphonomy and paleoecology of the early Middle Cambrian Kaili Lagerstätte in Guizhou, China. Acta Palaeontologica Sinica 38, 28-57.

Zhu, Z.-L., Lin, H.-L. \& Zhang, S.-G. 1988. Cambrian biostratigraphy of the Lower Yangtze Peneplatform in Jiangsu Region, 35-80. In Jiangsu Bureau of Petroleum Prospecting, Chinese Academy of Geological Sciences \& Nanjing Institute of Geology and Paleontology, AcadeMIA SinICA (eds) Stratigraphy and Palaeontology of the Jiangsu. Series 1. Nanjing University Press, Nanjing. [in Chinese] 